\title{
Disinflation, Fiscal Sustainability, and Labor Market Adjustment in Turkey
}

\author{
Pierre-Richard Agénor,*Henning Tarp Jensen,** \\ Mathew Verghis,*** and Erinc Yeldan****
}

World Bank Policy Research Working Paper 3804, January 2006

The Policy Research Working Paper Series disseminates the findings of work in progress to encourage the exchange of ideas about development issues. An objective of the series is to get the findings out quickly, even if the presentations are less than fully polished. The papers carry the names of the authors and should be cited accordingly. The findings, interpretations, and conclusions expressed in this paper are entirely those of the authors. They do not necessarily represent the view of the World Bank, its Executive Directors, or the countries they represent. Policy Research Working Papers are available online at http://econ.worldbank.org.

*University of Manchester, and Centre for Growth and Business Cycle Research; **University of Copenhagen; ***World Bank; and $* * * *$ Bilkent University. We are grateful to Vandana Chandra, Koray Alper, participants from Treasury, the State Planning Organization, and the Central Bank of Turkey at presentations made at the General Directorate of Economic Research of the Undersecretary of Treasury in Turkey, participants at seminars at Bogazici University and the World Bank, Vikram Nehru, Edgardo Favaro, Santiago Herrera, and especially Peter Montiel, for helpful comments and discussions. 


\section{Contents}

1 Introduction 4

2 Structure of the Model $\quad 8$

2.1 Production ..................... 8

2.1.1 Rural Sector . . . . . . . . . . . . . 9

2.1.2 Urban Informal Sector . . . . . . . . . . . . . . . 10

2.1.3 Urban Formal Private Sector . . . . . . . . . . . . . . . 10

2.1.4 Public Production . . . . . . . . . . . . . . 12

2.2 The Labor Market . . . . . . . . . . . . . . . . . . . . . . . 12

2.2.1 Rural Wages, Employment, and Migration . . . . . . . 14

2.2 .2 The Urban Labor Market . . . . . . . . . . . . . . . 16

2.2 .3 International Labor Migration . . . . . . . . . . . . . 22

2.3 Export Supply and Import Demand . . . . . . . . . . . . . . . 22

2.4 Aggregate Supply and Demand . . . . . . . . . . . . . . . 23

2.5 Profits and Income . . . . . . . . . . . . . . . . 25

2.6 Savings and Wealth Accumulation . . . . . . . . . . . . 27

2.7 Private Investment . . . . . . . . . . . . . . . . . . . 28

2.8 Asset Allocation and the Credit Market . . . . . . . . . . . . . 31

2.8.1 Households . . . . . . . . . . . . . . . 31

2.8 .2 Firms . . . . . . . . . . . . . . 35

2.8.3 Commercial Banks . . . . . . . . . . . . . . 35

2.8.4 Interest Rates and Risk Premia . . . . . . . . . . . . 38

2.9 Public Sector . . . . . . . . . . . . . . . . . . . . . 42

2.9.1 Central Bank . . . . . . . . . . . . . . 42

2.9.2 Government Budget . . . . . . . . . . . . . . 43

2.10 The Balance of Payments and the Exchange Rate . . . . . . . 45

2.11 Currency and Bond Market Equilibrium . . . . . . . . . . . 46

2.12 Price Determination . . . . . . . . . . . . . . . 47

2.13 Default Risk, Credibility, and Expectations . . . . . . . . . . 49

3 Calibration and Solution $\quad 53$

4 Policy Experiments $\quad 53$

4.1 Increase in Official Interest Rates . . . . . . . . . . . . . . . 54

4.2 Fiscal Adjustment . . . . . . . . . . . . . . . . . . . 59

4.2.1 Increase in the VAT Rate . . . . . . . . . . . 60 
4.2.2 Increase in the Tax Rate on Profit Earners . . . . . . . 63

5 Concluding Remarks $\quad 67$

$\begin{array}{ll}\text { Appendix A: List of Equations } & 70\end{array}$

$\begin{array}{ll}\text { Appendix B: Variable Names and Definitions } & 79\end{array}$

Appendix C: Calibration and Parameter Values 90

$\begin{array}{ll}\text { References } & 97\end{array}$ 


\section{Introduction}

For much of the past two decades, Turkey's economy has suffered from persistent fiscal imbalances, high inflation, financial volatility, and sharp swings in economic activity (see Figure 1). Large budget deficits during the 1990s fueled a rapid expansion in domestic public debt and sharp increases in real interest rates, with deposit rates for instance averaging 12.8 percent during that decade. In turn, high interest rates had an adverse effect on private investment and contributed to unsustainable debt dynamics. The overall balance of the consolidated public sector rose from 5.2 percent of GNP to 13.1 percent in 1997 and 22.3 percent in 1999 . The net debt of the public sector reached 61 percent in 1999. ${ }^{1}$ In late 1999, the government launched a 3 -year disinflation program based on a pre-announced exchange rate path. Despite some progress in 2000, with inflation falling and the public sector recording a sizable primary surplus, unfavorable debt dynamics and financial sector weaknesses combined with the rigidities imposed by the exchange rate peg led to a currency collapse and a full-blown financial crisis. ${ }^{2}$ Between the end of 1995 and the end of 2001, Turkey's public debt almost doubled in proportion to GNP, from 41.3 percent to 80 percent (see Figure 1) with a significant portion of the increase coming in 2001 as the cost of bank restructuring was borne by the budget. Inflation hit 68.5 percent at the end of 2001 and the nominal interest rate on treasury bills reached 99.1 percent.

Although short-lived (the economy started to recover in 2002), the crisis had severe economic and social costs. Real GNP fell by 9.5 percent in 2001 alone, whereas per capita GDP contracted by 13 percent between 1998 and 2001. The officially recorded unemployment rate rose from 6.4 percent in 1998 to 8.5 percent in 2001 and 10.6 percent during 2002 (see Figure 2). Real wages in manufacturing remained relatively constant throughout 2000 as nominal wage increases kept pace with inflation, but then declined sharply in 2001 - by 20 percent in the fourth quarter of that year, compared to the

\footnotetext{
${ }^{1}$ In 1995, foreign debt represented two thirds of total debt (or 30.7 percent of GNP), whereas in 2002 it amounted to 40 percent of the stock (or 32.1 percent of GNP). Moreover, a sizeable fraction of the domestic debt is now denominated in foreign currency or indexed on the exchange rate. In 2002 this debt amounted to 15.3 percent of GNP, with total domestic debt representing 47.7 percent. The sum of foreign debt and foreign-currency denominated domestic debt amounted therefore to 47.4 percent that same year.

${ }^{2}$ See Yilmaz and Boratav (2003) for an overview of developments leading up to the crisis.
} 
same period of the previous year (World Bank (2003)).World Bank estimates indicate that the urban headcount poverty index rose from 6.2 percent in 1994 to 17.2 percent in 2001. Credit to the private sector (particularly in the nontradables sector) fell sharply as a share of GDP and recovered only slowly - a typical pattern in the aftermath of financial crises in developing countries, as documented for instance by Tornell and Westermann (2003) and Schneider and Tornell (2004).

The development of the public debt overhang and the consequent need for continuous refinancing of the debt has led to a very close link between financial market participants' perceptions of credibility of the Government's program, key macroeconomic variables such as interest rates, exchange rates and inflation, and real variables such as employment and growth. Our premise in this paper is that a proper modeling of the structure of the labor market in Turkey, and a proper account of the linkages between the financial and real sides of the Turkish economy, are essential steps to understand the impact of the disinflation program on the evolution of output and employment. Accordingly, we develop a dynamic computable general equilibrium (CGE) model with a relatively aggregated productive sector, a segmented labor market and a full-blown financial sector. ${ }^{3}$ By itself, this endeavour is not new; over the years, a number of CGE models have been developed for Turkey. These include Lewis (1992), Yeldan (1997, 1998), Diao, Roe, and Yeldan (1998), Karadag and Westaway (1999), De Santis (2000), Voyvoda and Yeldan (2003), and Elekdag (2003). Those of Lewis (1992), Yeldan (1998), and Elekdag (2003) include a financial sector, whereas the others are "real" models focusing on tax and trade policy issues. In all of these models, however, the treatment of the labor market is fairly rudimentary and some important channels through which the real and financial sectors interact are absent. Indeed, as far as we are aware, some of these channels have been either ignored or improperly addressed in the previous literature; our framework should therefore be of independent interest to researchers focusing on other countries with large market-financed debt overhangs.

We pay particular attention to financial sector issues such as a high degree of exchange rate flexibility, risk premia in the banking sector, dollarization of

\footnotetext{
${ }^{3}$ The model developed in this paper is based on the IMMPA (for Integrated Macroeconomic Model for Poverty Analysis) framework developed by Agénor (2003a), Agénor, Izquierdo, and Fofack (2003), and Agénor, Fernandes, Haddad, and Jensen (2003). This class of models captures real and financial features that are common to many developing countries.
} 
loans and bank deposits, the link between market interest rates and official policy rates, and interactions between credibility, default risk on government debt, and inflation expectations. Understanding the link between credibility and inflation, in particular, is important to understand Turkey's experience in the immediate aftermath of the 2001 financial crisis. For instance, to the extent that inflation inertia is due to doubts about the commitment and ability of policymakers to keep prices in check, a disinflation program may entail a large output cost.

Accounting for default risk on public debt is another key feature of our analysis. It is well recognized that fiscal policy must be evaluated in a framework in which the government is subject to an intertemporal budget constraint (see, for instance, Uctum and Wickens (2000), Gunaydin (2003), and Salman (2003) for a discussion in Turkey's context). If the real rate of interest is above the real growth rate of the economy, a fiscal deficit today (brought about by either an increase in expenditure or a reduction in taxes) must be accompanied at some point in the future by either a fiscal contraction or a rise in seigniorage revenue. Otherwise, the increase in public debt will feed upon itself as the government borrows to finance the interest payments on the liabilities that it previously issued. If the government cannot meet its debt service payments without further borrowing, investors may be unwilling after a certain point to continue to accumulate government bonds. As a result, the government will have to either reduce its primary deficit or engage in an outright default. Although we do not account explicitly for the government's intertemporal budget constraint in our framework, we capture this "unwillingness" of investors to provide indefinite financing by assuming that there is a non-zero probability of default that depends on the existing stock of debt. In turn, the probability of default affects the expected rate of return on government bonds. The higher the perceived risk of default is, the higher will be the actual interest rate on these bonds, and the lower will be the degree of credibility of the fiscal stance. Lower credibility translates into higher inflation expectations and greater inflation persistence. ${ }^{4}$

\footnotetext{
${ }^{4}$ Diao, Roe, and Yeldan (1998) analyzed fiscal management issues in Turkey using an explicit intertemporal CGE framework that accounts for the existence of a risk premium associated with large public sector borrowing requirements. Specifically, the domestic real interest rate, $r$, is taken to diverge from the world interest $r^{*}$, by $r=(1+\theta) r^{*}$, with $\theta$ being a function of the ratio of the fiscal deficit to GDP. However, the model is "real" and thus the impact of interest rate changes on portfolio decisions and the supply side (through short-term bank borrowing) are not taken into account.
} 
Given our focus on the behavior of wages and unemployment during disinflation, the labor market plays also an important role in our analysis. Indeed, our framework captures many important features of the Turkish labor market - namely, a large informal urban economy, open unskilled urban unemployment, wage bargaining in the urban formal sector, and international migration, with remittance flows accounting for about 2 percent of GDP in 2002. In any model designed to study the response of the labor market to short-run macro shocks and structural adjustment measures, accounting for the informal sector is essential; in the case of Turkey, it is even more so. Some observers have argued that growth in that sector may explain the observed tendency for labor force participation to fall since the 1960s, that is, the growing gap between the labor force (the adult population either employed or looking for work, which was 22 million in 2001) and the adult population (of about 46 million adults in that same year).

The remainder of the paper is organized as follows. Section II describes the model. Section III considers two policy experiments and discusses the response of production, wages and unemployment, as well as the behavior of the public debt-to-GDP ratio. The first consists of a temporary increase in official interest rates. The second focuses on fiscal adjustment and involves tax reform, namely an increase in the VAT rate and a rise in the tax rate on income of profit earners. These simulations are important because the sustainability of Turkey's public debt remains a key policy issue. It has been argued by various observers that Turkey needs to run large primary surpluses over the medium and long term to lower its public debt burden, meet its disinflation targets, and convince markets that its debt is sustainable, for the risk premium embedded in interest rates on domestic debt to fall. The adjustment program introduced in May 2001 called for Turkey to maintain a primary surplus on the order of 6.5 percent of GNP over the medium term to lower its public debt to manageable proportions and achieve the goal of single digit inflation by 2005. ${ }^{5}$ Although we do not assess explicitly the validity of this target, our simulations allow us to quantify the impact of fiscal adjustment not only on the budget and domestic inflation, but also on the labor market (real wages and unemployment) and standards of living. The last

\footnotetext{
${ }^{5}$ These estimates are based on a variant of the consistency framework developed by Anand and van Wijnbergen (1989). This approach lacks a simultaenous determination of the rate of output growth, the real interest rate, fiscal variables, and the real exchange rate. Our analysis, by constrast, is cast in a general equilibrium setting, as in Voyvoda and Yeldan (2003).
} 
section summarizes the main results of the paper and offers some concluding remarks. Appendices A and B provide a list of equations and variable definitions, whereas Appendix $\mathrm{C}$ discusses the structure of the financial SAM that underlies the model, our calibration procedure, and the parameter values that are used in the behavioral equations.

\section{Structure of the Model}

Our model of the Turkish economy captures three features that we believe are essential to analyze the impact of disinflation and fiscal reforms on labor market adjustment and public debt sustainability. First, the linkages between the financial and the real sectors; second, the structure of the labor market; and third, the channels through which fiscal variables interact with financial variables to affect the economy. In addition, particular attention is paid to modeling monetary policy and the credit market. Specifically, we assume that the central bank sets a short-term policy interest rate (such as the repurchase rate) and has a perfectly elastic supply curve of liquidity to commercial banks at that rate. Credit to firms by commercial banks is also perfectly elastic (at the given lending rate), whereas lending to households is subject to rationing. Foreign borrowing by commercial banks is exogenous and equilibrium of the credit market is obtained by domestic borrowing from the central bank, at the given policy rate.

In this section we review the various building blocks of the model. We consider in turn the production side, the labor market, external trade, aggregate supply and demand, income formation, saving and investment, the financial sector and asset allocation decisions, the balance sheets and flow budget constraints of the public sector (comprising both the government and the central bank), the balance of payments, equilibrium conditions for the currency and bond markets, price formation, and the links between default risk, credibility, and inflation expectations.

\subsection{Production}

Given our focus on macroeconomic aspects, the production structure is kept fairly aggregate. The economy is divided between rural and urban sectors. The rural sector produces a homogeneous good, which is sold domestically and abroad. The urban sector consists of both formal and informal compo- 
nents; furthermore, the formal urban economy is separated between a private sector (which also produces a good sold on both domestic and foreign markets) and a public sector, which produces a single nontraded good.

\subsubsection{Rural Sector}

Gross output in the rural sector, $X_{A}$, is given by the sum of value added, $V_{A}$, and intermediate consumption:

$$
X_{A}=V_{A}+X_{A} \sum_{i} a_{i A},
$$

where the $a_{i j}$ are input-output coefficients measuring sales from sector $i$ to sector $j$. We also have $i, j=A, I, P, G$ where $A, I, P, G$ are used in what follows to refer, unless otherwise indicated, to the rural sector, the urban informal sector, the private urban formal sector, and the public sector, respectively.

Value added is produced with land, $L A N D$ (available in fixed supply), unskilled labor, $U_{A}$ (the only category of labor in the rural sector), and the economy-wide stock of public capital in infrastructure, $K_{I N F}$, which is treated as a pure public good and consists not only of roads and public transportation that may increase access to markets, but also power plants, hospitals, and other public goods that may contribute to an increase in the productivity of factors in private production. A two-level production structure is assumed. Specifically, $U_{A}$ and $K_{I N F}$ combine through a constant elasticity of substitution (CES) function to form a composite factor, which is then combined with land through a Cobb-Douglas technology:

$$
V_{A}=L A N D^{1-\eta_{X_{A}}}\left[\alpha_{X_{A}}\left\{\beta_{X_{A}} U_{A}^{-\rho_{X_{A}}}+\left(1-\beta_{X_{A}}\right) K_{I N F}^{-\rho_{X_{A}}}\right\}^{-\frac{1}{\rho_{X_{A}}}}\right]^{1-\eta_{X_{A}}},
$$

Thus, given the Cobb-Douglas specification, rural production exhibits decreasing returns to scale in the composite input. In what follows, the quantity of land is normalized to unity.

In standard fashion, output of the rural sector is allocated to domestic sales, $D_{A}$, and exports, $E_{A}$, through a constant elasticity of transformation (CET) function:

$$
X_{A}=\alpha_{E D_{A}}\left[\beta_{E D_{A}} E_{A}^{\rho_{E D_{A}}}+\left(1-\beta_{E D_{A}}\right) D_{A}^{\rho_{E D_{A}}}\right]^{\frac{1}{\rho_{E D_{A}}}},
$$

where, as discussed later, the ratio $E_{A} / D_{A}$ depends on relative prices. 


\subsubsection{Urban Informal Sector}

The second component of the production structure is the informal sector, whose share increased significantly in Turkey since the 1980s. The OECD (1996) estimated the size of the non-agricultural informal sector (defined as unpaid family workers, half of the self-employed, employers with fewer than four employees, and unregistered wage earners) to be 21 percent for 1993. Another study (cited by Onaran (2002)) using the same definition found 23 percent for 1997. The private formal sector was estimated at 19 percent of total employment, the public sector at 12 percent, with the rest (about 46 percent of total employment) being employed in the agricultural sector. Thus, the informal non-agricultural sector exceeded the size of the private formal sector. More recently, Taymaz and Ozler (2003) estimated that the informal sector accounts for more than 30 percent of output and 40 percent of employment in the manufacturing sector. Similar estimates are cited in Tunali (2003).

Gross production in the informal sector, $X_{I}$, is given as the sum of value added, $V_{I}$, and intermediate consumption:

$$
X_{I}=V_{I}+X_{I} \sum_{i} a_{i I}
$$

There is no physical capital in the informal sector, and value added is generated using only unskilled labor, $U_{I}$, with a decreasing returns to scale technology:

$$
V_{I}=\alpha_{X I} U_{I}^{\beta_{X I}}, \quad \alpha_{X I}>0, \quad 0<\beta_{X I}<1,
$$

from which the demand for labor can be derived as

$$
U_{I}^{d}=\beta_{X I}\left(\frac{P V_{I} V_{I}}{W_{I}}\right),
$$

with $W_{I}$ denoting the nominal wage and $P V_{I}$ the price of value added.

\subsubsection{Urban Formal Private Sector}

Gross production in the private urban formal sector, $X_{P}$, is again given by the sum of value added, $V_{P}$, and intermediate consumption:

$$
X_{P}=V_{P}+X_{P} \sum_{i} a_{i P}
$$


Value added is generated by combining both skilled and unskilled labor, as well as public and private physical capital, through a multi-level CES production structure. At the lowest level of factor combination, skilled labor, $S_{P}$, and private physical capital, $K_{P}$, are combined to form the composite input $J_{1}$, with a relatively low elasticity of substitution (as measured by $\left.\sigma_{X_{P} 1}=1 /\left(1+\rho_{X_{3} 1}\right)\right)$ between them:

$$
J_{1}\left(S_{P}, K_{P}\right)=\alpha_{X_{P} 1}\left[\beta_{X_{P} 1} S_{P}^{-\rho_{X_{P} 1}}+\left(1-\beta_{X_{P} 1}\right) K_{P}^{-\rho_{X_{P} 1}}\right]^{-\frac{1}{\rho_{X_{P} 1}}} .
$$

At the second level, this composite input is used together with unskilled labor, $U_{P}$, to form the composite input $J_{2}$ :

$$
J_{2}\left(J_{1}, U_{P}\right)=\alpha_{X_{P} 2}\left\{\beta_{X_{P} 2} J_{1}^{-\rho_{X_{P} 2}}+\left(1-\beta_{X_{P} 2}\right) U_{P}^{-\rho_{X_{P} 2}}\right\}^{-\frac{1}{\rho_{X_{P} 2}}} .
$$

In line with the evidence for middle-income developing countries (see Agénor $(1996,2003)$ ), the elasticity of substitution between $J_{1}$ and unskilled labor, measured by $\sigma_{X_{P} 2}=1 /\left(1+\rho_{X_{P} 2}\right)$, is taken to be higher than the elasticity between $S_{P}$ and $K_{P}$, that is

$$
\sigma_{X_{P} 2}>\sigma_{X_{P} 1}
$$

The final layer combines $J_{2}$ and $K_{I N F}$ (the stock of government capital in infrastructure) as production inputs: ${ }^{6}$

$$
V_{P}\left(J_{2}, K_{I N F}\right)=\alpha_{X_{P}}\left[\beta_{X_{P}} J_{2}^{-\rho_{X_{P}}}+\left(1-\beta_{X_{P}}\right) K_{I N F}^{-\rho_{X_{P}}}\right]^{-\frac{1}{\rho_{X_{P}}}} .
$$

As in the rural sector, firms in the private urban formal sector allocate their output to exports, $E_{P}$, or the domestic market, $D_{P}$, according to a CET function:

$$
X_{P}=\alpha_{E D_{P}}\left[\beta_{E D_{P}} E_{P}^{\rho_{E D_{P}}}+\left(1-\beta_{E D_{P}}\right) D_{P}^{\rho_{E D_{P}}}\right]^{\frac{1}{\rho_{E D_{P}}}} .
$$

This specification also implies, as shown later, that the ratio $E_{P} / D_{P}$ depends on relative prices.

\footnotetext{
${ }^{6}$ An alternative approach would be to follow Stokey (1996) and assume that physical capital (possibly defined as a composite of both public and private capital) and unskilled labor are substitutes, whereas both are complementary to skilled labor.
} 


\subsubsection{Public Production}

Gross production of public services, $X_{G}$, is given by the sum of value added, $V_{G}$, and intermediate consumption:

$$
X_{G}=V_{G}+X_{G} \sum_{i} a_{i G}
$$

Value added is generated by combining both categories of labor and public capital in infrastructure. Again, a two-level CES production structure is assumed. At the first level, skilled labor, $S_{G}$, and public capital in infrastructure, $K_{I N F}$, combine to produce a composite input, $J_{G}$, with a relatively low elasticity of substitution between them:

$$
J_{G}\left(S_{G}, K_{I N F}\right)=\alpha_{X_{G} J}\left[\beta_{X_{G} J} S_{G}^{-\rho_{X_{P} J}}+\left(1-\beta_{X_{G} J}\right) K_{I N F}^{-\rho_{X_{G} J}}\right]^{-\frac{1}{\rho_{X_{G} J}}} .
$$

At the second level, $J_{G}$ is combined with unskilled labor, $U_{G}$, to produce net output:

$$
V_{G}\left(J_{G}, U_{G}\right)=\alpha_{X_{G}}\left[\beta_{X_{G}} J_{G}^{-\rho_{X_{G}}}+\left(1-\beta_{X_{G}}\right) U_{G}^{-\rho_{X_{G}}}\right]^{-\frac{1}{\rho_{X_{G}}}} .
$$

We assume that the elasticity of substitution between $S_{G}$ and $K_{I N F}$, $\sigma_{X_{G} J}=1 /\left(1+\rho_{X_{G} J}\right)$, is lower than the elasticity of substitution between the composite input $J_{G}$ and $U_{G}, \sigma_{X_{G}}=1 /\left(1+\rho_{X_{G}}\right)$, in order to capture the fact that there is a greater degree of complementarity between physical capital and skilled labor (as in the private sector), and a greater substitutability between these two factors and unskilled labor:

$$
\sigma_{X_{G}}>\sigma_{X_{G} J}
$$

\subsection{The Labor Market}

As noted earlier, modeling the main features of the labor market in Turkey is one of the key objectives of our model. Accounting for labor regulations and government-induced sources of labor market segmentation are thus important. Turkey's labor laws are the strictest in the OECD in terms of employment protection; the country's severance pay requirements are higher than in any other country (except Portugal) and restrictions on the use of 
temporary workers are severe. ${ }^{7}$ In principle, employment protection rules are meant to enhance job security by making dismissals costly to the employer. They should therefore help to stabilize employment levels, all else being equal, reducing layoffs in downturns. But they also reduce hiring as the economy recovers. The evidence for Turkey (see Tunali (2003)) suggests that employment protection laws may have increased the insecurity faced by workers, as employers avoid paying severance altogether and hire short-term workers illegally, and may have shifted activity to the informal sector - with adverse effects on tax revenue.

Turkey has implemented a minimum wage law nationwide since 1974 . The minimum wage has been adjusted twice a year since 1999 to inflation. During the period 2000-2001, it represented only about 25 percent of the average daily wage in manufacturing (see Tunali (2003)). The extent to which it is enforced, even in the urban formal sector, remains a matter of debate. However, even if it is not "binding" per se, changes in the minimum wage may well play an important signaling role for wage setters in general, including trade unions. Similarly, it is widely believed that public sector wages have a strong signaling effect on wage setting in the private sector (see Tunali (2003)). Collective agreements between the government and the major trade unions - almost all civil servants and employees of state-owned enterprises are unionized - serve as a model for unions and workers in the formal private sector. ${ }^{8}$

In modeling the labor market we attempt to capture in a stylized way several of these features. Given that the model integrates an informal urban sector, we account for the fact that labor market regulations and other "distortions" in the formal economy may not be binding for a large segment of the labor market. Wages may therefore exhibit a high degree of flexibility. In light of the evidence suggesting that the power of trade unions has eroded significantly during the past two decades (see Onaran (2002)), we focus on the case where workers in the private formal sector negotiate wages directly

\footnotetext{
${ }^{7}$ As demonstrated formally by Saint-Paul (2002), employment protection is more likely to arise in economies with greater worker bargaining power.

${ }^{8}$ Tunali (2003) reports that the pair-wise correlation between average wages in the public sector and the private manufacturing sector was 0.46 in the first period and 0.78 in the second period. Note that Granger causality tests or impulse response functions from simple VAR models (involving, for instance, the rates of growth of public and private sector wages, inflation, and the cyclical component of output) could provide some useful additional information.
} 
with firms. We also assume that workers' reservation wage depends on wages in the public sector. We thus capture the "signaling" effect alluded to above. ${ }^{9}$

\subsubsection{Rural Wages, Employment, and Migration}

Unskilled workers in the economy may be employed either in the rural sector or in the urban sector, whereas skilled workers are employed only in the urban economy. We also assume that skilled workers who are unable to find a job in the formal sector do not opt to work in the informal economy, either because of a high perceived disutility of work there, or because they fear an adverse signaling effect on future employers.

Assuming profit maximization, and using the production function (2), the demand for labor in the rural sector is

$$
U_{A}^{d}=U_{A}^{d}\left(V_{A}, \frac{W_{A}}{P V_{A}}\right)=\left(\left(1-\eta_{X A}\right) V_{A}^{1+\frac{\rho_{X A}}{1-\eta_{X A}}} \frac{P V_{A}}{W_{A}} \cdot \frac{\beta_{X A}}{\alpha_{X A}^{\rho_{X A}}}\right)^{\frac{1}{1+\rho_{X A}}}
$$

where $W_{A}$ denotes the nominal wage and $P V_{A}$ the net output price in the rural sector.

Wages in the rural sector adjust to clear the labor market. Let $U_{R U R}^{s}$ denote labor supply in rural areas; the equilibrium condition is thus given by

$$
U_{R U R}^{s}=U_{A}^{d}\left(V_{A}, \frac{W_{A}}{P V_{A}}\right) .
$$

Over time, labor supply in the rural sector grows at an exogenous rate, $g_{R U R}$, net of worker migration to urban areas, $M I G$ :

$$
U_{R U R}^{s}=U_{R U R,-1}\left(1+g_{R U R}\right)-M I G .
$$

In the tradition of Harris and Todaro (1970), we assume that the incentives to migrate depend negatively on the ratio of the average expected wage in the rural sector to that prevailing in the urban sector. Unskilled workers in the urban economy may be employed either in the private formal sector, in which case they are paid a wage $W_{U P}$, or they can enter the informal

\footnotetext{
${ }^{9}$ As noted earlier, severance payments have long been a major source of frictions between unions and employers in Turkey. We do not explicitly introduce firing costs given the focus of our simulations in this paper; but this could be done along the lines suggested by Agénor (2003).
} 
economy and receive the going wage in that sector, $W_{I} \cdot{ }^{10}$ Assuming that unskilled workers in the private formal sector pay a social security tax at the rate $\operatorname{sstax}_{U}$, the expected unskilled urban wage, $E W_{U R B}$, is thus a weighted average of $\left(1-\operatorname{sstax}_{U}\right) W_{U P}$ and $W_{I}$ :

$$
E W_{U R B}=\theta_{U}\left(1-\operatorname{sstax}_{U}\right) W_{U P,-1}+\left(1-\theta_{U}\right) W_{I,-1},
$$

where $\theta_{U}$ is the probability of finding a job in the private urban formal sector, which is approximated by the proportion of unskilled workers actually employed in the private formal sector, $U_{P}$, relative to the total number of unskilled urban workers looking for a job, $U_{F}^{s}$, minus those employed in government, $U_{G}$. Assuming a one-period lag yields

$$
\theta_{U}=\frac{U_{P,-1}}{U_{F,-1}^{s}-U_{G,-1}} .
$$

In the rural sector, the employment probability is equal to unity, because workers can always find a job at the going wage. Assuming a one-period lag, the expected rural wage is thus $W_{A,-1}$.

The migration function can therefore be specified as

$$
M I G=U_{R U R,-1} \lambda_{M}\left[\sigma_{M} \ln \left(\frac{E W_{U R B}}{W_{A,-1}}\right)\right]+\left(1-\lambda_{M}\right) \frac{U_{R U R,-1}}{U_{R U R,-2}} M I G_{-1},
$$

where $0<\lambda_{M}<1$ measures the speed of adjustment and $\sigma_{M}>0$ measures the elasticity of migration flows with respect to expected wages. This specification assumes that costs associated with migration or other frictions may delay the migration process, introducing persistence in migration flows. Of course, other factors can be relevant in explaining these flows in Turkey. It has been argued, for instance, that the dramatic reductions in government subsidies to farming that started in the mid-1990s have made agriculture and the rural sector less and less attractive, encouraging rural-to-urban migration (see Tunali (2003)). ${ }^{11}$ This could be captured by defining subsidies as negative production taxes - which would raise value added prices (as discussed later) and affect rural wages, through the labor demand function (15) and the market equilibrium condition (16)).

\footnotetext{
${ }^{10}$ As noted later, there is no job turnover for either category of workers in the public sector; the employment probability in that sector is therefore zero. Public sector wages therefore do not affect the expected urban wage.

${ }^{11}$ Further reductions in subsidies to farming in agriculture may therefore continue to induce migration. Although this issue is beyond the scope of this paper, it has important implications for the design of fiscal adjustment.
} 


\subsubsection{The Urban Labor Market}

In the urban sector, as noted earlier, both public and private production require skilled and unskilled labor, whereas production in the informal urban sector requires only unskilled labor. We consider, in turn, the determination of wages and employment for both categories of labor, and then the determination of wages through bargaining.

Public Employment and Wage Formation Both skilled and unskilled employment in the public sector, $U_{G}$ and $S_{G}^{T}$, respectively, are considered exogenous. ${ }^{12}$ Wages of both categories or workers, $W_{U G}$ and $W_{S G}$, are assumed to be fully indexed on the urban consumption price index, $P_{U R B}$ :

$$
W_{j G}=\omega_{j G} P_{U R B}, \quad j=U, S,
$$

where $\omega_{j G}$ is an exogenous real base wage. ${ }^{13}$

Private Sector Wage Formation To determine the skilled and unskilled wage rates in the private formal sector, $W_{U P}$ and $W_{S P}$, we assume direct bargaining between workers and employers over the nominal wage, as in Agénor (2003). Consider first the case of skilled workers. If a bargain is reached, each worker receives $W_{S P}$, whereas the producer receives $P J_{1} m_{S}-$ $W_{S P}^{E}$, where $W_{S P}^{E}$ is the effective cost of labor, defined as

$$
W_{S P}^{E}=(1+I L)\left(1+\operatorname{paytax}_{S}\right) W_{S P},
$$

where $I L$ is the bank lending rate on domestic-currency loans, $\operatorname{paytax}_{S}$ the payroll tax rate on skilled labor, and $m_{S}=\partial J_{1}\left(S_{P}, K_{P}\right) / \partial S_{P}$ the physical marginal product of the worker, given by (from equation (8)):

$$
m_{S}=\left(\frac{\beta_{X_{P} 1}}{\rho_{X_{P} 1}}\right)\left(\frac{J_{1}}{S_{P}}\right)^{1+\rho_{X_{P} 1}} .
$$

\footnotetext{
${ }^{12} \mathrm{~A}$ good theory of what determines the share of public employment in Turkey (as in many other developing countries) would involve considerations that are well beyond the scope of this paper.

${ }^{13}$ To avoid a corner solution in which no worker wants to seek employment in the public sector, we assume that working for the government provides a nonpecuniary benefit (perhaps in terms of higher job security or reduced volatility of earnings) that is sufficiently large to ensure that the differential between $W_{j G}$ and $W_{j P}$, with $j=U, S$, is positive.
} 
The Nash bargaining problem can be formulated as

$$
\max _{W_{S P}}\left(W_{S P}-\Omega_{S}\right)^{\nu_{S}}\left(P J_{1} m_{S}-W_{S P}^{E}\right)^{1-\nu_{S}}, \quad 0<\nu_{S}<1,
$$

where $\Omega_{S}$ is the worker's reservation wage and $P J_{1} m_{S}-W_{S P}^{E}$ the firm's bargaining surplus. $\nu_{S}$ measures the bargaining strength of a skilled worker relative to the firm. The first-order condition is given by

$$
\nu_{S}\left(\frac{P J_{1} m_{S}-W_{S P}^{E}}{W_{S P}-\Omega_{S}}\right)^{1-\nu_{S}}-\frac{\left(1-\nu_{S}\right)(1+I L)}{\left(1+\operatorname{paytax}_{S}\right)^{-1}}\left(\frac{P J_{1} m_{S}-W_{S P}^{E}}{W_{S P}-\Omega_{S}}\right)^{-\nu_{S}}=0,
$$

that is,

$$
\nu_{S} \frac{P J_{1} m_{S}-W_{S P}^{E}}{W_{S P}-\Omega_{S}}-\left(1-\nu_{S}\right)(1+I L)\left(1+\operatorname{paytax}_{S}\right)=0 .
$$

From this equation, and given the definition of $W_{S P}^{E}$, the (equilibrium) negotiated wage can be derived as

$$
W_{S P}=\left(1-\nu_{S}\right) \Omega_{S}+\frac{\nu_{S} P J_{1} m_{S}}{(1+I L)\left(1+\text { paytax }_{S}\right)},
$$

which shows that the product wage is a weighted average of the reservation wage, $\Omega_{S}$, and the marginal product of labor adjusted for the cost of borrowing and payroll taxes. An increase in the cost of borrowing, or in the payroll tax rate, lowers the equilibrium wage.

We also assume that the worker's reservation wage, $\Omega_{S}$, is related positively to wages in the public sector, $W_{S G}$, and the expected level of prices in the urban sector, (measured by the quantity $P_{U R B,-1}(1+E I N F L)$, where $E I N F L$ is the expected inflation rate), and negatively to the skilled unemployment rate, $U N E M P_{S} \cdot{ }^{14}$ Wage-setting in the public sector is thus assumed to play a signaling role to wage setters in the rest of the economy, as discussed earlier. Given the exogeneity of public sector employment (which therefore cannot represent a job opportunity for those seeking employment),

\footnotetext{
${ }^{14}$ Note that the reservation wage could be made a function of the unemployment benefit rate as well. However, an unemployment insurance scheme was introduced in Turkey only in August 1999; premium collections started in June 2000 and the first payments were made in March 2002. There is no evidence so far that these benefits have started to affect wage formation.
} 
this signaling role may be the result of "fairness" considerations, rather than the perception of broader employment options.

The introduction of expected prices in the urban sector measures the extent to which the worker's reservation wage is driven by the desire to maintain its real purchasing power. To the extent that expectations of inflation display persistence (as a result of low credibility, itself resulting perhaps from a higher risk of default on public debt, as discussed later), real wage inertia may result. When unemployment is high, the probability of finding a job (at any given wage) is low. Consequently, the higher the unemployment rate, the greater the incentive for the worker to moderate his or her wage demands. Thus

$$
\Omega_{S}=\Omega_{S 0} \frac{W_{S G}^{\phi_{S}^{1}}\left[P_{U R B,-1}(1+E I N F L)\right]_{S}^{\phi_{S}^{2}}}{U N E M P_{S}^{\phi_{S}^{3}}},
$$

where $\Omega_{S 0}>0$ and the $\phi_{S}^{k}$ coefficients, with $k=1,2,3$, are all positive. Equations (23) and (24) indicate that lower unemployment, higher public sector wages, and higher expected inflation raise the level of skilled wages in the private sector. The link between the levels of unemployment and private sector wages is consistent with the "wage curve" predicted by various efficiency wage models, and has received partial support in the empirical literature on labor markets in Turkey (see Ilkkaracan and Selim (2002)). This specification differs significantly from Phillips-curve type of wage equations, in which unemployment affects the rate of growth of nominal wages. To the extent that the expected inflation rate depends on past inflation (as documented in various studies on Turkey, such as Agénor (2002), Agénor and Bayraktar (2003), and Lim and Papi (1997)), our specification may generate some significant degree of real wage rigidity. And depending on the structure of the coefficients $\phi_{S}^{k}$, a variety of alternative specifications of the behavior of skilled and unskilled wages can be obtained. For instance, to impose the assumption that the target wage for skilled workers is fully indexed on expected inflation and does not depend on any other variable would require setting $\phi_{S}^{1}=\phi_{S}^{3}=0$ and $\phi_{S}^{2}=1$.

To determine unskilled wages in the private formal sector, we also assume that workers are engaged in individual bargaining with firms. Following the same reasoning as above, the wage-setting equation is thus

$$
W_{U P}=\left(1-\nu_{U}\right) \Omega_{U}+\frac{\nu_{U} P J_{2} m_{U}}{(1+I L)\left(1+\text { paytax }_{U}\right)},
$$


where $\operatorname{paytax}_{U}$ is the payroll tax rate on unskilled labor, $0<\nu_{U}<1$ measures the bargaining strength of unskilled workers and, from equation (9),

$$
m_{U}=\left(\frac{\beta_{X_{P} 2}}{\rho_{X_{P} 2}}\right)\left(\frac{J_{2}}{U_{P}}\right)^{1+\rho_{X_{P} 2}}
$$

The reservation wage is now given by

$$
\Omega_{U}=\Omega_{U 0} \frac{W_{U G}^{\phi_{U}^{1}}\left[P_{U R B,-1}(1+E I N F L)\right]_{U}^{\phi_{U}^{2}} W_{M}^{\phi_{U}^{4}}}{U N E M P_{U}^{\phi_{U}^{3}}} .
$$

Equation (27) has the same structure as (24), with $U N E M P_{U}$ denoting the unskilled open unemployment rate, except for an additional term in $W_{M}$, the legally-set unskilled minimum wage. This specification aims to capture the signaling role that changes in the minimum wage may have on wagesetting in the private sector. Thus, the minimum wage is implicitly assumed to be non-binding; it could be made so by setting $\phi_{U}^{k}=0$, for $k=1,2,3$ $\phi_{U}^{4}=\Omega_{U 0}=1$, and $\nu_{U}=0$.

\section{Private Sector Employment, Labor Supply, and Skills Formation} The demand for unskilled labor by firms in the formal private sector is determined by firms' profit maximization subject to the wage set through bargaining with workers, $W_{U P}$, as determined above. These firms have access only to bank credit to finance their working capital needs. Specifically, they borrow to finance their wage bill (inclusive of payroll taxes) prior to the sale of output. Moreover, we assume that banks can borrow only in domestic currency to finance working capital needs, unlike borrowing for capital accumulation, which (as discussed later) can be done in either domestic or foreign currency. As a result, the effective price of labor includes the bank lending rate on domestic-currency loans, $I L$.

We assume also that firms pay a payroll tax, at the rate $0<$ paytax $_{U}<1$ for unskilled workers, which is proportional to the wage bill, $W_{U P} U_{P}{ }^{15}$ The demand for unskilled labor by (and actual unskilled employment in) the private formal sector is thus given by

$$
U_{P}^{d}=J_{2}\left\{\frac{P J_{2}}{(1+I L)\left(1+\text { paytax }_{U}\right) W_{U P}}\left(\frac{\beta_{X_{P} 2}}{\alpha_{X_{P} 2}}\right)\right\}^{\sigma_{X_{P} 2}} .
$$

\footnotetext{
${ }^{15}$ In Turkey, payroll taxes are paid both by employees (in the form of social security contributions) and employers; see Tunali (2003). We capture employee contributions in our definition of "take home" pay.
} 
As in Agénor (2005a), mobility of the unskilled labor force between the formal and informal sectors is imperfect. Implicit in this assumption is the idea that the labor market in Turkey is characterized by the absence (or poor functioning) of institutions capable of processing and providing in a timely manner relevant information on job opportunities to potential applicantsparticularly those with low levels of qualifications. As a result, low-skilled workers employed in the informal sector are unable to engage in on-the-job search. Looking for a job in the formal sector for that category of workers requires, literally, being physically present at the doors of potential employers.

Formally, migration flows between the formal and informal sectors are assumed to be determined (as for rural-urban migration) by expected income opportunities. Following a similar reasoning as before, the supply of unskilled workers in the formal sector thus evolves over time according to

$$
\frac{\Delta U_{F}^{s}}{U_{I,-1}}=\beta_{F}\left[\sigma_{F} \ln \left\{\frac{U_{P,-1}^{d}}{U_{F,-1}^{s}-U_{G,-1}} \cdot \frac{\left(1-\operatorname{sstax}_{U}\right) W_{U P,-1}}{W_{I,-1}}\right\}\right]+\left(1-\beta_{F}\right) \frac{\Delta U_{F-1}^{s}}{U_{I,-2}},
$$

where $\beta_{F}>0$ denotes the speed of adjustment and $U_{P,-1}^{d} /\left(U_{F,-1}^{s}-U_{G,-1}\right)$ measures the probability of being hired in the private sector, approximated by the ratio of employed workers to those seeking employment (with a one-period lag). Note that expected income in the private formal sector is measured net of social security taxes, as in (18)).

The rate of unskilled unemployment in the formal sector, $U N E M P_{U}$, is thus given by

$$
U N E M P_{U}=1-\frac{\left(U_{G}+U_{P}^{d}\right)}{U_{F}^{s}} .
$$

The supply of labor in the informal economy, $U_{I}^{s}$, is obtained by subtracting from the urban unskilled labor force, $U_{U}$, the quantity $U_{F}^{s}$ :

$$
U_{I}^{s}=U_{U R B}^{s}-U_{F}^{s} .
$$

The informal labor market clears continuously, so that $U_{I}^{d}=U_{I}^{s}$. From equations (6) and (31), the equilibrium wage is thus given by ${ }^{16}$

$$
W_{I}=\beta_{X I}\left(\frac{P V_{I} \cdot V_{I}}{U_{I}^{s}}\right) .
$$

\footnotetext{
${ }^{16}$ To ensure that unskilled urban workers will always seek employment in the private formal sector first, we assume throughout that $W_{I}<W_{U P}$.
} 
The urban unskilled labor supply, $U_{U R B}^{s}$, increases as a result of exogenous growth (at the rate $g_{U R B}$ ), and rural-to-urban migration, net of "outflows" due to skills acquisition, $S K L$ :

$$
U_{U R B}^{s}=U_{U R B,-1}^{s}\left(1+g_{U R B}\right)+M I G-S K L-I M I G .
$$

As noted earlier, private urban firms pay a payroll tax, at the rate $0<$ $\operatorname{paytax}_{S}<1$, on their skilled wage bill, $W_{S} S_{P}$. From (8), the demand for skilled labor in the private formal sector is therefore given by

$$
S_{P}^{d}=J_{1}\left\{\frac{P J_{1}}{(1+I L)\left(1+\text { paytax }_{S}\right) W_{S P}}\left(\frac{\beta_{X_{P} 1}}{\rho_{X_{P} 1}}\right)\right\}^{\sigma_{X_{P} 1}} .
$$

As noted earlier, skilled workers who are unable to find a job in the formal economy opt to remain openly unemployed, instead of entering the informal economy. The rate of skilled unemployment, $U N E M P_{S}$, is thus given by the ratio of skilled workers who are not employed either by the private or the public sector, divided by the total population of skilled workers:

$$
U N E M P_{S}=1-\frac{\left(S_{G}^{T}+S_{P}^{d}\right)}{S},
$$

where $S_{G}^{T}$ is total skilled employment in the public sector, defined as

$$
S_{G}^{T}=S_{G}+S_{G}^{E},
$$

with $S_{G}^{E}$ denoting the exogenous number of skilled workers involved in providing education.

The acquisition of skills by unskilled workers takes place through an education system operated (free of charge) by the public sector. ${ }^{17}$ Specifically, the flow of unskilled workers who become skilled, $S K L$, is taken to be a CES function of the number of skilled workers (teachers) in the public sector engaged in providing education, $S_{G}^{E}$, and the government stock of capital in education, $K_{E D U}$ :

$$
S K L=\left[\beta_{E} S_{G}^{E-\rho_{E}}+\left(1-\beta_{E}\right) K_{E D U}{ }^{-\rho_{E}}\right]^{-\frac{1}{\rho_{E}}} .
$$

\footnotetext{
${ }^{17}$ Note that we abstract from the cost of acquiring skills (as measured by the number of years of schooling multiplied by the average cost of education per year), which should also affect the propensity to invest in skills acquisition. We also do not account from privatelyprovided education. During the 1980s and 1990s, several new private universities were founded in Turkey. However, they still account for only a small fraction of the graduates produced by the higher education system as a whole.
} 
The evolution of the skilled labor force depends on the rate at which unskilled workers acquire skills:

$$
S=\left(1-\delta_{S}\right) S_{-1}+S K L
$$

where $0<\delta_{S}<1$ is the rate of "depreciation" of the skilled labor force.

\subsubsection{International Labor Migration}

In line with the evidence on international migration flows in Turkey, we assume that migrants are essentially unskilled workers, and that all potential migrants are in the urban sector (as captured in (33)). Moreover, international migration flows are taken to be determined by the expected urban wage for unskilled labor, $E W_{U R B}$, given by (18), relative to the foreign wage measured in domestic-currency terms, $E W_{F}$. Assuming a one-period lag, we have

$$
E W_{F}=E R_{-1} \cdot W_{F,-1},
$$

with $W_{F}$ denoting the foreign wage measured in foreign-currency terms, which is assumed exogenous. Adopting a specification similar to (20), the migration function is specified as

$I M I G=U_{U R B,-1} \lambda_{I M}\left[\sigma_{I M} \ln \left(\frac{E R_{-1} \cdot W_{F,-1}}{E W_{U R B}}\right)\right]+\left(1-\lambda_{I M}\right) \frac{U_{U R B,-1}}{U_{U R B,-2}} I M I G_{-1}$,

where $0<\lambda_{I M}<1$ measures the speed of adjustment, and $\sigma_{I M}>0$ the partial elasticity of migration flows with respect to expected wages. Because the employment probability affects the expected domestic wage, the prevailing unskilled unemployment rate in the formal urban sector affects indirectly the decision to migrate. Again, costs associated with migration (such as relocation costs) are assumed to introduce some degree of persistence. As discussed later, remittances associated with international migration flows of unskilled labor are assumed to benefit unskilled households in the urban formal and informal sectors.

\subsection{Export Supply and Import Demand}

Given the CET functions (3) and (11), the efficient allocation of production between domestic sales and exports in the rural and private urban formal 
sectors yields export supply equations that depend on the price of exports $\left(P E_{A}\right.$ and $P E_{P}$, respectively) vis-à-vis domestic prices $\left(P D_{A}\right.$ and $P D_{P}$, respectively):

$$
E_{i}=D_{i}\left(\frac{P E_{i}}{P D_{i}} \cdot \frac{1-\beta_{E D i}}{\beta_{E D i}}\right)^{\sigma_{E D i}}, \quad i=A, P .
$$

Imports in both of these sectors compete with domestic goods. In the Armington tradition, both categories of goods are combined through CES aggregation functions to give composite goods, $Q_{i}^{s}$ :

$$
Q_{i}^{s}=\alpha_{Q_{i}}\left\{\beta_{Q_{i}} D_{i}^{-\rho_{Q_{i}}}+\left(1-\beta_{Q_{i}}\right) M_{i}^{-\rho_{Q_{i}}}\right\}^{-\frac{1}{\rho_{Q_{i}}}}, \quad i=A, P .
$$

Assuming cost minimization, import demand for both sectors, $M_{A}$ and $M_{P}$, can be written solely as a function of relative prices:

$$
M_{i}=D_{i}\left(\frac{P D_{i}}{P M_{i}} \cdot \frac{\beta_{Q i}}{1-\beta_{Q i}}\right)^{\sigma_{Q_{i}}}, \quad i=A, P,
$$

where $P M_{i}$ is the domestic price of imports (inclusive of tariffs) and $\sigma_{Q_{i}}=$ $1 /\left(1+\rho_{Q_{i}}\right)$ the elasticity of substitution between domestic and imported goods.

\subsection{Aggregate Supply and Demand}

As noted earlier (see equation (41)), supply of rural and private urban formal sector goods consists of composite goods, which combine imports and domestically produced goods. Both the informal and public sector goods are nontraded; total supply in each sector is thus equal to gross production, that is

$$
Q_{i}^{s}=X_{i}, \quad i=I, G .
$$

Aggregate demand in the rural and informal sectors, $Q_{A}^{d}$ and $Q_{I}^{d}$, consists of intermediate consumption and demand for final consumption-by both the government and households for the former, $C_{A}$ and $G_{A}$, and by households only in the latter, $C_{I}$ (the government does not spend on informal sector goods). Aggregate demand for the public and private goods, $Q_{G}^{d}$ and $Q_{P}^{d}$, consists not only of intermediate consumption and final consumption, but 
also of investment demand by private firms in the urban formal sector, $Z_{P}^{G}$ and $Z_{P}^{P}$, and the government, $Z_{G}$ :

$$
\begin{gathered}
Q_{A}^{d}=C_{A}+G_{A}+I N T_{A}, \\
Q_{I}^{d}=C_{I}+I N T_{I}, \\
Q_{G}^{d}=C_{G}+G_{G}+Z_{P}^{G}+I N T_{G}, \\
Q_{P}^{d}=C_{P}+G_{P}+Z_{P}^{P}+Z_{G}+I N T_{P},
\end{gathered}
$$

where $I N T_{j}$ is defined as total demand (by all $i$ productions sectors) for intermediate consumption of good $j$ :

$$
I N T_{j}=\sum_{i} a_{j i} X_{i}
$$

Total real government consumption of goods and services, $G$, is allocated in fixed proportions to the rural, private formal, and public goods:

$$
G_{i}=g g_{i} \frac{P G \cdot G}{P C_{i}}, \quad \text { for } i=A, P, G,
$$

where $P G$ is the government consumption deflator, and $P C_{i}$ the sales price of good $i$, and $\sum_{i} g g_{i}=1$.

Private final consumption for each production sector $i, C_{i}$, is the summation across all categories of households of nominal consumption of good $i$, deflated by the sales price of good $i$ :

$$
C_{i}=\sum_{h} C_{i h}=\sum_{h} x_{i h}+\frac{\sum_{h} c c_{i h}\left(C O N_{h}-\sum_{i} P C_{i} x_{i h}\right)}{P C_{i}},
$$

where $C_{i h}$ is consumption of good $i$ by household $h, x_{i h}$ is the autonomous level of consumption of good $i$ by household $h$, and $C O N_{h}$ total nominal consumption expenditure by household $h$. Equations (50) are based on the linear expenditure system. Coefficients $c c_{i h}$ indicate how total consumption expenditure by household $h$ is allocated to each type of good. They satisfy the usual restrictions, $0<c c_{i h}<1$ and $\sum_{i} c c_{i h}=1, \forall h$.

Private investment by urban formal sector firms, $Z_{P}$, is allocated between purchases of both public services and private goods $\left(Z_{P}^{G}\right.$ and $Z_{P}^{P}$, respectively):

$$
Z_{P}^{i}=z z_{i} \frac{P K \cdot Z_{P}}{P C_{i}}, \quad z z_{G}+z z_{P}=1,
$$

where $P K$ is the price of capital goods. 


\subsection{Profits and Income}

Firms' profits in the rural and urban informal sectors are given by

$$
P R O F_{i}=P V_{i} V_{i}-W_{i} U_{i} \text {, for } i=A, I \text {. }
$$

In addition to wages paid to both categories of workers, firms in the private formal urban sector are subject to payroll taxes and pay interest on the loans that they receive for working capital needs. Their profits are thus

$$
P R O F_{P}=P V_{P} V_{P}-(1+I L)\left[\left(1+\operatorname{paytax}_{U}\right) W_{M} U_{P}+\left(1+\operatorname{paytax}_{S}\right) W_{S} S_{P}\right] .
$$

Firms in the formal urban economy also pay income taxes and interest on their domestic and foreign borrowing, which serves to finance investment. Their income therefore differs from profits, and is given by

$Y F_{P}=\left(1-\operatorname{ftax}_{P}\right) P R O F_{P}-I L \cdot D L_{P,-1}-I L F \cdot D L F_{P,-1}-I F^{W} \cdot E R \cdot F L_{P,-1}$,

where $\operatorname{ftax}_{P}$ is the corporate income tax rate, $D L_{P}$ and $D L F_{P}$ are investmentrelated domestic- and foreign-currency loans allocated by domestic banks, $F L_{P}$ foreign borrowing for the purpose also of physical capital accumulation, ILF the interest rate charged on foreign-currency loans by domestic banks, and $I F^{W}$ the interest rate on foreign loans.

Profits from public production are given by

$$
P R O F_{G}=P V_{G} V_{G}-\left(1+\operatorname{paytax}_{U}\right) W_{U G} U_{G}-\left(1+\operatorname{paytax}_{S}\right) W_{S G} S_{G} .
$$

Commercial banks' profits, $P R O F_{B}$, are defined as the difference between revenues from loans to firms (be it for working capital or investment needs, in domestic and foreign currencies) and formal sector households, $D L_{F}$, income from government bonds (perpetuities, whose nominal price is assumed fixed at unity), and interest payments on borrowing from the central bank plus interest payments on both households' deposits (denominated in domestic and foreign currencies) and foreign loans:

$$
\begin{gathered}
\operatorname{PROF}_{B}=I L \cdot\left(D L_{P,-1}+D L_{F,-1}\right)+I L F \cdot D L F_{P,-1} \\
+I L \cdot\left[\left(1+\operatorname{paytax}_{U}\right) W_{M} U_{P}+\left(1+\operatorname{paytax}_{S}\right) W_{S} S_{P}\right]+I B \cdot G B_{B,-1}^{T}, \\
-I R \cdot D L_{B,-1}-I D \sum_{h} D D_{h,-1}-I D F \cdot E R \sum_{h} F D_{h,-1}-I F^{W} \cdot E R \cdot F L_{B,-1},
\end{gathered}
$$


where $I R$ (respectively $I D$ ) is the interest rate on central bank financing (respectively domestic-currency denominated bank deposits), $I B$ the nominal rate of return on government bonds, IDF the domestic interest rate on foreign-currency deposits held in the domestic banking system by each category of household $h, F D_{h}, G B_{B}^{T}$ total government bond holdings by commercial banks, $D L_{B}$ (respectively $F L_{B}$ ) borrowing from the central bank (respectively abroad), and $D D_{h}$ domestic-currency deposits by household $h$.

We assume that there are four categories of households in the economy. Rural households, identified with the sub-index $A$, consist of all workers employed in the rural sector. Informal sector households, identified with the sub-index $I$, consist of all the (unskilled) workers employed in the informal economy. Formal sector households, identified with the sub-index $F$, consist of all workers (skilled and unskilled) employed in the formal sector, both public and private. For all three groups, income is based on the return to labor (salaries), distributed profits, government transfers, remittances from abroad, and interest receipts on holdings of financial assets (net of borrowing from domestic banks). The fourth group consists of profit earners, identified with the sub-index $E$, whose income comes from firms' net earnings in the rural and formal private sectors, profits of commercial banks, interest on deposits, and government transfers.

Profits from rural production are assumed to be distributed in proportion $0<s h p_{A}<1$ to rural households and $1-s h p_{A}$ to (urban) profit earners. Using (52), income of rural households is given by

$$
Y H_{A}=W_{A} U_{A}+\operatorname{shp}_{A} P R O F_{A}+\gamma_{A} T R H+I D \cdot D D_{A,-1},
$$

where $0<\gamma_{h}<1$ is the portion of total government transfers $(T R H)$ each household $h$ receives, so that $\sum_{h} \gamma_{h}=1$, and $D D_{h}$ domestic-currency deposits in domestic banks by households $h$. Rural and informal sector households are assumed not to hold foreign-currency deposits, either domestically or abroad.

To capture the fact that firms in the informal urban sector tend to be small, family-owned enterprises, we assume that households in that sector own the firms in which they are employed. Using again (52), income of the informal sector households is given by

$$
Y H_{I}=P V_{I} V_{I}+\gamma_{I} T R H+I D \cdot D D_{I,-1}+\tau_{I} E R \cdot R E M I T,
$$

where REMIT measures the foreign-currency value of the flow of remittances 
from (unskilled) workers employed abroad, and $0<\tau_{I}<1$ the fraction of these remittances that are allocated to households in the informal economy.

Income of the formal sector household consists of net salaries (that is, take-home pay) collected from private firms and the government, income from formal sector firms, transfers from the government, remittances from abroad, and interest receipts on deposits (in domestic and foreign currency, held both domestically and abroad), net of interest payments on borrowing from commercial banks:

$$
\begin{gathered}
Y H_{F}=\left(1-\operatorname{sstax}_{U}\right) \sum_{j=P, G} W_{U j} U_{j}+\left(1-\operatorname{sstax}_{S}\right) \sum_{j=P, G} W_{S j} S_{j}+\operatorname{sh} p_{P}^{F} Y F_{P}(59) \\
+W_{S G} S_{G}^{E}+\gamma_{F} T R H+I D \cdot D D_{F,-1}+E R\left(I D F \cdot F D_{F,-1}+I F_{R F}^{W} F D_{F,-1}^{W}\right) \\
-I L \cdot D L_{F,-1}+\left(1-\tau_{I}\right) E R \cdot R E M I T,
\end{gathered}
$$

where $0<\operatorname{sh} p_{P}^{F} \leq 1$ is the share of private formal sector firms' net income distributed to households in that sector, $F D_{F}$ foreign-currency deposits held domestically, $I F_{R F}^{W}$ the risk-free foreign interest rate on foreign-currency deposits held abroad by household $h, F D_{h}^{W}$, and $D L_{F}$ domestic borrowing from commercial banks. sstax $_{U}$ and sstax $_{S}$ are the social security taxes (assumed proportional to the wage) that workers employed in the private formal sector must pay.

Profit earners receive a fraction $0<s h p_{P}^{E} \leq 1-\operatorname{sh} p_{P}^{F}$ of private formal sector firms' retained earnings, as well as a share $1-s h p_{A}$ of profits from the rural sector, a share $0<s h p_{B}^{E}<1$ of commercial banks' income, $P R O F_{B}$, and interest on bank deposits (held both domestically and abroad). Thus, profit earners' income is:

$$
\begin{gathered}
Y H_{E}=\left(1-\operatorname{sh} p_{A}\right) P R O F_{A}+s h p_{P}^{E} Y F_{P}+s h p_{B}^{E} P R O F_{B} \\
+\gamma_{E} T R H+I D \cdot D D_{E,-1}+E R\left(I D F \cdot F D_{E,-1}+I F_{R F}^{W} F D_{E,-1}^{W}\right)+I B \cdot G B_{E,-1},
\end{gathered}
$$

where $G B_{E^{\prime}}$ denotes government bond holdings by profit earners, who are the only category of households to hold such bonds. Note also that profit earners do not borrow directly from commercial banks or abroad.

\subsection{Savings and Wealth Accumulation}

Each category of household $h$ saves a fraction, $0<$ srate $_{h}<1$, of its disposable income:

$$
S A V_{h}=\operatorname{srate}_{h}\left(1-\operatorname{inctax}_{h}\right) Y H_{h},
$$


where $0<\operatorname{inctax}_{h}<1$ is the income tax rate applicable to household category $h$.

The savings rate is a positive function of the expected real interest rate on domestic-currency deposits:

$$
\text { srate }_{h}=s_{0}^{h}\left(\frac{1+I D}{1+E I N F L}\right)^{\sigma_{S A V}^{h}}, \quad s_{0}^{h}>0 .
$$

In principle, given the portfolio structure described later, the expected rate of return on other interest-bearing assets should also affect the propensity to save. However, as illustrated in Figure 3, the evidence for Turkey suggests that it is mostly the real interest rate on domestic-currency deposits that matters for private savings (see Ozcan, Gunay, and Ertac (2003)). For simplicity, we therefore chose to exclude other rates of return from our specification.

The portion of disposable income that is not saved is allocated to consumption:

$$
C O N_{h}=\left(1-\operatorname{inctax}_{h}\right) Y H_{h}-S A V_{h} .
$$

The total flow of savings of each household category is channeled into the accumulation of financial wealth, $W T_{h}$, which also accounts for valuation effects on the stock of foreign-currency deposits held domestically and abroad, $F D_{h}$ and $F D_{h}^{W}$, associated with changes in the nominal exchange rate:

$$
W T_{h}=W T_{h,-1}+S A V_{h}+\Delta E R \cdot\left(F D_{h,-1}+F D_{h,-1}^{W}\right),
$$

with $F D_{h}=F D_{h}^{W}=0$ for $h=A, I$.

\subsection{Private Investment}

The determinants of private investment in Turkey have been the subject of a large literature, going back to, among others, Chibber and van Wijnbergen (1992), and including more recently studies by Guncavdi, Bleaney, and McKay (1998, 1999) and Erden (2002). Chibber and van Wijnbergen (1992), in a study over the period 1970-86, found that private investment in Turkey depends positively on the rate of capacity utilization (which captures aggregate demand pressures) and the ratio of private sector credit to GNP, and negatively on the real effective cost of borrowing and non-infrastructure 
public investment (which captures crowding out effects associated with public spending). Guncavdi, Bleaney, and McKay (1998) developed an errorcorrection model in which private investment depends in the long run on output and the relative cost of capital (as measured by the ratio of the cost of credit to the wage rate), but can be influenced in the short run by the availability of bank credit. Focusing on the period 1963-92, they found that, following the financial liberalization program implemented in the early 1980s, private investment in Turkey became less sensitive to credit supply and somewhat more sensitive to the cost of capital. By contrast, Erden (2002), in a study over the period 1968-98, found that both credit availability and uncertainty over the cost of credit (rather than its level) affect private investment, the first positively, and the second negatively. ${ }^{18}$ In a study covering the period 1968-94, Guncavdi, Bleaney, and McKay (1999) found that financial liberalization (as measured by a dummy coefficient for the post-1980 period) appears to have had an adverse effect on investment by raising the relative cost of capital, and a positive effect by reducing credit constraints. They also find evidence of a strong accelerator effect (in both the short and the long run) and overall public investment appears to have a significant, negative effect on private capital formation.

The specification of the determinants of private investment in our model dwells on these results. As noted earlier, only firms in the private formal urban sector invest in physical capital; their desired rate of capital accumulation is assumed to depend on several factors. The first is the public capital stock in infrastructure (in proportion of the urban labor force), which has a positive impact, through its complementarity effect. ${ }^{19}$ The second is the growth rate of real GDP, which captures the conventional accelerator effect. The third is the expected real cost of borrowing from domestic banks, which has a negative effect. Figure 4 illustrates well the positive correlation between changes in private investment and real output growth (the accelerator effect), as well as the tendency for private capital formation to evolve in opposite direction to movements in real interest rates. ${ }^{20}$

\footnotetext{
${ }^{18}$ Neither one of these two studies accounts for the impact of public investment, as in Chhibber and van Wijnbergen (1992). In addition, both studies use deposit rates to measure the cost of credit - a debatable assumption, as discussed subsequently.

${ }^{19}$ See Agénor and Montiel (1999) and Agénor (2004, Chapter 2) for a detailed discussion of this effect and a review of the empirical evidence in general.

${ }^{20}$ In Figure 3 the deposit rate is used instead of the lending rate, because we do not have sufficiently long time series on the latter variable. This is far from being a good proxy for
} 
We do not account explicitly for the quantity of credit, in addition to its cost, in our specification of the investment function, for two reasons. First, the evidence provided by Guncavdi, Bleaney, and McKay (1999), as well as others, suggests that the impact of credit constraints on investment is less significant nowadays than was the case in the early 1980s, following financial reforms; at the same time, the (expected) cost of credit appears to have become a more important consideration for firms. ${ }^{21}$ Second, even in the context of the recent crisis, there is no strong evidence that the fall in credit to private sector firms (at least the bigger ones) resulted from a credit crunch, that is, a supply-induced contraction in lending; on the contrary, a recent study by the World Bank (2003) suggests that demand-side factors (high interest rates, low economic activity) were largely to blame. In fact, as discussed later, we assume that the supply of bank loans to private sector firms is perfectly elastic at the prevailing interest rate, and that only formal sector households are subject to credit rationing.

Formally, the desired level of investment, $Z_{P}^{d}$, is given by

$$
\frac{P K \cdot Z_{P}^{d}}{N G D P_{-1}}=\left(\frac{K_{I N F}}{U_{U R B}^{s}+S}\right)^{\sigma_{K I N F}}\left(1+\frac{\Delta R G D P_{-1}}{R G D P_{-2}}\right)^{\sigma_{A C C}}\left(\frac{1+I L}{1+E I N F L}\right)^{-\sigma_{I L}},
$$

where $N G D P$ is nominal GDP at market prices, defined as the sum of value added and indirect taxes on goods and services (including tariff revenue):

$$
N G D P=\sum_{i} P V_{i} V_{i}+I N D T A X
$$

or equivalently, as the sum of expenditure and net exports:

$$
N G D P=\sum_{i} P C_{i}\left(C_{i}+G_{i}+Z_{P}^{i}\right)+Z_{G}+E R\left(w p e_{i} E_{i}-w p m_{i} M_{i}\right) .
$$

Real GDP, $R G D P$, is defined as, using base-period prices:

$$
R G D P=\sum_{i} P C_{i, 0}\left(C_{i}+G_{i}+Z_{P}^{i}\right)+Z_{G}+E R_{0}\left(w p e_{i, 0} E_{i}-w p m_{i, 0} M_{i}\right),
$$

the cost of credit, for reasons that we discuss later on.

${ }^{21}$ It should be noted that Sancak (2002) did not find any evidence that financial liberalization led to a relaxation of the borrowing constraints faced by Turkish firms in the 1980s and 1990s. However, the methodology that he used to test for structural breaks is rather weak. 
where $Z_{P}^{i}=0$ for $i=A, I, G_{i}=0$ for $i=I$, and $E_{i}=0$ for $i=I, G$.

Actual investment adjusts to its desired level through a partial adjustment mechanism:

$$
\Delta\left(\frac{P K \cdot Z_{P}}{N G D P_{-1}}\right)=\lambda_{P I N V}\left(\frac{P K \cdot Z_{P}^{d}}{N G D P_{-1}}-\frac{P K_{-1} \cdot Z_{P,-1}}{N G D P_{-2}}\right),
$$

where $0<\lambda_{P I N V}<1$.

The private capital stock depends on the flow level of investment and the depreciation rate of capital from the previous period, $0<\delta_{P}<1$ :

$$
K_{P}=K_{P,-1}\left(1-\delta_{P}\right)+Z_{P-1} .
$$

\subsection{Asset Allocation and the Credit Market}

We consider in turn the determination of the portfolio structure of each category of households, the demand for credit by firms, and the behavior of commercial banks. The balance sheets of all agents (including the central bank and the consolidated public sector) are summarized in Table 1.

\subsubsection{Households}

Households' financial wealth is allocated to five categories of assets: domestic money (cash holdings, which bear no interest), $H_{h}$, domestic currencydenominated bank deposits held at home, $D D_{h}$, foreign currency-denominated deposits held domestically, $F D_{h}$, foreign currency-denominated deposits held abroad, $F D_{h}^{W}$, and holdings of government bonds, $G B_{h}$. By allowing households to hold foreign-currency denominated deposits in the domestic banking system, we therefore account for the high level of dollarized liabilities of the Turkish financial system. Indeed, as shown in Figure 1, such deposits continue to account for a sizable share of total bank deposits in Turkey. ${ }^{22}$

Given liabilities of $D L_{h}$, net financial wealth, $W T_{h}$, is defined as

$$
W T_{h}=H_{h}+E R\left(F D_{h}+F D_{h}^{W}\right)+D D_{h}+G B_{h}-D L_{h} .
$$

As noted earlier, rural and informal sector households hold no foreigncurrency deposits, banks lend only to urban formal sector households (in

\footnotetext{
${ }^{22}$ See Civcir (2002) for a discussion of dollarization in Turkey. Note that our specification of dollarization on the asset side of banks' balance sheets accounts only for foreign-currency denominated loans to firms, not households.
} 
addition to formal sector firms), and only profit earners hold government bonds. Thus, in the above equation, $F D_{h}=F D_{h}^{W}=0$ for $h=A, I, D L_{h}=0$ for $h \neq F$, and $G B_{h}=0$ for $h \neq E$.

The demand function for currency by each household $h$ is taken to be positively related to consumption of that group (to capture a transactions motive), $C O N_{h}$, and negatively to expected inflation, EINFL, and the interest rate on domestic-currency deposits, $I D$. In addition, for formal sector households and profit earners, it also depends negatively on the rate of return on foreign-currency denominated assets, defined as a weighted average of the interest rates on foreign-currency deposits held at home and abroad, $1+I D F$ and $1+I F_{R F}^{W}$, with both rates adjusted for the expected rate of depreciation, $1+E D E P R:^{23}$

$$
H_{h}^{d}=\frac{C O N_{h}^{\theta_{C O N}^{h}} E I N F L^{-\theta_{E I N F L}^{h}}(1+I D)^{-\theta_{D D}^{h}}}{\left\{[(1+I D F)(1+E D E P R)]_{F D}^{\kappa_{F D}^{h}}\left[\left(1+I F_{R F}^{W}\right)(1+E D E P R)\right]^{1-\kappa_{F D}^{h}}\right\}^{\theta_{I F}^{h}}},
$$

or equivalently

$$
H_{h}^{d}=\frac{C O N_{h}^{\theta_{C O N}^{h}} E I N F L^{-\theta_{E I N F L}^{h}}(1+I D)^{-\theta_{D D}^{h}}}{\left\{(1+E D E P R)(1+I D F)^{\kappa_{F D}^{h}}\left(1+I F_{R F}^{W}\right)^{1-\kappa_{F D}^{h}}\right\}^{\theta_{I F}^{h}}},
$$

where $\theta_{I F}^{h}=0$ for $h=A, I$. The coefficient $\kappa_{F D}^{h}$ is the relative weight attached to the domestic interest rate on foreign-currency deposits held at home in the overall measure of the rate of return on foreign-currency denominated assets. It is calculated as the relative share of these deposits in the previous period:

$$
\kappa_{F D}^{h}=\frac{F D_{h,-1}}{F D_{h,-1}+F D_{h,-1}^{W}}, \quad h=F, E .
$$

The total demand for cash is thus

$$
H^{d}=\sum_{h} H_{h}^{d}
$$

\footnotetext{
${ }^{23}$ Note that in equation (70), as well as in (74), (75) and (76), it is the risk-free world interest rate (which is the relevant measure of the rate of return for lenders) that appears.
} 
To determine the allocation of bank deposits, we must distinguish between rural and urban informal sector households, on the one hand, and formal sector households and profit earners, on the other. For the first group, which holds no foreign-currency deposits, no government bonds, and does not borrow from banks, the demand for domestic-currency deposits can be obtained from the wealth equation (69), given that (64) determines $W T_{h}$ and (70) determines the demand for currency:

$$
D D_{h}^{d}=W T_{h}-H_{h}^{d}, \quad h=A, I .
$$

For formal sector households and profit earners, we assume that portfolio choices follow a two-step process similar to the one described in Agénor and Khan (1996). First, households determine the allocation between domesticand total foreign-currency denominated deposits (held either at home or abroad). Second, they decide how to allocate total foreign-currency denominated deposits between deposits in the domestic banking system and deposits abroad.

Formally, in the first stage formal sector households and profit earners determine the ratio $D D_{h} / E R\left(F D_{h}+F D_{h}^{W}\right)$ as a function of the interest rate on domestic-currency deposits, on the one hand, and the overall rate of return on foreign-currency denominated assets, defined again as a weighted average of the rates of return on foreign-currency deposits held at home and abroad:

$$
\frac{D D_{h}}{E R\left(F D_{h}+F D_{h}^{W}\right)}=\left\{\frac{1+I D}{(1+E D E P R)(1+I D F)^{\kappa_{F D}^{h}}\left(1+I F_{R F}^{W}\right)^{1-\kappa_{F D}^{h}}}\right\}^{\theta_{D D}^{h}},
$$

where $h=F, E$ and $\kappa_{F D}^{h}$ is as defined earlier. ${ }^{24}$

In the second stage, the allocation of foreign-currency denominated deposits between home and abroad is given by

$$
\frac{F D_{h}}{F D_{h}^{W}}=\left(\frac{1+I D F}{1+I F_{R F}^{W}}\right)^{\theta_{F D}^{h}}, \quad h=F, E
$$

which does not depend on exchange rate expectations.

\footnotetext{
${ }^{24}$ For profit earners, both the demand for cash (equation (70)) and the relative demand for domestic-currency deposits (equation (74)) could also be specified as negatively related to the expected rate of return on government bonds.
} 
The second-stage portfolio decision is generally non-trivial because households may not be indifferent as to the location of their deposits as a result, for instance, of high transactions costs associated with shifting funds across borders, or a perceived risk of confiscation - which could take for instance the form of a forced conversion of foreign-currency deposits held in domestic banks into assets denominated in domestic currency. If formal sector households and profit earners were indifferent as to the location of their foreigncurrency deposits, $F D_{h}$ and $F D_{h}^{W}$ would be perfect substitutes. In that case $\theta_{F D}^{h} \rightarrow \infty$ and, in the absence of capital controls, the following interest rate parity condition would hold exactly:

$$
1+I D F=1+I F_{R F}^{W} .
$$

This condition implies that the interest rate on foreign-currency denominated deposits at home cannot deviate from the world risk-free interest rate. In general, however, we will assume that foreign-currency deposits at home and abroad are imperfect substitutes, and that (as discussed later) IDF is set domestically by commercial banks.

The demand for government bonds by profit earners, $G B_{E}^{d}$, measured as a proportion of interest-bearing wealth, depends on rates of returns on all interest-bearing assets:

$$
\frac{G B_{E}^{d}}{W T_{E}-H_{E}}=\frac{(1+E I B)^{\theta_{G B}^{E}}(1+I D)^{-\theta_{D D}^{E}}}{\left[(1+E D E P R)(1+I D F)^{\kappa_{F D}^{E}}\left(1+I F_{R F}^{W}\right)^{1-\kappa_{F D}^{E}}\right]^{\theta_{F D}^{E}}},
$$

where $\kappa_{F D}^{E}$ is defined in $(71)$ and $E I B$ is the expected rate of return on government bonds.

Note that, given (64), (70), (74), (75), and (76), the budget constraint (69) can be used to determine residually the demand for one of the four interestbearing assets by profit earners - for instance the demand for domestic-currency bank deposits, in a manner similar to equation (73) for rural and informal sector households:

$$
D D_{E}=W T_{E}-H_{E}-E R\left(F D_{E}+F D_{E}^{W}\right)-G B_{E} .
$$

Similarly, for formal sector households,

$$
D D_{F}=W T_{F}-H_{F}-E R\left(F D_{F}+F D_{F}^{W}\right)+D L_{F} .
$$




\subsubsection{Firms}

Domestic firms borrow both domestically (in domestic and foreign currencies) and abroad not only to finance their working capital needs, as discussed earlier, but also to finance their investment plans. Borrowing on world capital markets, $F L_{P}$, is treated as exogenous. Taking into account retained earnings, the investment financing constraint requires that

$$
P K \cdot Z_{P}=\left(1-\operatorname{sh} p_{P}^{F}-s h p_{P}^{E}\right) Y F_{P}+\Delta D L_{P}^{T}+E R \cdot \Delta F L_{P},
$$

where $D L_{P}^{T}$ represents total domestic borrowing from commercial banks.

Equation (77) can be solved for $D L_{P}^{T}$, that is, total demand for bank loans:

$$
D L_{P}^{T}=D L_{P,-1}^{T}+P K \cdot Z_{P}-\left(1-\operatorname{sh} p_{P}^{F}-s h p_{P}^{E}\right) Y F_{P}-E R \cdot \Delta F L_{P} .
$$

\subsubsection{Commercial Banks}

The balance sheet of commercial banks shows, on the asset side, loans to formal sector households and private formal sector firms for investment purposes, $D L_{F}+D L_{P}^{T}$, holdings of government bonds, $G B_{B}^{T}$, and reserve requirements at the central bank, $R R$. On the liability side, it accounts for domesticand foreign-currency deposits by the public, $\sum_{h}\left(D D_{h}+E R \cdot F D_{h}\right)$, borrowing from the central bank, $D L_{B}$, and foreign loans (measured in domesticcurrency terms), $E R \cdot F L_{B}$. With $N W_{B}$ denoting commercial banks' net worth, their balance sheet can be written as

$D L_{F}+D L_{P}^{T}+G B_{B}^{T}+R R-N W_{B}=\sum_{h}\left(D D_{h}+E R \cdot F D_{h}\right)+D L_{B}+E R \cdot F L_{B}$.

Reserve requirements are assumed to be levied at the same proportional rate on both domestic- and foreign-currency denominated deposits:

$$
R R=\operatorname{rreq} \sum_{h}\left(D D_{h}+E R \cdot F D_{h}\right),
$$

where $0<$ rreq $<1$ is the (effective) reserve requirement rate. For simplicity, banks are assumed to hold no excess liquid reserves.

Firms' total domestic borrowing from commercial banks is defined as

$$
D L_{P}^{T}=D L_{P}+E R \cdot D L F_{P}
$$


which implies, using (78),

$$
D L_{P}=D L_{P}^{T}-E R \cdot D L F_{P}
$$

Foreign-currency loans to domestic firms are assumed to remain constant relative to banks' foreign currency liabilities, which consist of foreign borrowing and foreign currency deposits from households:

$$
E R \cdot D L F_{P}=\phi_{D L}^{P}\left(F L_{B}+\sum_{h} E R \cdot F D_{h}\right) .
$$

Commercial banks' holdings of government bonds, $G B_{B}^{T}$, are made up of two components:

$$
G B_{B}^{T}=G B_{B}^{p}+G B_{B}^{d}
$$

where $G B_{B}^{p}$ is direct placement of bonds by the government and $G B_{B}^{d}$ is additional commercial banks' demand for bonds. Direct bond placement with commercial banks is given as a constant share of the total outstanding stock of government bonds: ${ }^{25}$

$$
G B_{B}^{p}=\phi_{G B}^{B, p} \cdot G B^{s}, \quad \phi_{G B}^{B, p}>0 .
$$

The additional demand for government bonds by commercial banks (as a ratio of net wealth) is positively related to the interest rate on these bonds and negatively to their opportunity cost, that is, the lending rate:

$$
\frac{G B_{B}^{d}}{N W_{B}}=\phi_{G B}^{B, d}\left(\frac{1+E I B}{1+I L}\right)^{\theta_{G B}^{B}}, \quad \phi_{G B}^{B, d}>0,
$$

where $E I B$ is again the expected rate of return on government bonds. We assume that due to existing banking regulations, domestic banks cannot choose to allocate freely a fraction of their wealth to holdings of foreign bonds; as a result, we exclude the rate of return on foreign-currency assets from (85).

The demand for foreign loans by commercial banks depends on the cost of domestic funding from households and the central bank, in addition to the (premium-inclusive) cost of foreign borrowing. Given the arbitrage conditions described later (equations (89) and (91)), this demand function can be specified only as a function of the official interest rate, $I R$, and the world

\footnotetext{
${ }^{25}$ This placement rule can be thought of as accounting for the bonds held by public banks, which are not explicitly modelled.
} 
interest rate (inclusive of the external risk premium), $I F^{W}$, adjusted for expected depreciation:

$$
\frac{E R \cdot F L_{B}}{N W_{B}}=\phi_{F L}^{B}\left[\frac{1+I R}{\left(1+I F^{W}\right)(1+E D E P R)}\right]^{\theta_{F L}^{B}}, \quad \phi_{F L}^{B}>0 .
$$

This equation implies that if domestic and foreign borrowing are perfect substitutes (that is, $\theta_{F L}^{B} \rightarrow \infty$ ), then the central bank's refinancing rate cannot deviate from the premium-inclusive, and expectations-adjusted, world interest rate:

$$
1+I R=\left(1+I F^{W}\right)(1+E D E P R) .
$$

As indicated earlier, banks' net income is distributed in proportion $s h p_{B}^{E}$ to profit earners. Commercial banks' net worth therefore evolves over time according to

$$
\Delta N W_{B}=\left(1-\operatorname{sh} p_{B}^{E}\right) P R O F_{B}-\Delta E R\left(\sum_{h} F D_{h,-1}+F L_{B,-1}-D L_{F,-1}\right),
$$

where the first term on the right-hand side represents retained earnings by commercial banks and the second term represents capital losses (gains) associated with nominal exchange rate depreciations (appreciations).

Lending by commercial banks to formal sector households, $D L_{F}$, is assumed exogenous. This is consistent with the recent evidence suggesting that in Turkey households - and to some extent small businesses - appear to be significantly affected by supply-side constraints on the credit market (see World Bank (2003)). By contrast, lending to firms is taken to be demand determined, as shown in equation (78). At the same time, banks have access to an infinitely elastic supply of loans by the central bank at the prevailing official interest rate. They therefore borrow whatever residual liquidity they need, given their domestic deposit base and foreign borrowing. $D L_{B}$ is thus determined residually from the balance sheet constraint (79), that is, using (80):

$$
\begin{gathered}
D L_{B}=D L_{F}+D L_{P}^{T}+G B_{B}^{T} \\
-(1-r r e q) \sum_{h}\left(D D_{h}+E R \cdot F D_{h}\right)-E R \cdot F L_{B}-N W_{B} .
\end{gathered}
$$




\subsubsection{Interest Rates and Risk Premia}

Banks set both deposit and lending interest rates. The deposit rate on domestic currency-denominated deposits, $I D$, is set equal to the cost of funds provided by the central bank, IR:

$$
1+I D=1+I R .
$$

This specification implies that banks are indifferent as to the source of their domestic-currency funds - or, equivalently, they view domestic-currency deposits and loans from the central bank as perfect substitutes (at the margin). ${ }^{26}$ The lower panel of Figure 5 shows the behavior of the deposit rate, the money market rate (the rate at which banks borrow from each other) and the three-month repurchase rate (which can be viewed as the policy rate, $I R$ ). The figure shows that, although there are periods during which the three rates tend to evolve in different directions, the degree of synchronization appears to have increased in recent years. We therefore view the "pricing" (or arbitrage) condition (89) as a reasonable approximation to current facts.

The interest rate on foreign-currency deposits at home is set on the basis of the (premium-inclusive) marginal cost of borrowing on world capital markets:

$$
1+I D F=1+I F^{W} .
$$

In turn, $I F^{W}$ depends on the world risk-free interest rate, $I F_{R F}^{W}$, and an external risk premium, EXTPR:

$$
1+I F^{W}=\left(1+I F_{R F}^{W}\right)(1+E X T P R) .
$$

Combining equations (75), (90), and (91) implies that the allocation of foreign-currency deposits between home and abroad by formal sector house-

\footnotetext{
${ }^{26}$ Altnernatively, it could be assumed that there is imperfect substitution between borrowed reserves and deposits. The deposit rate could then be specified as a positive function of both the cost of borrowing from the central bank and variables such as the expected inflation rate.
} 
holds and profit earners depends only on the external risk premium: ${ }^{27}$

$$
\frac{F D_{h}}{F D_{h}^{W}}=(1+E X T P R)^{\theta_{F D}^{h}}, \quad h=F, E .
$$

The external risk premium consists of two components: an exogenous element, denoted $C O N T A G$, which captures idiosyncratic changes in "sentiment" on world capital markets (including contagion effects), and an endogenous component, which captures the perceived degree of country risk and depends on the ratio of the economy's total foreign debt to exports:

$$
E X T P R=C O N T A G+\frac{\kappa_{E R P}}{2}\left(\frac{\sum_{i=P, B, G} F L_{i}}{\sum_{i=A, P} w p e_{i} E_{i}}\right)^{2},
$$

where $\kappa_{E R P}>0$ and the quadratic form is used to capture the idea that the external risk premium is a convex function of the debt-to-export ratio. ${ }^{28}$

The impact of expectations of exchange rate depreciation on the interest rate on foreign-currency deposits in the domestic banking system can be gauged from Figure 6, which shows the behavior of three-month deposit rates on Turkish liras and U.S. dollars. The lower panel of the figure shows a dramatic fall in the expected depreciation rate in late 1999, which tends to indicate that the stabilization program introduced at that time gained rapid credibility. However, the data also show that the credibility gain disappeared equally rapidly in the ensuing months. Figure 7 displays a measure of the external risk premium for Turkey, J. P. Morgan's stripped spread for that country. The figure shows as well the behavior of the spread from J. P. Morgan's emerging markets bond index (EMBI). Co-movements in the two series tend to capture "contagion" effects, which are apparent in the period leading up to Argentina's peso crisis for instance.

The interest rate on domestic-currency loans, $I L$, is set as a premium over the marginal cost of funds. Given the arbitrage conditions (89) and

\footnotetext{
${ }^{27}$ Note the importance of distinguishing between the premium-inclusive world interest rate faced by domestic borrowers, $I F^{W}$, on the basis of which banks set the interest rate on foreign-currency deposits held domestically, and the risk-free rate faced by lenders, $I F_{R F}^{W}$, which affects the demand for deposits held abroad by households. In the absence of a risk premium, both rates would be equal and, given the pricing condition (90), equation (75) would imply that the ratio $F D_{h} / F D_{h}^{W}$ is constant over time.

${ }^{28}$ In line with the results of Fiess (2003) for several middle-income Latin American countries, the country risk premium could also be made a function of the domestic public debt to GDP ratio. This would provide an additional channel through which fiscal consolidation may affect the economy.
} 
(90), this cost is simply a weighted average of the cost of borrowing from the central bank (or, equivalently, the deposit rate), and borrowing on world capital markets. Taking into account as well the (implicit) cost of holding reserve requirements, the lending rate is thus determined by

$$
1+I L=\frac{\left\{(1+I R)^{\kappa_{D L}^{B}}\left[\left(1+I F^{W}\right)(1+E D E P R)\right]^{1-\kappa_{D L}^{B}}\right\}}{(1+D O M P R)^{-1}(1-\text { rreq })},
$$

where $0<\kappa_{D L}^{B}<1$ denotes the relative share of domestic-currency borrowing by banks in the previous period,

$$
\kappa_{D L}^{B}=\frac{\sum_{h} D D_{h,-1}+D L_{B,-1}}{\sum_{h} D D_{h,-1}+D L_{B,-1}+E R_{-1}\left(\sum_{h} F D_{h,-1}+F L_{B,-1}\right)},
$$

and $D O M P R$ is the domestic risk premium, which is inversely related to the ratio of firms' assets over their liabilities:

$$
D O M P R=\left[\frac{\delta_{c} P K_{-1} K_{P-1}}{D L_{P,-1}+E R_{-1}\left(D L F_{P,-1}+F L_{P,-1}\right)}\right]^{-\kappa_{D R P}},
$$

where $\kappa_{D R P}>0$ and $0<\delta_{c} \leq 1$.

The risk premium charged by banks reflects the perceived risk of default on their loans to domestic firms. The link between the premium and firms' net worth has been much emphasized in the recent literature on real-financial sector linkages. Bernanke, Gertler, and Gilchrist (2000), and Gertler, Gilchrist, and Natalucci (2001), in particular, emphasized the impact of collateralizable wealth on bank pricing decisions. ${ }^{29}$ The higher the value of firms' physical assets (which measures "pledgeable" collateral), $P K \cdot K_{P}$, or an "effective" fraction $\delta_{c}$ of that amount, relative to both domestic and foreign financial liabilities, $D L_{P}+E R \cdot\left(D L F_{P}+F L_{P}\right)$, the higher the proportion of total lending that banks can recoup in the event of default. This reduces the risk premium and the cost of borrowing.

This specification has important implications for understanding the interactions between the real and financial sides in the model. A large nominal

\footnotetext{
${ }^{29}$ Collateralizable wealth (or the net present value of firms' profits) could also act as a quantity constraint on bank borrowing, as for instance in the models of Krishnamurthy (2003), which extends the analysis of Kiyotaki and Moore (1997), and Xie and Yuen (2003). In both settings, shocks to credit-constrained firms are amplified through changes in collateral values and transmitted to output. See, however, Cordoba and Ripoll (2004) for a dissenting view on the ability of collateral constraints to generate output amplification.
} 
exchange rate depreciation (that is, a rise in $E R$ ), would reduce firms' net worth, thereby raising the cost of capital and leading to a contraction of private investment. In turn, this would exert contractionary pressures. The extent to which output contracts would depend, in a general equilibrium setting, on the elasticity of the demand for loans. In the model, the demand for loans is residually determined to finance investment expenditures (see equation (78)), whose desired level depends on both the growth rate of output and the real lending rate (see equation (65)). The direct effect of a rise in the lending rate resulting from lower net worth would reduce desired investment and the demand for domestic loans, thereby offsetting at least to some extent the impact of a currency depreciation on firms' financial liabilities (which operates through $E R \cdot\left(D L F_{P}+F L_{P}\right)$ ), by reducing $D L_{P}$ and $D L F_{P}$.

In addition, if households are net creditors in foreign currency (as is the case here), the depreciation could have a positive effect on private spending (through its impact on disposable income), thereby stimulating output. In general, therefore, the extent to which a currency depreciation is contractionary through its effect on the risk premium depends not only on the elasticity of the premium with respect to net worth but also the sensitivity of investment to the lending rate and the magnitude of wealth effects on consumption.

Changes in the risk premium may explain why, in practice, spreads between the loan and deposit rates appear to fluctuate significantly over time, as shown in Figure $5 .^{30}$ In fact, as suggested in Figure 8, the bank lending spread tends to follow a counter-cyclical pattern. This behavior is consistent with the view that, in downswings, the value of borrowers' collateral tends to fall - as a result of a fall in asset prices in general, and in our case more specifically a drop in the price of capital goods. ${ }^{31}$ With the perceived risk of default increasing, and the value of "seizable" collateral falling, banks may

\footnotetext{
${ }^{30}$ Other factors that affect the behavior of lending-deposit spreads include, of course, operating costs (which we abstract from), taxation, changes in banks' degree of risk aversion, and changes in market structure and the degree of competition. Indeed, in Turkey banks and borrowers are subject to a variety of taxes - the banking and insurance transaction tax, the foreign exchange transaction tax, and a tax levy on checks, among others. In addition, depositors must pay up to 20 percent in withholding tax on interest income. Spreads tend to be larger for loans in Turkish lira, as opposed to foreign currency. Nevertheless, we abstract from these other considerations.

${ }^{31}$ Note that the spread could also be made a direct function of the level of economic activity (or the output gap), as for instance in Atta-Mensah and Dib (2003).
} 
charge a higher premium, as hypothesized in (94). To our knowledge, there has not been any systematic study of the link between collateral and lending spreads in Turkey; given the obvious importance of this mechanism in the model, we will assess the sensitivity of the simulation results reported later to alternative values of $\kappa_{D R P}$, the parameter measuring the elasticity of the domestic premium to the "effective" collateral-to-liability ratio.

Banks are indifferent between lending in domestic or foreign currency. Thus, the interest rate on foreign-currency denominated loans, $I L F$, is determined from the arbitrage condition

$$
(1+I L F)(1+E D E P R)=1+I L .
$$

\subsection{Public Sector}

The public sector in our framework consists of the central bank and the government. We specify each agent's budget constraint (in stock and flow terms for the central bank) and account for transfers between them. We also discuss the determination of official interest rates, as well as the composition of public investment.

\subsubsection{Central Bank}

The balance sheet of the central bank consists of, on the asset side, loans to commercial banks, $D L_{B}$, foreign reserves, $F F$, changes in which are taken as exogenous (possibly reflecting central bank intervention aimed at managing the exchange rate), and government bonds, $G B_{C B}$. Liabilities consist of the monetary base, $M B$. With $N W_{C B}$ denoting the central bank's net worth, we have

$$
D L_{B}+E R \cdot F F+G B_{C B}-N W_{C B}=M B .
$$

The monetary base is the sum of currency in circulation, $H^{s}$, and required reserves, $R R$ :

$$
M B=H^{s}+R R .
$$

Assuming no operating costs, net profits of the central bank, $P R O F_{C B}$, are given by the sum of interest receipts on loans to commercial banks, and interest receipts on holdings of foreign assets and government bonds:

$$
P R O F_{C B}=I R \cdot D L_{B,-1}+I F_{R F}^{W} E R \cdot F F+I B \cdot G B_{C B,-1} .
$$


A fraction $s h p_{G}$ of the central bank's profits are transferred to the government. Thus, the central bank's net worth evolves over time according to:

$$
N W_{C B}=N W_{C B,-1}+\left(1-s h p_{G}\right) P R O F_{C B}+\Delta E R \cdot F F_{-1},
$$

where the last term represents valuation effects. Thus, exchange rate changes that affect the domestic-currency value of the central bank's stock of foreign reserves do not affect the monetary base; these capital gains and losses are instead absorbed via changes in the central bank's net worth. Taking first differences of (96) and using (99), the monetary base changes according to

$$
\Delta M B=\Delta D L_{B}+E R \cdot \Delta F F+\Delta G B_{C B}-\left(1-s h p_{G}\right) P R O F_{C B}
$$

where the last term is zero if all central bank profits are transferred to the government $\left(\operatorname{sh} p_{G}=1\right)$.

As noted earlier, the supply of liquidity to commercial banks by the central bank is taken to be perfectly elastic at the prevailing official interest rate $I R$, which is itself treated as predetermined. Alternatively, we could endogenize the official interest rate by specifying a monetary policy reaction function that would relate $I R$ to, say, the output gap, and deviations of inflation from a target value, as in Taylor-type rules (see Svensson (2003)). Experiments with feedback rules of this type would be particularly important for Turkey, given the expected move to a (flexible) inflation targeting framework in the near future.

\subsubsection{Government Budget}

The government primary balance, $P R B A L$, can be defined as

$$
\begin{gathered}
P R B A L=T X R E V+P R O F_{G}+s h p_{G} P R O F_{C B}, \\
-W_{S G} S_{G}^{E}-T R H-P G \cdot G-P C_{P} Z_{G}
\end{gathered}
$$

where $T X R E V$ represents total tax revenues, $P R O F_{G}$ profits by the government from sales of the public good (defined in (55)), $s h p_{G} P R O F_{C B}$ the share of central bank profits transferred to the government, $W_{S G} S_{G}^{E}$ salaries of teachers in public education, TRH total government transfers to households, and $G$ real government consumption of goods and services. Public investment, $Z_{G}$, is valued at the sales price of the composite private formal sector good, $P C_{P}$, because it is assumed to consist of expenditure on the private formal composite good only. 
The overall fiscal balance, $O V B A L$, is defined as

$$
O V B A L=P R B A L-I F_{G}^{W} \cdot E R \cdot F L_{G,-1}-I B \cdot G B_{-1},
$$

where the last two terms account for interest payments on foreign loans (at an exogenous rate $I F_{G}^{W}$ ) and payments on government bonds held by commercial banks, the central bank, and profit earners - the stock of which is denoted $G B^{s}: 32$

$$
G B^{s}=G B_{B}^{T}+G B_{C B}+G B_{E} .
$$

Total tax revenues consist of direct taxes, DIRTAX, indirect taxes on goods and services, INDTAX, as well as payroll taxes on employers in the formal private sector and in public production, and social security contributions by employees in the private sector: ${ }^{33}$

$$
\begin{gathered}
\text { TXREV }=\text { DIRTAX+INDTAX } \\
+\operatorname{sstax}_{U} \sum_{j=P, G} W_{U j} U_{j}+\operatorname{sstax}_{S} \sum_{j=P, G} W_{S j} S_{j}+\sum_{j=U, S} \operatorname{paytax}_{j}\left(W_{j G} j_{G}+W_{j P} j_{P}\right) .
\end{gathered}
$$

Direct income taxes are levied on households (except those in the informal sector) and private formal sector firms:

$$
\operatorname{DIRTAX}=\sum_{h=A, F, E} \operatorname{inctax}_{h} Y H_{h}+\operatorname{ftax}_{P} P R O F_{P}
$$

Indirect taxes consist of revenue from import tariffs, taxes on gross production (at the rate $\operatorname{protax}_{i}$ ), and taxes on domestic sales (at the rate $\left.\operatorname{saltax}_{i}\right)$ :

$$
\begin{aligned}
\text { INDTAX }= & E R \sum_{i=A, P} \text { wpm }_{i} \operatorname{tm}_{i} M_{i}+\sum_{i \neq I} \operatorname{protax}_{i} P X_{i} X_{i} \\
& +\sum_{i=A, P} \operatorname{saltax}_{i} P Q_{i} Q_{i} .
\end{aligned}
$$

\footnotetext{
${ }^{32}$ Note that non-residents are assumed not to hold domestic government bonds, in line with the evidence for Turkey, which suggests that such holdings are relatively small. This component - which would alter not only (103) but also the balance-of-payments equilibrium condition (108) - can be easily added.

${ }^{33}$ Although payroll taxes incurred in the production of public services appear in the definition of total tax revenues, they have no effect on the primary balance because (as shown in (55)) they are netted out of profits transferred to the government.
} 
Public investment consists of investment in infrastructure (roads, power plants, hospitals, and so on), $I_{I N F}$, and investment in education (school buildings, libraries, and so on, $I_{E D U}$, which are both considered given in real terms:

$$
Z_{G}=I_{I N F}+I_{E D U} .
$$

Accumulation of each type of capital evolves according to

$$
K_{i}=\left(1-\delta_{i}\right) K_{i,-1}+I_{i,-1}, \quad i=I N F, E D U
$$

where $0<\delta_{i}<1$ is a depreciation rate.

The model closure specifies a fixed growth path for government bond issuing and foreign borrowing. With no central bank financing, and exogenous foreign borrowing (in foreign-currency terms), the government budget deficit, $-O V B A L$, is therefore given from "below the line":

$$
-O V B A L=E R \cdot \Delta F L_{G}+\Delta G B^{s} .
$$

Given the path of the overall fiscal balance set by (107), equation (102) is solved for the primary balance, $P R B A L$, and (101) residually for the level of transfers to households, $T R H$.

\subsection{The Balance of Payments and the Exchange Rate}

Because foreign reserves are constant, the balance-of-payments constraint implies that any current account imbalance must be compensated by a net flow of foreign capital, given by the sum of changes in households' holdings of foreign-currency denominated deposits abroad, $\sum_{h} \Delta F D_{h}^{W}$, changes in foreign loans made to the government, $\Delta F L_{G}$, and to private firms, $\Delta F L_{P}$ (both taken to be exogenous), changes in loans to domestic banks, $\Delta F L_{B}$, minus the change in official reserves (also assumed to be exogenous), $\Delta F F$, all measured in foreign-currency terms:

$$
\begin{aligned}
0= & \sum_{i=A, P}\left(w p e_{i} E_{i}-w p m_{i} M_{i}\right)+I F_{R F}^{W} \sum_{h=F, E} F D_{h,-1}^{W} \\
& +R E M I T+I F_{R F}^{W} F F-I F^{W} \sum_{h=P, B} F L_{j,-1}-I F_{G}^{W} F L_{G,-1} \\
& -\sum_{h=F, E} \Delta F D_{h}^{W}+\sum_{j=G, P, B} \Delta F L_{j}-\Delta F F
\end{aligned}
$$


where REMIT is the flow of remittances, defined as

$$
R E M I T=\kappa_{R E M} W_{F} F O R L_{-1}, \quad 0<\kappa_{R E M}<1,
$$

with $W_{F}$ denoting again the foreign wage (measured in foreign-currency terms), FORL the number of Turkish nationals working abroad, and $\kappa_{R E M}$ the share of wages being remitted. In turn, FORL is given by

$$
F O R L=\left(1-\delta_{I M I G}\right) F O R L_{-1}+I M I G,
$$

where $0<\delta_{I M I G}<1$ is the rate of "attrition" of the stock of migrants and $I M I G$ is determined by equation (39). Equation (108) determines implicitly the equilibrium nominal exchange rate.

\subsection{Currency and Bond Market Equilibrium}

With equation (100) determining changes in the monetary base, $M B$, the supply of domestic currency can be derived from equation (97):

$$
H^{s}=M B-R R \text {. }
$$

Equality between the supply and demand for cash requires that, using (72):

$$
H^{s}=H^{d}=\sum_{h} H_{h}^{d}
$$

The equilibrium condition of the market for government bonds, which can be solved for the expected interest rate $E I B$, is given as

$$
G B^{s}=G B_{E}^{d}+G B_{B}^{T}+G B_{C B},
$$

or, using (76), as well as (83), (84) and (85):

$$
\begin{gathered}
\left(1-\phi_{G B}^{B, p}\right) G B^{s}=N W_{B} \phi_{G B}^{B, d}\left(\frac{1+E I B}{1+I L}\right)^{\theta_{G B}^{B}}+G B_{C B} \\
+\frac{\left(W T_{E}-H_{E}\right)(1+E I B)^{\theta_{G B}^{E}}(1+I D)^{-\theta_{D D}^{E}}}{\left[(1+E D E P R)(1+I D F)^{\kappa_{F D}^{E}}\left(1+I F_{R F}^{W}\right)^{1-\kappa_{F D}^{E}}\right]^{\theta_{F D}^{E}}} .
\end{gathered}
$$

This equation can be solved for the expected bond rate, EIB. 


\subsection{Price Determination}

Value added prices, $P V_{i}$, are given by adjusting gross prices, $P X_{i}$, for production taxes and the cost of intermediate inputs:

$$
P V_{i}=V_{i}^{-1}\left\{P X_{i}\left(1-\operatorname{protax}_{i}\right)-\sum_{j} a_{j i} P C_{j}\right\} X_{i}
$$

where $\operatorname{protax}_{I}=0$ because there is no indirect taxation of informal sector output.

The world prices of imported and exported goods, $w p e_{i}$ and $w p m_{i}$, are taken to be exogenously given. The domestic currency price of these goods is obtained by adjusting the world price by the nominal exchange rate, with import prices also adjusted by the tariff rate, $t m$ :

$$
\begin{gathered}
P E_{i}=w_{p e} E R, \text { for } i=A, P, \\
P M_{i}=w_{p} m_{i}\left(1+t m_{i}\right) E R, \text { for } i=A, P .
\end{gathered}
$$

Gross output prices of the rural and urban private goods, $P X_{A}$ and $P X_{P}$, are derived from the expenditure identity:

$$
P X_{i}=\frac{P D_{i} D_{i}+P E_{i} E_{i}}{X_{i}}, \text { for } i=A, P .
$$

For the informal and public sectors (both of which do not export and do not compete with imports), the price of gross output is equal to the domestic price, $P D_{i}$, only:

$$
P X_{i}=P D_{i}, \text { for } i=I, G \text {. }
$$

For the rural sector and formal private urban production, the composite price is determined accordingly by the expenditure identity: ${ }^{34}$

$$
P Q_{i}=\frac{P D_{i} D_{i}+P M_{i} M_{i}}{Q_{i}}, \text { for } i=A, P .
$$

\footnotetext{
${ }^{34}$ In principle, the cost functions derived from first-order conditions for the CET and CES aggregation functions (3), (11) and (41) could be used to determine $P X$ and $P Q$ prices in these two sectors. However, because CES and CET functions are linearly homogeneous, the cost functions can be replaced with the accounting identities shown in equations (117) and (119); the first-order conditions are incorporated in the export supply and import demand functions, (40) and (42).
} 
Prices of the composite inputs $J_{1}$ and $J_{2}$ are derived in similar fashion, as a result of the linear homogeneity of the nested CES production functions imposed in the production of private formal urban goods:

$$
\begin{aligned}
& P J_{1}=J_{1}^{-1}\left\{P R O F_{P}+\left(1+I L_{-1}\right)\left(1+\operatorname{paytax}_{S}\right) W_{S P} S_{P}\right\}, \\
& P J_{2}=J_{2}^{-1}\left\{P J_{1} \cdot J_{1}+\left(1+I L_{-1}\right)\left(1+\operatorname{paytax}_{U}\right) W_{U P} U_{P}\right\},
\end{aligned}
$$

where $P R O F_{P}$, as defined earlier, denotes profits of private firms in the urban formal sector.

The price of capital is defined as a geometric weighted average of the sales prices of the goods for which there is investment demand, namely, the public good and the private formal urban good (see equation (51)):

$$
P K=\prod_{i=G, P} P C_{i}^{z z_{i}}
$$

where $P C_{i}=P D_{i}$ for $i=G$.

The price of government spending, $P G$, is defined in similar fashion (see equation (49)):

$$
P G=\prod_{i=A, G, P} P C_{i}^{g g_{i}}
$$

Markets for informal goods and government services clear continuously; equilibrium conditions are thus given by

$$
Q_{I}^{s}=Q_{I}^{d}, \quad Q_{G}^{s}=Q_{G}^{d} .
$$

These conditions are used to determine $P D_{I}$ and $P D_{G}$.

As in Karadag and Westaway (1999), the value added tax is modeled as an ad valorem tax on purchases of final goods. ${ }^{35}$ Specifically, the sales price for the rural and formal private sector goods, $P C_{i}$, differs from the composite price as a result of a sales tax, levied at the rate $0<$ saltax $_{i}<1$ :

$$
P C_{i}=\left(1+\text { saltax }_{i}\right) P Q_{i} \text {, for } i=A, P .
$$

The consumption price index for the rural and urban sectors are given by

$$
P_{R U R}=\prod_{i} P C_{i}^{w r_{i}}, \quad P_{U R B}=\prod_{i} P C_{i}^{w u_{i}}
$$

\footnotetext{
${ }^{35}$ Indeed, in Turkish fiscal accounts, what is referred to as the "value added tax" is actually an ad valorem sales tax. We therefore chose to model it as applying to composite good prices, instead of value added prices.
} 
where $0<w r_{i}, w u_{i}<1$ are the relative weights of good $i$ in each index. These weights sum to unity $\left(\sum_{i} w r_{i}=\sum_{i} w u_{i}=1\right)$ and are fixed according to the share of each of these goods in rural and urban consumption in the base period. Finally, the aggregate price level, $C P I$, is defined as a weighted average of rural and urban prices:

$$
C P I=P_{R U R}^{w c p} \cdot P_{U R B}^{1-w c p},
$$

where $0<w c p<1$ is the relative share of spending by rural households in total consumption. The inflation rate is simply

$$
I N F L=\triangle C P I / C P I_{-1} .
$$

\subsection{Default Risk, Credibility, and Expectations}

Our analysis of default risk dwells on the presumption that, faced with an unsustainable fiscal deficit, a government can either take fiscal measures to increase revenue, or be tempted to default at some point in the future either through monetization or outright repudiation. In practice, governments are often tempted to resort to monetization as deficits and public debt rise because of constraints in the ability to adjust taxes; the increase in tax rates or in the tax base necessary to balance the budget may be large and politically unfeasible. The inflation tax may be an easier option, because it is the accumulation of debt that leads to a perverse increase in interest payments. In addition, there are no explicit costs associated with collecting the inflation tax, whereas with "conventional" taxes collection costs may be a convex function of the amount of revenue raised. In the Turkish case, however, we also view outright debt repudiation as a source of concern by asset holders. Expectations concerning the possibility of default will therefore affect their current behavior.

Specifically, we assume that the demand for government bonds is affected by the probability that the government will opt for (partial) default, in the form of either outright repudiation or monetization to finance its deficits. ${ }^{36}$ Private investors assign a nonzero probability to default in the current period. The expected rate of return will reflect this probability, and they will demand

\footnotetext{
${ }^{36}$ In principle, as noted by Masson (1985), changes in the perceived risk of default will also afect the marginal rate of substitution across periods, and thus saving. In the present setting, however, intertemporal considerations by households are not directly captured, and thus we ignore this effect.
} 
compensation in the form of a higher nominal interest rate on government bonds. Thus, the expected rate of return on government bonds, EIB, can be defined as

$$
E I B=(1-P D E F) I B,
$$

where $P D E F$ is the subjective probability of default, which is supposed to depend (with a one-period lag) on the current debt-to-tax revenues ratio: ${ }^{37}$

$$
P D E F=1-\exp \left[-\alpha_{0}\left(\frac{G B_{-1}}{T A X R E V_{-1}}\right)\right]
$$

This specification shows that, when debt is zero, the probability of default is also zero; by contrast, as the stock of debt (relative to tax revenues) increases without bounds, the perceived risk of default approaches unity. Put differently, the larger the stock of debt is in relation to the capacity to repay, the higher the perceived risk of default. ${ }^{38}$

The view underlying our specification in (128) is that tax revenues are constrained by some upper bound, whereas the real value of the outstanding debt (and of the debt service) can be significantly reduced by a surprise increase in the rate of inflation. ${ }^{39}$ The outcome of a postponement of action on the deficit would then eventually translate into a steadily increasing interest rate on government bonds, as a result of two factors. First, demand for these bonds depends on the expected rate of return, which is the product of the probability of repayment times the interest rate, as shown in equation (127). For a given probability of default, a continued increase in the supply of bonds will require an increase in interest rates, to induce investors to hold them. This can be seen by combining the solution to condition (113) and equation (127), to write the actual, equilibrium interest rate on government bonds as

$$
I B=\frac{\Lambda\left(G B^{s}, \ldots\right)}{1-P D E F}
$$

\footnotetext{
${ }^{37}$ Note that using GDP as a scale variable instead of tax revenue in the probability of default would not be appropriate here, because neither agriculture nor the informal sector are subject to taxation. Thus, an increase in GDP resulting from higher output from either one of those sectors would not signal a greater capacity to repay.

${ }^{38}$ In principle, the government could meet its debt obligations by cutting spending (or selling assets) instead of raising taxes. Our view, however, is that (given the large share of spending allocated to wages and interest payments) most of the adjustment to cover obligations in case of default would have to come from higher tax revenues.

${ }^{39}$ See Spaventa (1987) for a detailed discussion of the view that governments typically face a limit to the tax burden that they can impose on their citizens - notably because of adverse effects on incentives and income distribution.
} 
where $\Lambda(\cdot)$ is a functional form that depends positively on $G B^{s}$ and the dots represent the other determinants of the demand for government bonds by domestic banks and profit earners. An increase in the supply of bonds $G B^{s}$, fueled by an increase in the government deficit, would indeed raise the equilibrium bond rate, everything else equal.

Second, an increase in the stock of public debt will lead (with a oneperiod lag) to a rise in the perceived probability of default by investors, which will also tend to lead to higher interest rates on government bonds. As can be inferred from the previous equation, an increase in $P D E F$ would indeed raise the equilibrium bond rate. The rise in interest rates would in turn worsen the overall deficit of the government-making the adoption of corrective fiscal policies inevitable. Higher interest rates therefore make an unsustainable fiscal policy more unsustainable, hastening the need for policy reforms.

To model credibility, we assume that the expected rate of inflation (which affects directly the demand for domestic currency, private investment, saving rates, and wage formation in the private formal sector), is given as a weighted average of the perceived (or explicitly announced) inflation target of the central bank, INF $L^{T A R G}$, and the one-period lagged inflation rate:

$$
E I N F L=C R E D I B \cdot I N F L^{T A R G}+(1-C R E D I B) I N F L_{-1},
$$

where $I N F L$ is defined in (126) and $0<C R E D I B<1$ is our measure of credibility, defined as

$$
C R E D I B=1-P D E F .
$$

Credibility in our framework depends therefore only on fiscal policy; the stance or effectiveness of monetary policy (as measured, for instance, by deviations between actual and target inflation rates) plays no role. ${ }^{40}$ Full credibility $(C R E D I B=1)$ occurs only if the probability of default $P D E F$ is zero. An increase in the probability of default lowers credibility and leads

\footnotetext{
${ }^{40}$ In Ozatay (2000) and Civcir (2002), credibility is measured by the average maturity of new domestic non-indexed public debt issues. However, maturity is treated as an exogenous variable, instead of being (inversely) related to the debt-to-GDP ratio, as one would expect. For other ways of modeling credibility involving forward-looking expectations in stochastic models, see Laxton, Ricketts, and Rose (1994), Huh and Lansing (1999), Isard, Laxton, and Eliasson (2001), and Erceg and Levin (2003). For econometric studies, see Ruge-Murcia (1995) and Agénor and Taylor (1992).
} 
agents to reduce the weight attached to the inflation target in forming expectations (thereby imparting greater persistence to inflation), because default is associated with a perceived increase in the risk of monetization and thus higher future inflation. In a sense, therefore, inflation expectations depend essentially on the fiscal stance - in line with the empirical results of Celasun, Gelos and Prati (2004), based on survey data for Turkey. Although they do not provide a formal characterization of their argument, they note (p. 494) that "...A credible fiscal consolidation is probably the key to reducing inflation, because inflation expectations will decline only if the public perceives that the need to monetize fiscal deficits or inflate away the debt stock has come to an end." 41

The expected nominal depreciation rate, EDEPR, which affects portfolio decisions and the pricing rules of commercial banks, is defined as a weighted average of its past value and expected changes in the real exchange rate, measured as the difference between expected domestic inflation (given in (130)) and foreign inflation, FINFL, with a one-period lag:

$$
E D E P R=\chi E D E P R_{-1}+(1-\chi)\left(E I N F L-F I N F L_{-1}\right),
$$

where $0<\chi<1$. Thus, when domestic inflation is expected to exceed foreign inflation, that is, when the real exchange rate is expected to appreciate, agents will also expect the nominal exchange rate to depreciate, to prevent a loss in competitiveness. ${ }^{42}$

Note that in the model exogenous changes in the probability of default lead in general to an inverse correlation between credibility and the government bond rate. An increase in $P D E F$, for instance, raises directly the bond

\footnotetext{
${ }^{41}$ They also found that inflation expectations appear to be forward-looking, rather than backward-looking. However, this result is not consistent with those obtained by Agénor and Bayraktar (2002), who found that forward- and backward-looking components have similar weights in expectations.

${ }^{42}$ Alternatively, it could be assumed that expectations are rational (or, more precisely, model consistent), so that the expected depreciation rate is equal to the one-period ahead "actual" rate, as derived from the model itself. This, however, is a lot more involved from a computational standpoint. Other options, as suggested to us by Peter Montiel, would be to make the expected future exchange rate a function of the current spot rate (with some elasticity parameter linking the two, and with perhaps a "shift" term to capture exogenous changes in exchange rate expectations), or to make the expected future exchange rate proportional to the model's steady-state solution for the exchange rate, with the factor of proportionality representing the perceived rate at which the exchange rate converges to its steady-state value.
} 
rate, as implied by (129). At the same time, it also reduces credibility, as implied by (131), thereby raising expected inflation, as can be inferred from (130), as long as $I N F L_{-1}>I N F L^{T A R G}$. In turn, higher expected inflation raises the expected rate of depreciation of the nominal exchange rate, as implied by (132). From (76), and the equilibrium condition (113), the rise in $E D E P R$ lowers the demand for government bonds by households. With a fixed supply of bonds, this requires an offsetting increase in $E I B$, that is, a rise in $I B$ itself (as implied by (127)), which compounds the initial effect of the increase in $P D E F$ on the actual bond rate.

\section{Calibration and Solution}

Appendix $\mathrm{C}$ reviews the structure of the financial SAM that underlies the model, our calibration procedure, and the parameter values (estimated and non-estimated) that we use in the behavioral equations. A more detailed description of the data and adjustment procedures used to construct the financial SAM is provided in Jensen and Yeldan (2004). Essentially, the calibration of the model was done by building a Financial Social Accounting Matrix (FSAM). The FSAM itself was built in two steps: $a$ ) construction of a MacroSAM; and $b$ ) disaggregation into a MicroSAM. The construction of the MacroSAM was split into a real MacroSAM and a financial MacroSAM. The link between the two types of MacroSAMs was made through the savingsinvestment balance account.

The solution of the model is performed with GAMS. When solving the model, the equilibrium condition (111) is dropped from the system as a result of Walras' law - if all other markets but the money market are in continuous equilibrium, then the money market must be in continuous equilibrium as well. That this is indeed the case is checked automatically when solving the model.

\section{Policy Experiments}

In this section, we report two sets of experiments. The first aims to analyze the real and financial effects of a disinflation program taking the form of a permanent increase in the official interest rate. The second set relates to fiscal adjustment and considers two scenarios: an increase in the VAT rate 
and an increase in the tax rate on income of profit earners. The public sector closure rule implies that transfers to households adjust to clear the public sector budget. ${ }^{43}$ In both cases we focus on the impact of these policies on the sustainability of domestic public debt and the behavior of the labor market. We refer to effects occurring in the first two years as the "short run," those occurring between the third and fifth years as the "medium run," and those occurring between the seventh and the tenth year as the "long run."

As noted earlier, the growth path for domestic bond financing is exogenously specified in the baseline solution. ${ }^{44}$ The bond market also includes a placement rule whereby the government places a pre-determined fraction of the outstanding stock of bonds with commercial banks. The remaining share of outstanding bonds are allocated among commercial banks and profit earners according to their respective portfolio-balance equations. As can be inferred from (113) and (129), it is this secondary allocation of bond holdings that determines (together with the supply of bonds, the probability of default, and interest rates on alternative assets) the equilibrium bond rate. The two fiscal experiments are carried out using a non-neutral public sector closure. Thus, given that the overall balance is fixed by (107), the tax adjustment affects the size of the primary balance (as implied by (102)) and transfers to households (as inferred from (101)). In turn, transfers affect households' disposable income, private spending, and tax revenue. As a result of this closure rule, in each experiment deviations of the probability of default from its baseline value will reflect essentially changes in tax revenues, which are themselves closely correlated with activity in the formal sector (given that the rural and informal sectors are essentially untaxed).

\subsection{Increase in Official Interest Rates}

We first consider a permanent, 5 percentage point increase in the official interest rate, $I R$. Results are presented in Tables 2 and 3. The inflation rate is reduced significantly in the short run by almost 3.8 percent, and remains below its baserun value until period 6 . The medium run maximum reduction

\footnotetext{
${ }^{43}$ Given this closure rule, the simulation results would be significantly affected if we were to assume that in the probability of default it is taxes net of transfers that matter, instead of taxes per se. However, doing so would implicitly amount to assuming that transfers would not be cut to redeem the debt in case of default.

${ }^{44}$ Note that, because GDP changes across experiments, the debt-to-GDP ratio will also change, despite the fact that the growth rate of the stock of public debt is constant.
} 
in the price level (in both rural and urban areas) is around 9 percent while the long-run reduction is around 5.5 percent. The general reduction in the level of prices is the consequence of changes in factor costs and the relative demand and supply of goods and services. Indeed, the increase in the official rate raises the lending rate, which in turn exerts two types of direct effects: first, it leads to a reduction in formal sector wages through an increase in the cost of working capital; second, it leads to a strong decline in investment demand for formal sector goods.

The reduction in formal sector wages leads to a fall in real disposable income for the formal sector household. Because formal sector households have a relatively high consumption share of formal sector goods, the relative demand for formal sector goods tends to decline. In this way, the reduction in formal sector wages tends to be self-reinforcing. At the same time, the reduction in formal sector disposable income is exacerbated by the strong increase in the bond rate, despite a concomitant increase in deposit rate. The increase in the bond rate leads to higher interest payments by the government on its debt and (as a result of the public sector budget closure) a decline in transfers to households. The reduction in household transfers affects mostly the formal sector household and profit earners, because they are the main beneficiaries of public transfers. But the reduction in income is more pronounced for formal sector households, because they are affected adversely not only by the reduction in transfers, but also by the increase in the cost of borrowing. Indeed, because formal sector households (which are the only ones borrowing from banks) are net debtors in the initial scenario, their net borrowing costs increase, despite the fact that the increase in the deposit rate (which matches the increase in the official rate) cushions the impact of the higher lending rate. Overall, real disposable income of formal sector households decline by around 12 percent in the medium run (see Table 3, period 5) and 5 percent in the long run (see Table 3, period 10). In contrast, profit earners (who do not borrow directly from banks) benefit relatively strongly from increasing interest receipts on their deposits held with commercial banks and from government bond holdings. Real disposable income of this group of households increase by around 10 percent in the medium run and 6 percent in the long run (see, again, Table 3).

The bond rate increases strongly until period 5. Most of the upward pressure on the bond rate results from the fact that the increase in deposit rates tends to reduce the demand for bonds by profit earners; the net worth of commercial banks remain low through the medium run (making them 
therefore reluctant to increase bond holdings above direct placement holdings), and central bank holdings are exogenous. Given that the supply of bonds does not change across experiments, the bond rate must increase to maintain market equilibrium and maintain bond holdings of profit earners around baserun levels. ${ }^{45}$ The impact on the bond rate reaches a maximum of 11 percentage points in period 5, after which increases in the net worth of commercial banks start to kick in. The bond rate therefore increases less strongly after that period, by about 6 percentage points in the long run.

Banks' net worth is negatively affected by the increasing cost of central bank funding. However, it is positively affected by the increase in the bond and lending rates. The lending rate on domestic-currency loans increases by 4.8 percent in the short run and 4.5 percent in the medium run. This reflects the countering effects of $a$ ) the initial increase in the official rate of 5 percent; and $a$ ) the subsequent reductions in the expected rate of depreciation of the nominal exchange rate and a slight fall in the domestic premium. Declining expectations of nominal depreciation follow from a general decline in actual exchange rate depreciation. This affects the cost of funding through foreign-currency deposits and therefore lowers the lending rate. The domestic premium also declines slightly due to the exchange rate appreciation, which lowers the domestic-currency value of firms' foreign liabilities and therefore increases the value of their net collateral-debt ratio.

The nominal exchange rate appreciates by around 10 percent in the medium run, and 6 percent in the long run. The growth path of the nominal exchange rate closely resembles the growth path of the domestic price level, and this is reflected in a relatively stable real exchange rate. Indeed, the real exchange rate depreciates by about 0.3 percent in the short run and appreciates by about 0.5 percent in the medium run, before settling down to a real appreciation of only 0.1 percent in the long run. Movements in the real exchange rate are mirrored in the trade balance and the current account, which improves in the short run but deteriorates slightly in the medium and long run.

As noted earlier, the increase in lending rates induced by the hike in official interest rates affects the real economy through two main channels: $a$ ) reduced investment demand; and $b$ ) increased costs of working capital. The

\footnotetext{
${ }^{45}$ This is so despite the fact that savings by profit earners tend to increase as a result of the rise in deposit rates - an increase that tends to raises total financial wealth over time (as implied by (64)) and thus to increase the demand for bonds (as implied by (76)).
} 
first channel directly reduces demand for private formal sector investment goods. Combined with the reduction in formal sector disposable income and consumption, this leads to a sharp reduction in demand for private formal sector goods compared to other sectors of the economy. In addition, the medium and long run impact of lower investment (or more accurately, the reduction in the stock of private physical capital that it entails) is to lower production capacity and reduce the marginal product of other production factors (most notably skilled labor) in the private formal sector. Value added in the urban formal sector is therefore particularly affected and declines by 0.8 percent in the long run. The urban informal sector also experiences a small decline in value added of less than 0.1 percent in the long run, whereas value added in the rural sector expands by 0.2 percent. These developments are mainly due to relative price effects and the reduced outflow of workers from rural to urban areas. Overall, GDP declines by 0.3 percent in the long run.

The decline in real GDP is the outcome of the decline in private investment demand dominating the real increase in consumption. Over time, private investment declines strongly not only as a result of the increasing lending rate but also because of the negative accelerator effect emanating from the decline in GDP itself. In contrast, private consumption increases due to the income effect (alluded to above) of the increase in the deposit and bond rates, particularly on the disposable income of profit earners. Combined with a decline in relative formal sector prices, this leads to a sharp increase in real consumption of that category of households. The increase in overall real household consumption is moderated by the decline in disposable income and consumption by the formal sector household, for the reasons discussed earlier.

Wages in the labor market generally mirror changes in the overall price level. Fully indexed public sector wages move (downward) with the urban formal sector consumer price index. In addition, lower public sector wages (through their signaling effect), together with higher lending rates, higher (skilled) unemployment, and declining private sector investment, combine to lower relative wages in the formal private sector. The decline in formal sector wages spills over into declines in rural and informal sector wages as well. The former fall by more, implying that the expected wage differential between the formal and informal urban sectors drops by about 8 percentage points in the medium run (periods 4 and 5 in Table 2) and 4 percentage points in the long run, whereas the wage differential between the rural and 
urban sectors drops by about 3 percentage points in the medium run and 0.3 percentage point in the long run. Movements in these wage differentials lead to reduced migration of labor between sectors, and account for the increase in employment and value added in the rural sector, and the drop in both variables in the informal sector.

The external premium faced by domestic banks (as shown in (92)) fluctuates essentially with changes in exports. The initial exchange rate depreciation increases exports. The fall in the ratio of foreign debt (which does not change across simulations) to exports therefore lowers the external premium in the short run. The subsequent exchange rate appreciation and associated reduction in exports means, however, that the external premium increases in the long run. This leads to a higher interest rate on foreign-currency deposits held domestically (as implied by (90) and (91)), as well as higher rates charged on domestic- and foreign-currency loans by domestic banks (as implied by (91), (93), and (95)). In principle, the effect of interest rates on foreign-currency deposits and loans could be significant. For instance, the increase in interest rates on foreign-currency loans raises interest payments for firms in the private formal sector (which reduces income distributed to profit earners and thus dampens the increase in that group's consumption expenditure); at the same time, it raises banks' profits and thus income received by profit earners. However, because these effects tend to offset each other, and because the quantity of domestic loans denominated in foreign currency is relatively small, the net quantitative impact is not large.

The probability of government default increases due to the reduction in nominal tax revenues and the resulting increase in the debt-to-tax revenues ratio. ${ }^{46}$ This increase in the default probability is matched by a similar decline in credibility, due to increased expectations of monetization or outright default. As a result, the bond rate tends to rise (compounding the demand effects discussed earlier) and expectations of inflation tend to increase. Over time, the rise in expected inflation tends to mitigate the positive impact of the rise in deposit rates on households' savings rates (see equation (62)). For private investment, by contrast, the rise in expected inflation tends to reduce the initial magnitude of the increase in the real lending rate, thereby dampening over time the adverse effect of a higher cost of borrowing on

\footnotetext{
${ }^{46}$ Note that in Table 2 the ratio of total tax revenues to GDP increases throughout the simulation period. This is because, although both variables fall, the reduction in GDP exceeds that of tax revenues.
} 
private capital formation.

Finally, it can be noticed that the government primary surplus-to-GDP ratio increases both in the short and the long run. The increase reaches a maximum of 5.6 percentage points over the reference path (Table 2, period $5)$, reflecting a sharp decline in government transfers to households. These transfers are squeezed due to the strong increase in the bond interest payments resulting from our assumption that bond financing is maintained at baserun levels, implying that (with exogenous foreign borrowing in foreigncurrency terms) the government deficit is given from "below the line."

It is worth noting that the magnitude of the long-run decline in GDP would of course be smaller if, as a result of a Taylor-type rule, the authorities were to lower interest rates in response to lower inflation. It is also interesting to note that this experiment, a disinflation attempt based on a rise in official interest rates, leads to a rise in the probability of default (essentially because the increase in interest rates has a contractionary effect, which translates into lower tax revenues), and an initial real depreciation (see Table 3). These results are consistent with those derived by Blanchard (2004) in a very different setting, characterized by a direct link between the probability of default, capital flows, and movements in the exchange rate. Nevertheless, our experiment carries a similar note of caution: in an inflation targeting framework (in which interest rates are used to achieve a specific level of inflation), an initial inflationary shock can have perverse effects. An increase in real interest rates to "choke off" inflationary pressures can lead to a real depreciation, and thus higher inflation, which may lead in turn to further increases in interest rates. In our experiment, fiscal policy is also an important potential tool to reduce inflation: by issuing less domestic debt and reducing the debt-to-tax ratio, the government would mitigate the increase in the probability of default, which would in turn dampen the rise in the bond rate. This would reduce pressure on cutting the primary deficit through a drop in transfers, thereby dampening the adverse effect on activity and tax revenues.

\subsection{Fiscal Adjustment}

As noted earlier, we discuss two types of fiscal adjustment policies: an increase in the VAT rate and a rise in the tax rate on income of profit earners. 


\subsubsection{Increase in the VAT Rate}

We first consider fiscal adjustment in the form of a permanent, 2.5 percentage point increase in the value added tax, which (as noted earlier) applies solely to private formal sector goods. Results are presented in Tables 4 and 5 .

The increase in the tax rate raises both the level and the growth rate of prices. Overall inflation rises by about 3.6 percent in the short and medium run (see Table 4, period 4). The inflationary impact becomes negative after period 6 , before returning to slightly positive values in the long run. In level terms, prices increase by about 15 percent above their baserun value in the long run. This general increase is driven by changes in relative demand and supply of goods and services. First, the tax hike leads directly to an increase in the price of the private formal sector good. This tends to lower demand for that good, lowering production and increasing unemployment (particularly among the unskilled) in the formal sector. At the same time, the increase in government revenues is transferred back to households, due to the public sector closure rule; this tends to stimulate consumption spending across all categories of goods and to put further upward pressure on prices. Furthermore, the bond rate declines markedly, thereby lowering interest payments and borrowing needs by the government, and reinforcing the increase in demand through higher household transfers (which increase by about 3.4 percent of GDP in the long run). Reduced investment demand for formal sector goods pulls in the other direction. Investment is negatively affected by increasing lending rates and the "reverse" accelerator effect associated with a decline in the growth rate of GDP. However, improved credibility (through its effect on inflation expectations and the real lending rate, as discussed later) reduces the impact of this effect in the medium and long run.

The bond rate declines by less than 1 percentage point on impact and reaches a maximum reduction of 8 percentage points in the medium run (see Table 4, period 5). In the long run, it declines by about 6 percentage points. This decline results essentially from the increase in the nominal disposable income of profit earners. While these households experience a strong drop in real disposable income due to falling commercial bank profits (see Table 5), the impact of inflation on nominal income, and thus savings and wealth, is such that the nominal demand for bond holdings increases. With the supply of bonds exogenously fixed, the increase in demand tends to lower bond rates. The smaller long-run decline in the bond rate is due to movements in the net worth of commercial banks. Indeed, the declining bond rate exerts over time 
a self-correcting feedback effect through lower commercial banks' profits and net worth. This lowers the overall demand for bonds and creates pressure for a (partial) long-run correction in the drop in the bond rate.

Banks' net worth is also affected by a slight increase in the interest rate on domestic-currency loans, of the order of 0.3 percentage point in the long run. This increase follows mainly from a rise in the domestic premium, which results in turn from actual exchange rate depreciation: by increasing the domestic-currency value of foreign-currency loans, the nominal depreciation reduces the net value of firms' collateral. At the same time, expectations of exchange rate depreciation remain relatively unchanged. The reason is that the higher actual rate of exchange rate depreciation is mitigated by lower expected inflation in the long run, due to improved credibility and declining inflation in the long run. In turn, credibility improves because increasing (nominal) tax revenues lower the debt-to-tax ratio, thereby lowering the probability of default. In turn, the reduction in the probability of default (that is, the credibility gain) tends to lower the actual bond rate, thereby contributing to the decline discussed earlier.

The nominal exchange rate depreciates by around 13 percent in the medium run and 10 percent in the long run. The growth path of the nominal exchange rate resembles the growth path of the domestic price level, but less so than in the case of an increase in the official interest rate (as discussed earlier). Accordingly, the real exchange rate tends to appreciate, remaining around 0.5 percent below the baserun level in the long run (see Table 5). Nevertheless, both the trade balance and the current account tend to improve in the long run. This occurs both because of the decline in real total consumption induced by the fall in disposable income (which reduces overall spending on the composite private formal sector good) and because the relative price of private formal sector goods declines strongly - in spite of the increase in the tax rate. Combined with strong nominal depreciation, this leads to a decline in the relative demand for imports of the private good and (despite an appreciation of the "overall" real exchange rate) a slight improvement in the current account in the long run.

The combination of an increasing lending rate and tax-induced increases in the price of formal sector investment goods leads to a strong reduction in investment demand initially. In the short run, increased expectations of inflation due to high actual inflation reduce the cost of borrowing, which tends to mitigate the fall in investment demand over the medium run. However, improved credibility and declining actual inflation lead to lower expected in- 
flation in the long run, pushing the real cost of borrowing back up. The increase in the (expected) real lending rate, combined with a negative accelerator effect, tend to reduce real private investment again, by 3.6 percent in the long run. Over time, lower levels of investment lead to lower production capacity and a reduction in the marginal product of other production factors in the private formal sector. The general decline in demand for formal sector goods therefore leads to a sharp long-run reduction in unskilled employment, of about 4.3 percent, whereas skilled employment drops by about 0.2 percent. As a consequence, value added in the urban formal sector declines by 0.8 percent in the long run. Urban informal sector value added also declines by 0.3 percent, whereas value added in the rural sector improves by about 0.6 percent in the long run. Increasing value added in the rural sector and reduced value added in the urban informal sector result mainly from lower migration of workers from rural to urban areas, itself reflecting movements in wage differentials. Overall, GDP declines by 0.3 percent in the long run.

The decline in real GDP mainly reflects the diverging growth paths of components of aggregate demand. While private investment demand declines strongly at first, recovers somewhat, and starts declining again, real private consumption remains relatively unchanged in the long run; it experiences an initial short-run expansion of 0.4 percent, followed by a medium-run contraction of the same magnitude. These movements reflect the behavior of the real disposable income of profit earners, which declines strongly by 11 percent in the medium run and by 9 percent in the long run. In turn, as noted earlier, the declining income of profit earners is mainly due to the sharp drop in interest income from bond holdings.

Over time, declining real investment tends to reduce the capital stock in the private formal sector - and therefore the demand for skilled labor, given the high degree of complementarity between these factors. Combined with reduced demand for formal sector goods, this leads to a reduction in skilled employment, but only by a moderate amount in the long run (0.2 percent). In contrast, the long-run reduction in unskilled employment amounts to 4.3 percent, indicating that bargained wages for unskilled workers are increasing too fast. Partly because of the marked increase in formal sector unemployment, the wage differential between formal and informal sector declines strongly. This (together with a reduction in the probability of finding a job in the private formal sector) implies that migration toward the formal sector is reversed in the long run. Nevertheless, the reduced level of formal sector migration cannot fully compensate for reduced employment in that sector. Unskilled 
open unemployment therefore increases by 1.4 percent in the long run. By contrast, skilled unemployment increases by a much smaller proportion (0.1 percent) at the same horizon.

Finally, the results indicate that the hike in the tax rate leads to a sharp increase (by 11 percent) in the ratio of tax revenues to domestic debt in the long run. This is partly due to the direct impact of an increased VAT rate, but mostly due to the impact of higher prices on tax revenues. Combined with the strong decline in the bond rate, this leads to a significant long-run reduction in the interest payments-to-tax revenue ratio. Furthermore, the reduced interest payments implies that there is less need for a government primary surplus. Accordingly, the reduction in interest payments leads to increased household transfers (and thus higher spending, as noted earlier) and a long-run reduction in the primary surplus of around 2.4 percent of GDP.

\subsubsection{Increase in the Tax Rate on Profit Earners}

We next consider a permanent, 5 percentage point increase in the tax rate on income of profit earners. Results are reported in Tables 6 and 7.

The main impact of the tax increase is to lower real disposable income of profit earners (by about 3.2-3.8 percent in the short and long run) and to increase real disposable income of other urban sector households. It also leads to an in increase in government revenues amounting to 1 percent of GDP in the short to medium run, and 1.2 percent of GDP in the long run.

As a result of our public budget closure rule (which, again, keeps the supply of bonds fixed and treats foreign borrowing as exogenous), the increase in government revenue translates into higher transfers to households. Given the initial distribution of these transfers, they go mainly toward urban formal households and profit earners. Nevertheless, urban informal households are initially the main beneficiaries of the increased transfers, with their real disposable income rising by 2.0 percent in the short run, compared to 0.9 percent for urban formal households and -0.2 percent for rural households. The strong relative increase in informal sector income is due to $a$ ) increasing demand for informal sector goods and production input (labor); and $b$ ) the fact that informal sector households are not subject to direct tax payments. Profit earners have relatively low consumption shares in informal sector goods. The redistribution of household income therefore increases demand for informal sector goods by a relatively large amount. In turn, this 
raises informal sector output, labor demand, and wages, thereby leading to higher real disposable income.

In the medium run (period 5), formal sector households enjoy a relatively strong increase in real disposable income ( 2.9 percent) compared to urban informal households (1.9 percent). The income of profit earners is relatively high in the medium run, and tax-induced redistribution toward formal sector households is therefore relatively high. In the long run, the initial pattern reestablishes itself: urban informal households gain the most (about 2 percent) compared to urban formal households (1 percent) and rural households (-0.3 percent).

Inflation is high in the short run but declines toward zero in the medium run. Rural and urban price levels reach a maximum increase of 3.1-3.4 percent (see Table 7, period 5). In subsequent periods, inflation turns negative and price levels return gradually to values close to their baserun levels. Price movements are driven by the increase in sectoral demand (relative to supply) for goods and services and tend to be reflected in movements of the nominal exchange rate. The real exchange rate appreciates somewhat in the short and medium run, but remains virtually unchanged in the long run. The initial exchange rate appreciation worsens the current account slightly in the short run. In the longer run, however, there is no discernible impact on external balance.

Similar to price levels, nominal wage levels reach a maximum increase in the medium run. High wage increases of about 5.5 percent are experienced by informal sector workers. In comparison, private formal skilled and unskilled workers benefit from smaller increases, of the order of 1.5 and 2.3 percent, respectively. In the long run, the informal sector wage level increases by 2.7 percent whereas formal sector wages (both skilled and unskilled) decline. This decline is due to a combined switch in consumption and investment demand away from formal sector goods. The fall in unskilled wages in the formal private sector is somewhat mitigated in the medium and long run as a result of an increase in the reservation wage due to increasing public sector wages (private formal unskilled workers benefit from a high public sector leadership effect on their wages), and subsequently due to declining unskilled unemployment.

The long-run decline in unskilled unemployment (following an increase in the short and medium run) results mainly from a reduction in the supply of unskilled labor to the formal sector. The reason is that the increase in the informal sector wage relative to the private formal unskilled wage lowers 
the expected wage differential between the formal and informal sectors. This reduces migration into the formal sector (and thus the number of unskilled job seekers in that sector) and gradually eliminates the increase in unemployment that occurred during the short and medium run. As for rural-urban migration, the expected wage differential between urban and rural areas gets smaller relative to the baseline, because of the decline in relative formal sector wages (and in spite of the increase in informal sector wages). The subsequent "reverse" migration from urban to rural areas implies that informal sector employment contracts slightly in the medium run; it also expands in the long run, when migration out of urban areas tapers off. Labor movements imply that rural employment continuously expands during the simulation horizon.

Unskilled employment in the urban formal sector declines both in the short and the long run, as a result of declining demand for formal sector goods. Skilled employment also declines (marginally) in the short run, but increases (marginally) in the medium term due to increasing investment and capital accumulation. As noted earlier, skilled workers benefit from the complementarity between physical capital accumulation and skilled labor employment. But because the increases in real private investment recorded between periods 2 and 6 are subsequently reversed (see below), this complementarity effect is muted. Skilled employment remain essentially unchanged in the long run.

Overall, the redistributive policy of increasing taxation of profit earners leaves real GDP unchanged in the long run. Migration increases employment and real value added in rural areas by a small amount (0.1 percent). By contrast, reduced demand for formal sector goods leads to reduced relative formal sector wages, reduced formal sector migration, and lower value added in the formal sector (-0.1 percent). The net effect of increased migration to rural areas and reduced formal sector migration means that value added in the informal sector remains virtually unchanged in the long run.

Real investment declines on impact due to the accelerator effect. During the following periods (and until period 6), real investment expands because increasing inflationary expectations reduce the expected cost of borrowing for investment purposes. By the same token, real investment declines in the long run as expected inflation and the expected cost of borrowing drop. Real consumption falls in line with disposable income, whereas overall disposable income itself declines due to increasing consumer prices.

Regarding the financial sector, the interest rate on domestic-currency loans increases marginally in the medium run, and declines slightly in the 
long run. The medium-run increase follows from small increases in domestic and external risk premia, whereas the long-run decline follows from improved credibility, which spills over into declining expectations of inflation and exchange rate depreciation - thereby lowering the expected cost of funds. Improved credibility is the mirror image of a declining probability of default, which itself follows directly from the increase in tax revenues. The reduction in the probability of default puts downward pressure on the actual bond rate. Overall, however, the bond rate increases in both the short and the long run, as a result of a decline in the demand for bonds by profit earners, induced by lower disposable income, lower savings, and thus lower wealth accumulation over time for that category of households. In between, during the medium run, the bond rate declines slightly because of a wealth-induced increase in demand for government bonds by commercial banks. Nominal exchange rate depreciation increases the net worth of commercial banks in the medium run, and this indeed stimulates their demand for bonds.

Public finance indicators show that tax revenues expand significantly as a proportion of domestic debt throughout the adjustment period, reaching 2.4 percent in the long run. The increase in government resources implies that interest payments as a proportion of tax revenues decline strongly during the medium term. However, the subsequent increase in the bond rate implies that the interest payments-tax revenue ratio returns to a value close to its baserun level in the long run. Due to the model closure rule (flexible household transfers balancing the public sector budget), the primary budget surplus naturally reflects additional financing needs. Accordingly, the primary budget balance follows movements in the bond rate: as a proportion of GDP, the primary surplus deteriorates in the medium term, and improves (by about 0.7 percentage point) in the long run.

Finally, in evaluating the fiscal effects of a tax increase on profit earners, it should be kept in mind that the model does not account for the possibility that higher tax rates may increase incentives for tax evasion (thereby reducing the increase in the "effective" tax rate) and/or reduce incentives to participate in the labor force (which would affect output growth in the medium and long run). Both effects may lead to lower increases in tax revenues than those indicated by our simulation results. At the same time, however, there is limited evidence that participation rates are highly sensitive to tax rates in Turkey. 


\section{Concluding Remarks}

The purpose of this paper has been to analyze the effects of monetary and fiscal adjustment on public debt sustainability and the behavior of wages and unemployment in Turkey. The model on which the analysis is based captures a number of important structural characteristics of the Turkish economy, such as rural-urban migration, a large urban informal sector, bilateral bargaining in the formal sector, dollarization of the banking system (on both asset and liability sides), as well as the interactions between credibility, default risk on government debt, and inflation expectations. Accounting for default risk on public debt is indeed a key feature of the model, despite its deterministic nature. Our basic assumption is that if the government must engage in large-scale borrowing to meet its debt service payments and finance its deficit, investors will be unwilling to accumulate public bonds indefinitely. We endogenized investors' behavior by assuming that there is a non-zero perceived probability of default that depends on the debt-to-tax revenue ratio. The higher the perceived risk of default is, the lower will be the degree of credibility of the fiscal stance. Lower credibility, in turn, translates into greater inflation persistence and upward pressure on interest rates on government bonds. Thus, an unsustainable fiscal policy may force the government to adjust, as a result of growing pressure on borrowing costs.

Various simulations were performed. Specifically, we conducted two sets of experiments: a restrictive monetary policy taking the form of a permanent increase in official interest rates, and fiscal adjustment, taking the form of an increase in the VAT rate and an increase in the tax rate on income of profit earners. The results highlighted the importance of accounting for general equilibrium effects in interest rate determination, as well as the link between default risk and credibility in understanding the real and financial effects of adjustment policies. In addition, they also indicated the importance of a broad range of fiscal measures for putting domestic public debt on a sustainable path. These results are consistent with those of several other recent studies of the Turkish economy. For instance, Voyvoda and Yeldan (2003), using an overlapping-generations framework, found that whether the primary surplus target of 6.5 percent of GDP embedded in the May 2001 program is sustainable depended heavily on the vulnerability of the Turkish economy to adverse growth shocks. In addition, the debt-to-GDP ratio was likely to fall only gradually. They called for further fiscal reform to ensure a speedier fall in that ratio - and therefore allow domestic risk premia (or default 
probabilities) to fall and interest rates to come down, as in our framework.

As one would naturally expect in a model of this type, our simulation results depend very much on the type of closure rule that we adopted for the government budget. Instead of assuming that the supply of bonds follows an exogenous path and that any residual budget gap is "closed" through an adjustment in transfers to households - a plausible adjustment scenario for a country where the recent crisis has led to a dramatic drop in real wages and a sharp increase in poverty - we could have assumed for instance that the supply of domestic bonds (or foreign borrowing) is endogenous, with an adjustment rule involving either a change in government spending on goods and services produced in the formal sector, or a change in the VAT tax rate, when the ratio of domestic (or foreign) debt to tax revenues reaches a particular level. Such threshold rules are attractive from an empirical standpoint to the extent that they describe quite well the way policymakers tend to respond to excessive growth in their liabilities. Intuitively, the implications for our model are quite clear: by allowing the debt-to-tax ratio to fluctuate a lot more, the probability of default would also fluctuate more, thereby implying a larger effect of default risk (or, equivalently here, credibility) on the actual bond rate. In turn, fluctuations in the bond rate would imply larger effects of any given shock on the financial sector and the real economy.

In addition to the policies considered in this paper, the model can be used to analyze the fiscal and labor market effects of a wide range of shocks. For instance, the model could be used to study the impact of various interest rate rules on output, inflation, and unemployment, or alternative fiscal rules aimed at limiting discretion in spending and ensuring public debt sustainability in the long run (see, for instance, Perry (2003) and Wyplosz (2002)). An analysis of the performance of alternative interest rate rules - which could capitalize on some of the recent research by Berument and Malatyali (2001), Berument and Tasci (2004), and Elekdag (2003) — would be particularly desirable, given Turkey's planned transition to inflation targeting. The response of Turkey's economy to various types of external shocks (such as contagion effects, autonomous changes in sentiment on world capital markets, as in Agénor (2005b), or terms-of-trade disturbances) could also be analyzed in the model.

On the labor market side, an important experiment would be to examine the impact of a cut in payroll taxation. Employer-paid social security contributions averaged about 36 percent of total labor costs during 19962000; it has been argued that these high social security taxes create strong 
disincentives to job creation. More generally, many observers have called for a thorough overhaul of Turkey's social insurance system. A key issue in this context is how to shift the main pillar of unemployment protection from the severance payment system to the unemployment insurance scheme established in June 2000, and the extent to which this shift will promote labor adjustment in response to changing economic conditions. ${ }^{47}$ The model could also be used to analyze the macroeconomic effects of a reduction in employment of unskilled workers in government. This last simulation is quite important because some observers have argued that continued fiscal adjustment in Turkey may require a sustained retrenchment in public sector employment, given a public sector wage bill that accounted for about 24 percent of central government expenditure in recent years. ${ }^{48}$

Finally, although already quite complex, our model can be extended or modified in various directions. We assumed that the market for bank credit was imperfectly competitive. Alternatively, it could be assumed that the banking system is oligopolistic, as for instance in Beenstock et al. (2003). This type of market structure could lead to higher, and more rigid, bank lending spreads. Second, workers' reservation wage could be made a function of severance payments, as for instance in Agénor's (2003) specification of the wage target of trade unions. This would allow the model to address an important issue for the Turkish labor market (see Tunali (2003)): the wage and employment effects of a reduction in firing costs. Finally, we did not model the stock market. Although the existing evidence suggests that the stock market does not play a significant financial role in Turkey at the present time, its importance may increase in the future - and so will, therefore, its potential effects on private investment and portfolio allocation.

\footnotetext{
${ }^{47}$ Social security could be modeled along the lines of Agénor, Nabli, Yousef, and Jensen (2004).

${ }^{48}$ During the period 1999-2001, public sector employment increased by 5 percent, whereas private employment fell by 6 percent.
} 


\section{Appendix A}

\section{List of Equations ${ }^{49}$}

\section{PRODUCTION}

$$
\begin{gathered}
X_{j}=V_{j}+\sum_{i} a_{i j} X_{j} \\
V_{A}=\left[\alpha_{X A}\left\{\beta_{X A} U_{A}^{-\rho_{X A}}+\left(1-\beta_{X A}\right) K_{I N F}^{-\rho_{X A}}\right\}^{-\frac{1}{\rho_{X A}}}\right]^{1-\eta_{X A}} \\
X_{A}=\alpha_{E D_{A}}\left[\beta_{E D_{A}} E_{A}^{\rho_{E D_{A}}}+\left(1-\beta_{E D_{A}}\right) D_{A}^{\rho_{E D_{A}}}\right]^{\frac{1}{\rho_{E D_{A}}}} \\
V_{I}=\alpha_{X I} U_{I}^{\beta_{X I}} \\
J_{1}=\alpha_{X_{P} 1}\left[\beta_{X_{P} 1} S_{P}^{-\rho_{X_{P}}}+\left(1-\beta_{X_{P} 1}\right) K_{P}^{-\rho_{X_{P} 1}}\right]^{-\frac{1}{\rho_{X_{P} 1}}} \\
J_{2}=\alpha_{X_{P} 2}\left\{\beta_{X_{P} 2} J_{1}^{-\rho_{X_{P} 2}}+\left(1-\beta_{X_{P} 2}\right) U_{P}^{-\rho_{X_{P} 2}}\right\}^{-\frac{1}{\rho_{X_{P}}}} \\
V_{P}=\alpha_{X_{P}}\left[\beta_{X_{P}} J_{2}^{-\rho_{X_{P}}}+\left(1-\beta_{X_{P}}\right) K_{I N F}^{-\rho_{X_{P}}}\right]^{-\frac{1}{\rho_{X_{P}}}} \\
X_{P}=\alpha_{E D_{P}}\left[\beta_{E D_{P}} E_{P}^{\rho_{E D_{P}}}+\left(1-\beta_{E D_{P}}\right) D_{P}^{\rho_{E D_{P}}}\right]^{\frac{1}{\rho_{E D_{P}}}} \\
J_{G}=\alpha_{X_{G} J}\left[\beta_{X_{G} J} S_{G}^{-\rho_{X_{P} J}}+\left(1-\beta_{X_{G} J}\right) K_{I N F}^{-\rho_{X_{G} J}}\right]^{-\frac{1}{\rho_{X_{G} J}}} \\
V_{G}=\alpha_{X_{G}}\left[\beta_{X_{G}} J_{G}^{-\rho_{X_{G}}}+\left(1-\beta_{X_{G}}\right) U_{G}^{-\rho_{X_{G}}}\right]^{-\frac{1}{\rho_{X_{G}}}} \\
N G D P=\sum_{i} P V_{i} V_{i}+I N D T A X \\
R G D P=\sum_{i}\left(C_{i}+G_{i}+Z_{P}^{i}+E i-E R \cdot w p m_{i} M_{i}\right)+Z_{G}
\end{gathered}
$$

\footnotetext{
${ }^{49}$ In both Appendices $\mathrm{A}$ and $\mathrm{B}$, the index $i$ or $j$ (respectively, $h$ ) is used below to refer to all production sectors (household groups, respectively), that is, $A, G, I$, and $P(A, I$, $F$, and $E$, respectively), unless otherwise indicated.
} 


\section{LABOR MARKET}

$$
\begin{aligned}
& U_{A}^{d}=\left(\left(1-\eta_{X A}\right) V_{A}^{1+\frac{\rho_{X A}}{1-\eta_{X A}}} \frac{P V_{A}}{W_{A}} \cdot \frac{\beta_{X A}}{\alpha_{X A}^{\rho_{X A}}}\right)^{\frac{1}{1+\rho_{X A}}} \\
& U_{R U R}^{s}=U_{A}^{d}\left(V_{A}, \frac{W_{A}}{P V_{A}}\right) \\
& U_{R U R}^{s}=U_{R U R,-1}\left(1+g_{R U R}\right)-M I G \\
& E W_{U R B}=\theta_{U}\left(1-\operatorname{sstax}_{U}\right) W_{U P,-1}+\left(1-\theta_{U}\right) W_{I,-1} \\
& \theta_{U}=\frac{U_{P,-1}}{U_{F,-1}^{s}-U_{G,-1}} \\
& M I G=U_{R U R,-1} \lambda_{M}\left[\sigma_{M} \ln \left(\frac{E W_{U R B}}{W_{A,-1}}\right)\right]+\left(1-\lambda_{M}\right) \frac{U_{R U R,-1}}{U_{R U R,-2}} M I G_{-1} \\
& W_{j G}=\omega_{j G} P_{U R B}, \quad j=U, S \\
& W_{S P}=\left(1-\nu_{S}\right) \Omega_{S}+\frac{\nu_{S} P J_{1} m_{S}}{(1+I L)\left(1+\operatorname{paytax}_{S}\right)} \\
& \Omega_{S}=\Omega_{S 0} \frac{W_{S G}^{\phi_{S}^{1}}\left[P_{U R B,-1}(1+E I N F L)\right]^{\phi_{S}^{2}}}{U N E M P_{S}^{\phi_{S}^{3}}} \\
& W_{U P}=\left(1-\nu_{U}\right) \Omega_{U}+\frac{\nu_{U} P J_{2} m_{U}}{(1+I L)\left(1+\operatorname{paytax}_{U}\right)} \\
& \Omega_{U}=\Omega_{U 0} \frac{W_{U G}^{\phi_{U}^{1}}\left[P_{U R B,-1}(1+E I N F L)\right]^{\phi_{U}^{2}} W_{M}^{\phi_{U}^{4}}}{U N E M P_{U}^{\phi_{U}^{3}}} \\
& U_{P}^{d}=J_{2}\left(\frac{P J_{2}}{\left(1+I L_{-1}\right)\left(1+\operatorname{paytax}_{U}\right) W_{U P}} \frac{\beta_{X P 2}}{\alpha_{X P 2}^{\rho_{X P 2}}}\right)^{\sigma_{X P 2}} \\
& \frac{\Delta U_{F}^{s}}{U_{I,-1}}=\beta_{F}\left[\sigma_{F} \ln \left(\frac{U_{P,-1}^{d}}{U_{F,-1}^{s}-U_{G,-1}} \frac{\left(1-\operatorname{sstax}_{U}\right) W_{U P,-1}}{W_{I,-1}}\right)\right]+\left(1-\beta_{F}\right) \frac{\Delta U_{F-1}^{s}}{U_{I,-2}} \\
& U N E M P_{U}=1-\frac{\left(U_{G}+U_{P}^{d}\right)}{U_{F}^{s}}
\end{aligned}
$$




$$
\begin{gathered}
U_{I}^{s}=U_{U R B}^{s}-U_{F}^{s} \\
W_{I}=\beta_{X I}\left(\frac{P V_{I} \cdot V_{I}}{U_{I}^{s}}\right) \\
U_{U R B}^{s}=U_{U R B,-1}^{s}\left(1+g_{U R B}\right)+M I G-S K L-I M I G \\
S_{P}^{d}=J_{1}\left(\frac{P J_{1}}{\left(1+I L_{-1}\right)\left(1+p a y t a x_{S}\right) W_{S P}} \cdot \frac{\beta_{X P 1}}{\alpha_{X P 1}^{\rho_{X P 1}}}\right)^{\sigma_{X P 1}} \\
U N E M P_{S}=1-\frac{\left(S_{G}^{T}+S_{P}^{d}\right)}{S} \\
S_{G}^{T}=S_{G}+S_{G}^{E}
\end{gathered}
$$

\section{EXTERNAL TRADE}

$$
\begin{gathered}
E_{i}=D_{i}\left(\frac{P E_{i}}{P D_{i}} \cdot \frac{1-\beta_{E D i}}{\beta_{E D i}}\right)^{\sigma_{E D i}}, \quad i=A, P \\
M_{i}=D_{i}\left(\frac{P D_{i}}{P M_{i}} \cdot \frac{\beta_{Q i}}{1-\beta_{Q i}}\right)^{\sigma_{Q_{i}}}, \quad i=A, P
\end{gathered}
$$

\section{AGGREGATE SUPPLY AND DEMAND}

$$
\begin{aligned}
& Q_{I}^{s}=X_{I}, \quad i=I, G \\
& Q_{i}^{s}=\alpha_{Q_{i}}\left\{\beta_{Q_{i}} D_{i}^{-\rho_{Q_{i}}}+\left(1-\beta_{Q_{i}}\right) M_{i}^{-\rho_{Q_{i}}}\right\}^{-\frac{1}{\rho_{Q_{i}}}}, \quad i=A, P \\
& Q_{A}^{d}=C_{A}+G_{A}+I N T_{A} \\
& Q_{I}^{d}=C_{I}+I N T_{I} \\
& Q_{G}^{d}=C_{G}+G_{G}+Z_{P}^{G}+I N T_{G} \\
& Q_{P}^{d}=C_{P}+G_{P}+Z_{P}^{P}+Z_{G}+I N T_{P}
\end{aligned}
$$




$$
\begin{gathered}
I N T_{j}=\sum_{i} a_{j i} X_{i} \\
G_{i}=g g_{i} \frac{P G \cdot G}{P C_{i}}, \quad \text { for } i=A, P, G, \quad \sum_{i} g g_{i}=1 \\
C_{i}=\sum_{h} C_{i h}=\sum_{h} x_{i h}+\frac{\sum_{h} c c_{i h}\left(C O N_{h}-\sum_{i} P C_{i} x_{i h}\right)}{P C_{i}} \\
Z_{P}^{i}=z z_{i} \frac{P K \cdot Z_{P}}{P C_{i}}, \quad z z_{G}+z z_{P}=1
\end{gathered}
$$

\section{PROFITS AND INCOME}

$$
P R O F_{i}=P V_{i} V_{i}-W_{i} U_{i}, \text { for } i=A, I
$$

$P R O F_{P}=P V_{P} V_{P}-\left(1+I L_{-1}\right)\left[\left(1+\operatorname{paytax}_{U}\right) W_{M} U_{P}+\left(1+\operatorname{paytax}_{S}\right) W_{S} S_{P}\right]$

$Y F_{P}=\left(1-\operatorname{ftax}_{P}\right) P R O F_{P}-I L_{-1} D L_{P,-1}-I L F_{-1} D L F_{P,-1}-I F^{W} \cdot E R \cdot F L_{P,-1}$

$$
P R O F_{G}=P V_{G} V_{G}-\left(1+\operatorname{paytax}_{U}\right) W_{U G} U_{G}-\left(1+\operatorname{paytax}_{S}\right) W_{S G} S_{G} \text { (A52) }
$$$$
P R O F_{B}=I L_{-1}\left(D L_{P,-1}+D L_{F,-1}\right)+I L F_{-1} D L F_{P,-1}
$$

$$
+I L_{-1}\left[\left(1+\operatorname{paytax}_{U}\right) W_{M} U_{P}+\left(1+\operatorname{paytax}_{S}\right) W_{S} S_{P}\right]+I B \cdot G B_{B,-1}^{T}
$$

$-I R \cdot D L_{B,-1}-I D \sum_{h} D D_{h,-1}-I D F \cdot E R \sum_{h} F D_{h,-1}-I F^{W} \cdot E R \cdot F L_{B,-1}$

$Y H_{A}=W_{A} U_{A}+\operatorname{shp}_{A} P R O F_{A}+\gamma_{A} T R H+I D \cdot D D_{A,-1}$

$Y H_{I}=P V_{I} V_{I}+\gamma_{I} T R H+I D \cdot D D_{I,-1}+\tau_{I} E R \cdot R E M I T$

$Y H_{F}=\left(1-\operatorname{sstax}_{U}\right) \sum_{j=P, G} W_{U j} U_{j}+\left(1-\operatorname{sstax}_{S}\right) \sum_{j=P, G} W_{S j} S_{j}+W_{S G} S_{G}^{E}$

$+\operatorname{sh} p_{P}^{F} Y F_{P}+\gamma_{F} T R H+I D \cdot D D_{F,-1}+E R\left(I D F \cdot F D_{F,-1}+I F_{R F}^{W} F D_{F,-1}^{W}\right)$

$-I L_{-1} D L_{F,-1}+\left(1-\tau_{I}\right) E R \cdot R E M I T$

$$
Y H_{E}=\left(1-s h p_{A}\right) P R O F_{A}+s h p_{P}^{E} Y F_{P}+s h p_{B}^{E} P R O F_{B}
$$

$+\gamma_{E} T R H+I D \cdot D D_{E,-1}+E R\left(I D F \cdot F D_{E,-1}+I F_{R F}^{W} F D_{E,-1}^{W}\right)+I B \cdot G B_{E,-1}$ 
SAVINGS AND WEALTH

$$
\begin{gathered}
S A V_{h}=\text { srate }_{h}\left(1-\text { inctax }_{h}\right) Y H_{h} \\
\text { srate }_{h}=s_{0}^{h}\left(\frac{1+I D}{1+E I N F L}\right)^{\sigma_{S A V}^{h}} \\
C O N_{h}=\left(1-\text { inctax }_{h}\right) Y H_{h}-S A V_{h} \\
W T_{h}=W T_{h,-1}+S A V_{h}+\Delta E R\left(F D_{h,-1}+F D_{h,-1}^{W}\right)
\end{gathered}
$$

\section{PRIVATE INVESTMENT}

$$
\begin{gathered}
\frac{P K \cdot Z_{P}^{d}}{N G D P_{-1}}=\left(\frac{K_{I N F}}{U_{U R B}^{s}+S}\right)^{\sigma_{K I N F}}\left(1+\frac{\Delta R G D P_{-1}}{R G D P_{-2}}\right)^{\sigma_{A C C}}\left(\frac{1+I L}{1+E I N F L}\right)_{(\mathrm{A} 62)}^{-\sigma_{I L}} \\
\Delta\left(\frac{P K \cdot Z_{P}}{N G D P_{-1}}\right)=\lambda_{P I N V}\left(\frac{P K \cdot Z_{P}^{d}}{N G D P_{-1}}-\frac{P K_{-1} \cdot Z_{P,-1}}{N G D P_{-2}}\right) \\
K_{P}=K_{P,-1}\left(1-\delta_{P}\right)+Z_{P,-1}
\end{gathered}
$$

\section{CREDIT MARKET AND PORTFOLIO ALLOCATION}

$$
\begin{gathered}
W T_{h}=H_{h}+E R\left(F D_{h}+F D_{h}^{W}\right)+D D_{h}+G B_{h}-D L_{h} \\
H_{h}^{d}=\frac{C O N_{h}^{\theta_{C O N}^{h}} E I N F L^{-\theta_{E I N F L}^{h}}(1+I D)^{-\theta_{D D}^{h}}}{\left\{(1+E D E P R)(1+I D F)^{\kappa_{F D}^{h}}\left(1+I F_{R F}^{W}\right)^{1-\kappa_{F D}^{h}}\right\}_{I F}^{\theta_{h}^{h}}} \\
\kappa_{F D}^{h}=\frac{F D_{h,-1}}{F D_{h,-1}+F D_{h,-1}^{W}}, \quad h=F, E \\
\frac{H^{d}=\sum_{h} H_{h}^{d}}{E R\left(F D_{h}+F D_{h}^{W}\right)}=\left\{\frac{(\mathrm{A} 66)}{\left(1+E T_{h}-H_{h}, \quad h=A, I\right.}\right. \\
\frac{F D_{h}}{F D_{h}^{W}}=\left(\frac{1+I D F}{1+I F_{R F}^{W}}\right)^{\theta_{F D}^{h}}, \quad h=F, E
\end{gathered}
$$




$$
\begin{aligned}
& \frac{G B_{E}^{d}}{W T_{E}-H_{E}}=\frac{(1+E I B)^{\theta_{G B}^{E}}(1+I D)^{-\theta_{D D}^{E}}}{\left[(1+E D E P R)(1+I D F)^{\kappa_{F D}^{E}}\left(1+I F_{R F}^{W}\right)^{1-\kappa_{F D}^{E}}\right]^{\theta_{F D}^{E}}} \\
& D L_{P}^{T}=D L_{P}+E R \cdot D L F_{P} \\
& E R \cdot D L F_{P}=\phi_{D L}^{P}\left(F L_{B}+\sum_{h} E R \cdot F D_{h}\right) \\
& D L_{P}^{T}=D L_{P,-1}^{T}+P K \cdot Z_{P}-\left(1-s h p_{P}^{F}-s h p_{P}^{E}\right) Y F_{P}-E R \cdot \Delta F L_{P} \\
& R R=\operatorname{rreq} \sum_{h}\left(D D_{h}+E R \cdot F D_{h}\right) \\
& G B_{B}^{T}=G B_{B}^{p}+G B_{B}^{d} \\
& G B_{B}^{p}=\phi_{G B}^{B, p} \cdot G B^{s} \\
& \frac{G B_{B}^{d}}{N W_{B}}=\phi_{G B}^{B, d}\left(\frac{1+E I B}{1+I L}\right)^{\theta_{G B}^{B}} \\
& \frac{E R \cdot F L_{B}}{N W_{B}}=\phi_{F L}^{B}\left[\frac{1+I R}{\left(1+I F^{W}\right)(1+E D E P R)}\right]^{\theta_{F L}^{B}}
\end{aligned}
$$

\section{INTEREST RATES AND RISK PREMIA}

$$
\begin{gathered}
1+I D=1+I R \\
1+I D F=1+I F^{W} \\
1+I F^{W}=\left(1+I F_{R F}^{W}\right)(1+E X T P R) \\
E X T P R=C O N T A G+\frac{\kappa_{E R P}}{2}\left(\frac{\sum_{i=P, B, G} F L_{i}}{\sum_{i=A, P} w p e_{i} E_{i}}\right)^{2} \\
1+I L=\frac{\left\{(1+I R)^{\left.\kappa_{D L}^{B}\left[\left(1+I F^{W}\right)(1+E D E P R)\right]^{1-\kappa_{D L}^{B}}\right\}}\right.}{(1+D O M P R)^{-1}(1-r r e q)} \\
\kappa_{D L}^{B}=\frac{\sum_{h} D D_{h,-1}+D L_{B,-1}}{\sum_{h} D D_{h,-1}+D L_{B,-1}+E R_{-1}\left(\sum_{h} F D_{h,-1}+F L_{B,-1}\right)}
\end{gathered}
$$




$$
\begin{aligned}
D O M P R= & {\left[\frac{\delta_{c} P K_{-1} K_{P-1}}{D L_{P,-1}+E R_{-1}\left(D L F_{P,-1}+F L_{P,-1}\right)}\right]^{-\kappa_{D R P}} } \\
& (1+I L F)(1+E D E P R)=1+I L
\end{aligned}
$$

\section{CENTRAL BANK}

$$
\begin{gathered}
P R O F_{C B}=I R \cdot D L_{B,-1}+I F_{R F}^{W} E R \cdot F F+I B \cdot G B_{C B,-1} \\
N W_{C B}=N W_{C B,-1}+\left(1-s h p_{G}\right) P R O F_{C B}+\Delta E R \cdot F F_{-1} \\
M B=M B_{-1}+\Delta D L_{B}+E R \cdot \Delta F F+\Delta G B_{C B}-\left(1-s h p_{G}\right) P R O F_{C B}
\end{gathered}
$$

\section{GOVERNMENT}

$$
\begin{aligned}
& P R B A L=T X R E V+P R O F_{G}+\operatorname{shp}_{G} P R O F_{C B} \\
& -W_{S G} S_{G}^{E}-T R H-P G \cdot G-P C_{P} Z_{G} \\
& O V B A L=P R B A L-I F_{G}^{W} \cdot E R \cdot F L_{G,-1}-I B \cdot G B_{-1}^{T} \\
& G B^{s}=G B_{B}^{T}+G B_{C B}+G B_{E} \\
& T X R E V=D I R T A X+I N D T A X \\
& +\operatorname{sstax}_{U} \sum_{j=P, G} W_{U j} U_{j}+\operatorname{sstax}_{S} \sum_{j=P, G} W_{S j} S_{j}+\sum_{j=U, S} \operatorname{paytax}_{j}\left(W_{j G} j_{G}+W_{j P} j_{P}\right) \\
& \operatorname{DIRTAX}=\sum_{h=A, F, E} \operatorname{inctax}_{h} Y H_{h}+\operatorname{ftax}_{P} P R O F_{P} \\
& I N D T A X=E R \sum_{i=A, P} w_{p m} t m_{i} M_{i}+\sum_{i \neq I} \operatorname{protax}_{i} P X_{i} X_{i} \\
& +\sum_{i=A, P} \operatorname{saltax}_{i} P Q_{i} Q_{i} \\
& Z_{G}=I_{I N F}+I_{E D U} \\
& K_{i}=\left(1-\delta_{i}\right) K_{i,-1}+I_{i,-1}, \quad i=I N F, E D U \\
& -O V B A L=E R \cdot \Delta F L_{G}+\Delta G B^{s}
\end{aligned}
$$


BALANCE OF PAYMENTS AND THE EXCHANGE RATE

$$
\begin{gathered}
0=\sum_{i=A, P}\left(w_{p e} E_{i}-w p m_{i} M_{i}\right)+I F_{R F}^{W} \sum_{h=F, E} F D_{h,-1}^{W} \\
+R E M I T+I F_{R F}^{W} F F-I F^{W} \sum_{h=P, B} F L_{j,-1}-I F_{G}^{W} F L_{G,-1} \\
-\sum_{h=F, E} \Delta F D_{h}^{W}+\sum_{j=G, P, B} \Delta F L_{j}-\Delta F F \\
R E M I T=\kappa_{R E M} W_{F} F O R L_{-1} \\
F O R L=\left(1-\delta_{I M I G}\right) F O R L_{-1}+I M I G
\end{gathered}
$$

CURRENCY AND BOND MARKET EQUILIBRIUM

$$
\begin{gathered}
H^{s}=M B-R R \\
H^{s}=H^{d} \\
\left(1-\phi_{G B}^{B, p}\right) G B^{s}=N W_{B} \phi_{G B}^{B, d}\left(\frac{1+E I B}{1+I L}\right)^{\theta_{G B}^{B}}+G B_{C B} \\
+\frac{\left(W T_{E}-H_{E}\right)(1+E I B)^{\theta_{G B}^{E}}(1+I D)^{-\theta_{D D}^{E}}}{\left\{(1+E D E P R)(1+I D F)^{\kappa_{F D}^{E}}\left(1+I F_{R F}^{W}\right)^{1-\kappa_{F D}^{E}}\right\}^{\theta_{F D}^{E}}}
\end{gathered}
$$

PRICE DETERMINATION

$$
\begin{aligned}
& P V_{i}=V_{i}^{-1}\left\{P X_{i}\left(1-\operatorname{protax}_{i}\right)-\sum_{j} a_{j i} P C_{j}\right\} X_{i} \\
& P E_{i}=w p e_{i} E R, \quad i=A, P \\
& P M_{i}=w_{p m}\left(1+t m_{i}\right) E R, \quad i=A, P \\
& P X_{i}=\frac{P D_{i} D_{i}+P E_{i} E_{i}}{X_{i}}, \quad i=A, P \\
& P X_{i}=P D_{i}, \quad i=I, G \\
& P Q_{i}=\frac{P D_{i} D_{i}+P M_{i} M_{i}}{Q_{i}}, \quad i=A, P
\end{aligned}
$$




$$
\begin{gathered}
P J_{1}=\frac{P R O F_{P}+\left(1+I L_{-1}\right)\left(1+\operatorname{paytax}_{S}\right) W_{S P} S_{P}}{J_{1}} \\
P J_{2}=\frac{J_{1} P J_{1}+\left(1+I L_{-1}\right)\left(1+\operatorname{paytax}_{U}\right) W_{U P} U_{P}}{J_{2}} \\
P K=\prod_{i=G, P} P C_{i}^{z z_{i}} \\
P G=\prod_{i=A, G, P} P C_{i}^{g g_{i}} \\
P C_{i}=(1+\operatorname{saltax}) P Q_{i}, i=A, P \\
P_{R U R}=\prod_{i} P C_{i}^{w r_{i}} \\
P_{U R B}=\prod_{i} P C_{i}^{w u_{i}} \\
C P I=P_{R U R}^{w c p} \cdot P_{U R B}^{1-w c p} \\
P I N F=I N F L=\Delta C P I / C P I_{-1}
\end{gathered}
$$

\section{DEFAULT RISK, CREDIBILITY, AND EXPECTATIONS}

$$
\begin{gathered}
E I B=(1-P D E F) I B \\
P D E F=1-\exp \left[-\alpha_{0}\left(\frac{G B_{-1}}{T A X R E V_{-1}}\right)\right] \\
E I N F L=C R E D I B \cdot I N F L^{T A R G}+(1-C R E D I B) I N F L_{-1} \\
C R E D I B=1-P D E F \\
E D E P R=\chi E D E P R_{-1}+(1-\chi)\left(E I N F L-F I N F L_{-1}\right)
\end{gathered}
$$




\section{Appendix B \\ Variable Names and Definitions}

$\begin{array}{ll}\text { Endogenous Variables } \\ \text { Name } & \text { Definition } \\ C_{i h} & \text { Consumption of good } i \text { by household category } h \\ C_{i} & \text { Aggregate consumption of good } i \\ C O N_{h} & \text { Consumption by household category } h \\ C P I & \text { Aggregate price level } \\ C R E D I B & \text { Credibility index } \\ D_{A} & \text { Domestic demand for domestic rural good } \\ D D_{A} & \text { Domestic deposits by households in rural sector } \\ D D_{E} & \text { Domestic deposits by profit earners and capitalists } \\ D D_{F} & \text { Domestic deposits by households in the formal sector } \\ D D_{I} & \text { Domestic deposits by households in the informal sector } \\ D D_{S} & \text { Domestic deposits by skilled household } \\ D D_{U F} & \text { Domestic deposits by unskilled household in formal sector } \\ D D_{U I} & \text { Domestic deposits by households in the informal sector } \\ D E F & \text { Government deficit } \\ D I R T A X & \text { Direct tax revenue } \\ D L_{B} & \text { Borrowing from the central bank } \\ D L_{F} & \text { Borrowing abroad from commercial banks } \\ D L F_{P} & \text { Foreign-currency loans by domestic banks } \\ D L_{P} & \text { Domestic-currency loans by banks to formal firms } \\ D L_{P}^{T} & \text { Total domestic borrowing from commercial banks } \\ D O M P R & \text { Domestic risk premium } \\ D_{P} & \text { Domestic demand for domestic private urban good } \\ E_{A} & \text { Export of rural sector goods } \\ E_{P} & \text { Export of private urban (formal) good } \\ E D E P R & \text { Expected rate of depreciation of nominal exchange rate } \\ E I B & \text { Expected rate of return on government bonds } \\ E I N F L & \text { Expected inflation rate } \\ E X T P R & \text { External risk premium } \\ E W_{F} & \text { Expected foreign wage, in domestic-currency terms } \\ E W_{U R B} & \text { Expected unskilled urban wage, } \\ F D_{A} & \text { Foreign deposits by households in rural sector } \\ & \end{array}$


$F D_{E} \quad$ Foreign deposits by profit earners and capitalists

$F D_{F} \quad$ Foreign-currency deposits held at home by formal household

$F D_{h}^{W} \quad$ Foreign-currency deposits held abroad by household $h$

$F D_{S} \quad$ Foreign deposits by skilled household

$F D_{U F} \quad$ Foreign deposits by households in formal urban sector

$F D_{U I} \quad$ Foreign deposits by households in informal sector

$F F \quad$ Foreign reserves

$F L_{B} \quad$ Banks' foreign liabilities

$F L_{G} \quad$ Foreign loans made to the government

FORL Number of Turkish nationals working abroad

$G \quad$ Government expenditures

$G_{A} \quad$ Government spending on rural sector good

$G_{G} \quad$ Government spending on public sector good

$G_{P} \quad$ Government spending in private urban sector good

$G B \quad$ Government bonds held by commercial banks, the central bank, and profit earners

$G B_{C B} \quad$ Government bonds held by the central bank

$G B_{E} \quad$ Holdings of government bonds, profit earners/capitalists

$G B_{h} \quad$ holdings of government bonds by household $h$

$G B^{B} \quad$ Holdings of government bonds, commercial banks

$G B^{s} \quad$ Supply of government bonds

$G B_{B}^{T} \quad$ Total government bond holdings by commercial banks

$G B_{B}^{d} \quad$ Additional commercial bank demand for government bonds

$G B_{B}^{p} \quad$ Direct bond placements by commercial banks

$G B_{E}^{d} \quad$ Demand for government bonds by profit earners

$H^{d} \quad$ Total demand for money

$H_{h}^{d} \quad$ Demand for currency by household $h$

$H^{s} \quad$ Money supply

$H_{A} \quad$ Money held by households in rural sector

$H_{E} \quad$ Money held by profit earners

$H_{S} \quad$ Money held by skilled household

$H_{U F} \quad$ Money held by households in formal urban sector

$H_{U I} \quad$ Money held by households in informal sector

$I B \quad$ Rate of interest on public bonds

INDTAX Indirect taxes on goods and services

IR Cost of funds provided by the central bank

IL Interest rate for domestic loan 
IMIG Migration to foreign countries

INDTAX Indirect taxes on goods and services

INFL Consumer price index inflation rate

$I N F L^{T A R G}$ Inflation target of the central bank

$I N T_{A} \quad$ Intermediate good demand for rural sector good

$I N T_{I} \quad$ Intermediate good demand for informal good

$I N T_{P} \quad$ Intermediate good demand for formal private sector good

$I N T_{G} \quad$ Intermediate good demand for public good

$J_{1} \quad$ Composite input from $J_{2}$ and unskilled labor

$J_{2} \quad$ Composite input from physical capital and skilled labor

$J_{G} \quad$ Composite input from skilled labor and public capital in infrastructure

$K_{E D U} \quad$ Public capital in education

$K_{I N F} \quad$ Public capital in infrastructure

$K_{P} \quad$ Private capital

$M_{A} \quad$ Import of rural sector good

$M B \quad$ Money base

MIG Net of worker migration to urban areas

$M_{P} \quad$ Import of private urban (formal) good

$m_{S} \quad$ Physical marginal product of skilled worker

$m_{U} \quad$ Physical marginal product of unskilled worker

NGDP Nominal GDP at market prices

$N W_{B} \quad$ Net worth of commercial banks

$N W_{C B} \quad$ Net worth of the central bank

$\Omega_{S}, \Omega_{U} \quad$ Reservation wages of skilled and unskilled workers

$O V B A L$ Overall fiscal balance

$P_{R U R} \quad$ Rural price index

$P C_{i} \quad$ Sales price of good $i$

$P D_{A} \quad$ Price of domestic sales of rural sector good

$P_{U R B} \quad$ Urban consumption price index

$P D_{G} \quad$ Domestic price of public good

$P D_{I} \quad$ Domestic price of informal sector good

$P D_{P} \quad$ Domestic price of domestic sales of private urban good

$P D E F \quad$ Probability of default on government debt

$P E_{A} \quad$ Price of exported rural good

$P E_{P} \quad$ Price of exported private urban good

$P G \quad$ Government consumption deflator 
PINF Inflation rate

$P J_{1} \quad$ Price of composite input $J_{1}$

$P J_{2} \quad$ Price of composite input $J_{2}$

$P K \quad$ Price of capital

$P M_{A} \quad$ Price of imported rural sector good

$P M_{P} \quad$ Price of imported private urban sector good

$P Q_{A} \quad$ Composite good price of rural sector good

$P Q_{G} \quad$ Composite good price of public good

$P Q_{I} \quad$ Composite good price of informal sector good

$P Q_{P} \quad$ Composite good price of private urban sector good

$P R B A L$ Government primary balance

$P R O F_{A} \quad$ Profits from rural production

$P R O F_{B} \quad$ Commercial banks' profits

$\mathrm{PROF}_{G} \quad$ Profits from public production

$P R O F_{I} \quad$ Profits from informal sector production

$P R O F_{P} \quad$ Profits from private urban formal production

$P R O F_{C B} \quad$ Profits of the central bank

$P V_{A} \quad$ Value added price of rural sector good

$P V_{I} \quad$ Value added price of informal good

$P V_{P} \quad$ Value added price of private formal good

$P V_{G} \quad$ Value added price of rural sector good

$P X_{A} \quad$ Sales price of agricultural good

$P X_{G} \quad$ Sales price of public good

$P X_{I} \quad$ Sales price of informal good

$P X_{P} \quad$ Sales price of private urban (formal) good

$Q_{A} \quad$ Demand of nontraded agricultural composite good

$Q_{G} \quad$ Demand of public composite good

$Q_{I} \quad$ Demand of informal composite good

$Q_{P} \quad$ Demand of private urban composite good

$Q_{A}^{d} \quad$ Aggregate demand for rural sector good

$Q_{G}^{d} \quad$ Aggregate demand for public good

$Q_{I}^{d} \quad$ Aggregate demand for informal good

$Q_{P}^{d} \quad$ Aggregate demand for urban private formal sector good

$Q_{A}^{s} \quad$ Quantity supplied in the rural sector

$Q_{G}^{s} \quad$ Quantity supplied in the public sector

$Q_{I}^{s} \quad$ Quantity supplied in the informal sector

$Q_{P}^{s} \quad$ Quantity supplied in the urban private formal sector 


$\begin{array}{ll}R G D P & \text { Real GDP } \\ R R & \text { Reserve requirements } \\ S & \text { Skilled workers } \\ S_{P}^{d} & \text { Demand for skilled labor in the urban private formal sector } \\ S A V_{A} & \text { Saving by rural sector household } \\ S A V_{E} & \text { Saving by profit earners and capitalists } \\ S A V_{F} & \text { Saving by urban formal sector household } \\ S A V_{I} & \text { Saving by informal sector household } \\ \text { srate }_{A} & \text { Saving rate of rural household } \\ \text { srate }_{E} & \text { Saving rate of profit earners and capitalists } \\ s r a t e_{F} & \text { Saving rate of formal sector household } \\ s r a t e_{I} & \text { Saving rate of informal sector household } \\ S K L & \quad \text { Flow of newly-skilled workers } \\ S_{P} & \text { Skilled labor employed in private urban formal } \\ T R H & \text { Total government transfers } \\ T X R E V & \text { Tax revenues } \\ U_{A} & \text { Unskilled labor employed in rural sector } \\ U_{I} & \text { Unskilled labor employed in informal sector } \\ U_{P} & \text { Unskilled labor employed in private urban formal sector } \\ U_{R U R} & \text { Supply of unskilled labor in rural sector } \\ U_{U R B}^{s} & \text { Urban unskilled labor supply } \\ U_{A}^{d} & \text { Demand for labor in the rural sector } \\ U_{I}^{d} & \quad \text { Demand for labor in the informal sector } \\ U_{P}^{d} & \quad \text { Demand for labor in the urban formal private sector } \\ U_{F}^{s} & \quad \text { Supply of unskilled workers in the formal sector } \\ U_{I}^{s} & \quad \text { Supply of labor in the informal sector } \\ U_{R U R}^{s} & \text { Labor supply in rural sector } \\ U_{U R B}^{s} & \quad \text { Urban unskilled labor supply } \\ U N E M P_{U} & \text { Unskilled unemployment rate, urban formal sector } \\ U N E M P_{S} & \text { Skilled unemployment rate } \\ V_{A} & \text { Value added in rural sector } \\ V_{I} & \text { Value added in informal sector } \\ V_{G} & \text { Value added in public sector } \\ & \end{array}$


$V_{P} \quad$ Value added in private urban formal sector

$W_{A} \quad$ Nominal wage in rural sector

$W_{I} \quad$ Nominal wage in informal sector

$W_{S} \quad$ Nominal wage rate for skilled labor, private formal sector

$W_{S G} \quad$ Nominal wage rate for skilled labor, public sector

$w_{S G} \quad$ Real wage rate for skilled labor, public sector

$W_{S P} \quad$ Skilled wage rate in the private formal sector

$W_{U G} \quad$ Nominal wage rate for unskilled labor, public sector

$w_{U G} \quad$ Real wage rate for unskilled labor, public sector

$W_{U P} \quad$ Nominal wage for urban unskilled labor, private formal sector

$W T_{A} \quad$ Total wealth of rural sector household

$W T_{E} \quad$ Total wealth of profit earners and capitalists

$W T_{F} \quad$ Total wealth of urban formal sector household

$W T_{I} \quad$ Total wealth of informal sector household

$x_{i h} \quad$ Subsistence level of consumption of good $i$ by household $h$

$X_{A} \quad$ Production of rural sector good

$X_{G} \quad$ Production of public good

$X_{I} \quad$ Production of informal sector good

$X_{P} \quad$ Production of private formal urban sector good

$Y F_{P} \quad$ Income by private formal urban sector firm

$Y H_{A} \quad$ Income of rural sector household

$Y H_{E} \quad$ Income of profit earners and capitalists

$Y H_{F} \quad$ Income of formal sector household

$Y H_{I} \quad$ Income of informal sector household

$Z_{G} \quad$ Investment demand for rural sector good

$Z_{P} \quad$ Investment demand for private urban formal sector good

$Z_{P}^{d} \quad$ Desired level of investment

$Z_{P}^{G} \quad$ Private investment by urban formal sector firms allocated to purchases of public services

$Z_{P}^{P} \quad$ Private investment by urban formal sector firms allocated to purchases of private goods 


$\begin{array}{ll}\text { Exogenous } & \text { Variables } \\ \text { Name } & \text { Definition } \\ C O N T A G & \text { Change in "sentiment" on world capital markets } \\ E R & \text { Nominal exchange rate } \\ F I N F L & \text { Foreign inflation } \\ F L_{G} & \text { Foreign borrowing by government } \\ F L_{P} & \text { Foreign borrowing by private formal urban firms } \\ f_{\text {tax }} & \text { Corporate income tax rate } \\ g_{R U R} & \text { Population growth in rural economy } \\ g_{U R B} & \text { Population growth in urban economy } \\ I D & \text { Interest rate on domestic deposits } \\ I D F & \text { Domestic interest rate on foreign-currency deposits held } \\ & \text { in the domestic banking system } \\ I_{E D U} & \text { Investment in education } \\ I F W & \text { Interest rate paid on foreign loans } \\ I F_{G}^{W} & \text { Interest rate on government foreign loans } \\ I F_{R F}^{W} & \text { Risk-free foreign interest rate on } F D_{h}^{W} \\ I_{I N F} & \text { Investment in infrastructure } \\ I L F & \text { Interest rate on foreign-currency loans by domestic banks } \\ i n c t a x_{h} & \text { Income tax rate for households } h \\ \text { paytax }_{S} & \text { Payroll tax rate on skilled labor } \\ \operatorname{paytax}_{U} & \text { Payroll tax rate on unskilled labor } \\ \operatorname{protax}_{i} & \text { Tax rate on gross production } \\ R E M I T & \text { Foreign-currency value of remittances from abroad } \\ S_{G}, S_{G}^{E} & \text { Skilled workers in public production, and public education } \\ S_{G}^{T} & \text { Total number of skilled workers in the public sector } \\ \operatorname{saltax}_{i} & \text { Tax rate on domestic sales } \\ \operatorname{sstax}_{S} & \text { Social security tax on skilled workers in private formal sector } \\ \text { sstax }_{U} & \text { Social security tax on unskilled workers in private formal sector } \\ \operatorname{tm}_{A}, t m_{P} & \text { Import tariff on rural sector goods, private urban sector goods } \\ U_{G} & \text { Unskilled workers in public sector } \\ W_{F} & \text { Foreign wage measured in foreign-currency terms } \\ W_{M} & \text { Nominal wage rate for unskilled labor, private formal sector } \\ w p e_{i} & \text { World price of exports of good } i, \text { with } i=A, P \\ w p m_{i} & \text { World price of imports of good } i, \text { with } i=A, P \\ & \end{array}$




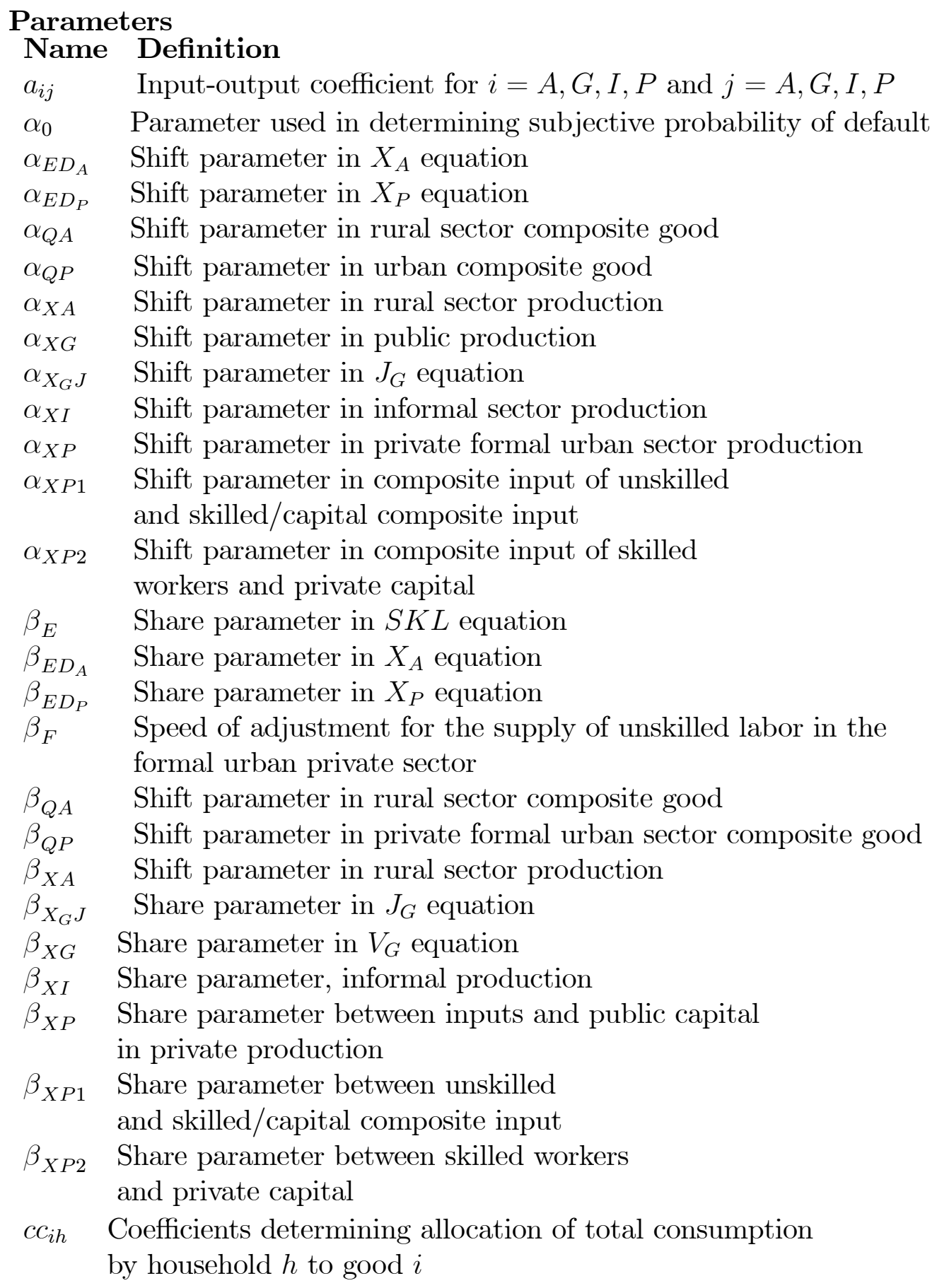




$\begin{array}{ll}\delta_{c} & \text { Collateral parameter } \\ \delta_{E D U} & \text { Depreciation rate of education capital } \\ \delta_{I M I G} & \text { Rate of "attrition" of the stock of migrants } \\ \delta_{I N F} & \text { Depreciation rate of infrastructure capital } \\ \delta_{P} & \text { Depreciation rate of private capital } \\ \delta_{S} & \text { Rate of depreciation of the skilled labor force } \\ \eta_{X A} & \text { Coefficient of returns to scale in rural production } \\ \gamma_{B h} & \text { Share of domestic deposits in total deposits for household } h \\ \gamma_{E} & \text { Share of transfers allocated to profit earners and capitalists } \\ \gamma_{A} & \text { Share of transfers allocated to rural sector household } \\ \gamma_{F} & \text { Share of transfers allocated to formal sector household } \\ \gamma_{I} & \text { Share of transfers allocated to informal sector household } \\ g g_{A} & \text { Share of public expenditure on rural good } \\ g g_{G} & \text { Share of public expenditure on public good } \\ g_{P} & \text { Share of public expenditure on formal private urban good } \\ \kappa_{D L}^{B} & \text { Parameter used in determining the lending rate } \\ \kappa_{E R P} & \text { Parameter used in determining external risk premium } \\ \kappa_{F D}^{h} & \text { Measure of relative weight of the domestic interest rate } \\ & \text { on foreign-currency deposits held at home for household } h \\ \kappa_{R E M} & \text { Share of wages being remitted } \\ \lambda_{I M} & \text { Speed of adjustment rate on international migration } \\ \lambda_{M} & \text { Speed of adjustment rate on migration } \\ \lambda_{P I N V} & \text { Partial adjustment parameter for actual investment } \\ \Omega_{j 0} & \text { Shift parameters in reservation wages of skilled and } \\ \phi_{D L}^{P} & \text { unskilled workers, } j=S, U \\ \phi_{F L}^{B} & \text { Parameter used in determining the composition of } \\ \phi_{G B}^{B, d} & \text { Parameter used in determining demand for foreign loans by } \\ \phi_{G}^{i} & \text { Parameter used in determining additional demand for } \\ \phi_{S}^{i} & \text { government bonds by commercial banks (ratio of net wealth) } \\ & \text { Phare of direct bond placement with commercial banks } \\ \text { for } i=1,2,3 \\ \end{array}$




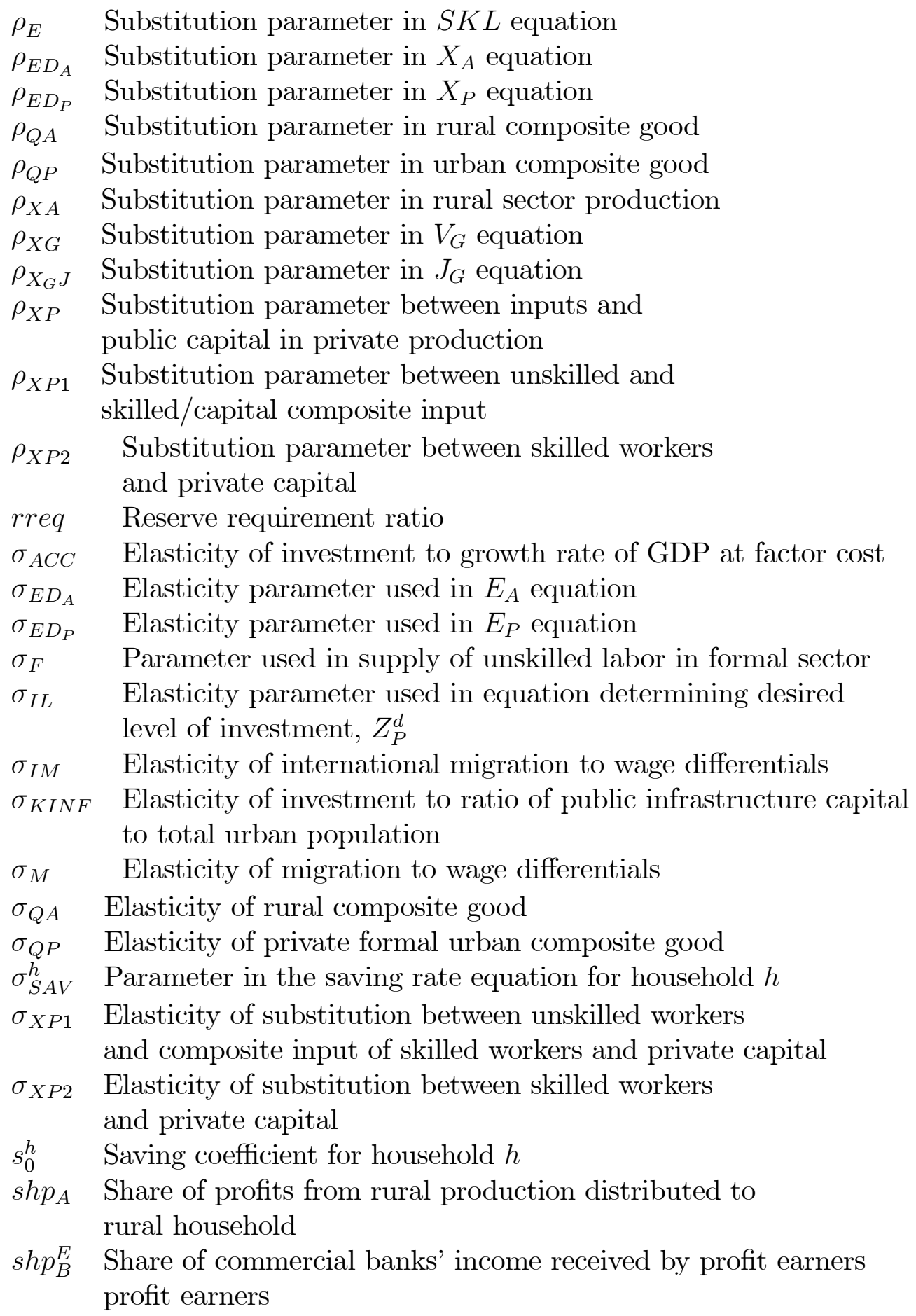


$s h p_{G} \quad$ Share of the central bank's profits transferred to the government

$s h p_{P}^{F} \quad$ Share of private formal sector firms' net income distributed to formal sector household

$s h p_{P}^{E} \quad$ Share of private formal sector firms' net income received by profit earners

$\theta_{U} \quad$ Share of urban unskilled workers employed in formal sector

$\theta_{C O N}^{h} \quad$ Parameter in $H_{h}^{d}$ equation

$\theta_{D D}^{E} \quad$ Parameter used in determining the equilibrium condition of the market for government bonds

$\theta_{D D}^{h} \quad$ Parameter used in determining ratio $D D_{h} / E R\left(F D_{h}+F D_{h}^{W}\right)$

$\theta_{E I N F L}^{h} \quad$ Parameter used in $H_{h}^{d}$ equation

$\theta_{F D}^{E} \quad$ Parameter used in equilibrium condition of the market for government bonds

$\theta_{F D}^{h} \quad$ Parameter used in determining ratio $F D_{h} / F D_{h}^{W}$

$\theta_{F L}^{B} \quad$ Parameter used in determining demand for foreign loans by commercial banks

$\theta_{G B}^{B} \quad$ Parameter used in determining additional demand for government bonds by commercial banks (ratio of net wealth)

$\theta_{G B}^{E} \quad$ Parameter used in determining the equilibrium condition of the market for government bonds

$\theta_{I F}^{h} \quad$ Parameter used in $H_{h}^{d}$ equation

$\tau_{I} \quad$ Fraction of remittances allocated to informal households

$\nu_{S}, \nu_{U} \quad$ Firms' bargaining power relative to skilled, unskilled, workers

$w r_{i} \quad$ Initial share of good $i$ in rural consumption price index

$w u_{i} \quad$ Initial share of good $i$ in urban consumption price index

wcp Share of spending by rural households in total consumption

$\chi \quad$ Parameter used in determining expected nominal depreciation

$z z_{G} \quad$ Share of investment expenditure on public goods

$z z_{P} \quad$ Share of investment expenditure on formal private goods 


\section{Appendix C Calibration and Parameter Values}

The calibration of our IMMPA model for Turkey was carried out using a) a 1996 Financial Social Accounting Matrix (FSAM); b) an auxiliary data set; and $c$ ) a set of non-calibrated parameters. A summary description of each of these sources of information is provided in this appendix. A complete description of the creation of the 1996 Turkey FSAM and the auxiliary data set, as well as the derivation of non-calibrated parameter estimates, can be found in Jensen and Yeldan (2004).

The main data sources for the creation of the FSAM include the website of the Turkish State Planning Organization (SPO), http://www.dpt.gov.tr, and various publications by the State Institute of Statistics (SIS) and the Central Bank of Turkey (CBT). The FSAM itself was built in two steps: a) construction of a MacroSAM; and b) disaggregation into a MicroSAM. The construction of the MacroSAM was split into a real MacroSAM and a financial MacroSAM. The link between the two types of MacroSAMs was made through the savings-investment balance account. Accordingly, this account was forced to be identical in the two SAMs. In the following, the construction and key characteristics of the real and financial MacroSAMs are described. The more disaggregated characteristics are presented in the publication mentioned above.

The real MacroSAM was built around final demand and cost components of GDP data from the SIS. SIS publications were generally preferred as the main data source for the input-output part of the MacroSAM, because they allowed for better correspondence with other data sources. Intermediate consumption, however, was derived from the 1996 Turkey Input-Output table.

SPO data were used as the main source for public sector budget data, whereas the CBT publications were used as the main source for the current account of the balance of payments. Data regarding commercial banks and the Central Bank of Turkey were mainly obtained from the SIS publications. The balanced real MacroSAM is presented in Table C1.

The real MacroSAM indicates that foreign trade (as measured by the sum of exports and imports) makes up around 50 percent of GDP, implying that Turkey is a fairly open economy. Exports make up around 13 percent of total production, while imports make up around 13 percent of absorption. The large current account deficit, which amounts in the MacroSAM to about 5 
percent of GDP, indicates that absorption is significantly larger than production. Accordingly, the trade balance deficit amounts to more than 20 percent of export earnings.

Looking at savings rates, the data show that firms save around 20 percent of their disposable income whereas households save around 14 percent of their disposable income. In comparison, the government primary surplus amounts to 3.4 percent of GDP. Finally, it can be noticed that interest payments by the public sector amount to around 39 percent of tax revenues, indicating that the public sector is running an unsustainable overall budget deficit of 6.9 percent of GDP.

The financial MacroSAM was built around the savings and investment aggregates from the real MacroSAM. Accordingly, the correspondence between the savings-investment balance accounts of the two SAMs were ensured by construction. The main data sources used in the construction of the financial MacroSAM, as noted earlier, were CBT and SIS publications. SIS publications were used to obtain information about public sector financial flows as well as private sector borrowing in foreign currency. The remaining data in the financial MacroSAM were derived from CBT publications. The balanced financial MacroSAM is presented in Table C2.

The financial MacroSAM shows that government bond issuing was around 7.1 percent of GDP. This is slightly higher than the overall financing need of 6.9 percent, reflecting the fact that the Turkish government reduced foreign borrowing slightly in 1996. The increase in bond holdings of commercial banks accounts for around 90 percent of the total increase in government bonds. Profit earners and the CBT hold the remaining 10 percent of newly issued bonds. Money issuing, including lending to commercial banks, stood at 2.4 percent of GDP. This is a relatively small number, but it reflects the fact that inflation was high in 1996. Money issuing would therefore represent a substantially higher proportion of lagged GDP, reflecting significant use of the inflation tax in 1996. Foreign exchange reserves increased by around 6.1 percent of imports. Again, the current import number is inflated by strong depreciation of the exchange rate in 1996. The change in foreign exchange reserves would therefore be significant when compared to lagged imports, indicating that significant exchange reserve accumulation took place in 1996. Households increased borrowing from commercial banks by around 2.9 percent of GDP or 25 percent of household savings. In comparison, firms increased their borrowing by around 9.3 percent of GDP or 95 percent of firms' savings. This pattern indicates that commercial banks mainly invest their 
funds in a) loans to firms for investment purposes; and b) government bonds. Finally, it may be noticed that commercial banks mainly funds themselves out of domestic deposits. The share of deposits in total additional funding was around 65 percent in 1996.

The auxiliary data set includes mainly level data and interest rates that could not be directly derived from the 1996 Turkey FSAM. The Turkish economy was characterized by much instability over the 1996-2003 period. The base year of 1996 was a relatively normal year, but it was still characterized by very high inflation and underlying volatility. Accordingly, it does not make much sense to use 1995-96 financial stock data to derive implicit interest rates, or to use 1995-96 interest rates to derive implicit data on financial stocks. Instead, initial and lagged values for interest rates, inflation rates and depreciation rates were chosen (in close correspondence with country experts) so as to match 2003 values and to give rise to reasonable stock numbers. In sum, auxiliary data on financial stocks were derived by applying the chosen interest rates to the interest payments recorded in the FSAM.

The auxiliary data for the labor market indicate that unskilled labor is overwhelmingly employed in the rural and informal sectors. Specifically, 49 percent of the unskilled employed workers are working in the rural sector while 39 percent are working in the urban informal sector. In comparison, 11 percent of unskilled employed are working in the urban private formal sector while only 1 percent is initially employed in the public sector. Skilled employment is more of an urban public sector phenomenon. Indeed, the data indicate that 62 percent of employed skilled workers are working in the urban private formal sector whereas 38 percent of the total are working in the urban public sector. Initial rates of open unemployment among workers in the urban formal sector can be derived from estimates of sectoral labor supply. Initial unemployment rates are estimated to be 11 percent among unskilled workers and 15 percent among skilled workers.

Initial levels of the private formal sector capital stock, as well as public capital stocks of infrastructure and education capital, were derived from a combination of initial data and sensitivity analyses. Depreciation rates were estimated to be 2.1 percent for public sector infrastructure capital and 3.4 percent for public sector education capital and private formal sector capital.

Growth rates of rural and urban labor stocks were estimated to be respectively 0.1 percent and 2.3 percent. The reason why the rural labor supply growth rate is so low is because of the relatively high level of migration of families from rural to urban areas. While fertility levels remain relatively 
high in rural compared to urban areas, migration of families bring children into urban areas before they reach the age for entering the labor market.

The relatively high levels of migration between segments of the Turkish labor market is evident from the data as well. Estimates indicate that yearly migration from rural to urban areas amounts to around 2.5 percent of the rural labor force. In comparison, overseas migration amounts to around 1.5 percent of the urban labor force, while migration between the informal and formal labor market segments amounts to around 0.9 percent of the informal sector labor force. Accordingly, migration plays a very important role for labor market developments in Turkey. In addition, the yearly number of unskilled workers receiving education to achieve skilled status, is estimated to be around 1.7 percent of the urban labor force.

The initial inflation rate was set at around 30 percent while the initial depreciation rate of the nominal exchange rate was set at around 10 percent. The initial expected depreciation rate was also set at 10 percent. In addition, the levels of bond holdings of profit earners, commercial banks, and the CBT, were set so as to imply an initial bond rate of about 16 percent (consistent with the interest payments on government bonds given in the FSAM). The initial bond rate was allowed to be relatively low so as to achieve a sensible balance between the financial stocks and flows. Accordingly, these initial levels allowed for a public debt stock of around 66 percent of GDP. Nevertheless, inflation and exchange rate depreciation were allowed to increase to levels around 30-40 percent (and the bond rate around $45-50$ percent) as part of the baserun solution underlying the simulations reported in this paper. In addition, the level of household deposits with commercial banks, as well as commercial bank borrowing from the CBT, were set so as to allow for a deposit rate/official rate of 25 percent and a foreign-currency deposit rate of about 10 percent. In addition, the stock of money holdings by households were set so as to allow for a reserve requirement ratio of around 5 percent.

Levels of household and firm loan stocks with commercial banks were subsequently set so as to allow for a lending rate around 35 percent. Given the levels of domestic deposit rates and expected depreciation, as well as the reserve requirement ratio and the lending rate, a domestic premium of about 3 percent was derived. Again, the initial level of the domestic premium was set at a relatively low level in order to allow for a sensible balance between financial stocks and flows. Nevertheless, the domestic premium was allowed to increase to levels of 5-8 percent as part of the baserun solution underlying the simulations reported in the text. 
The probability of default was initially set at 50 percent, but was allowed to decline to levels around 30-40 percent over the baserun. The mirror image of the decline in the probability of default was that credibility was allowed to increase from an initial level of 50 percent to around 60-70 percent over the baserun period. This also meant that expected inflation was allowed to decline slightly from an initial level of about 18 percent over the baserun. The expected depreciation rate was subsequently allowed to increase gradually from an initial level of around 10 percent (as noted above) to levels slightly below expected inflation over the baserun. Foreign inflation was set at an exogenous rate of 2 percent per year.

Most of the non-calibrated parameters were estimated from time-series data. The relative wage elasticity of rural-urban migration was estimated to be 0.019 whereas the relative wage elasticity of overseas migration was estimated to be 0.012. The partial adjustment (weighting) parameters were estimated to be respectively 0.56 and 0.28 . Subsequently, the wage elasticity and partial adjustment speed of informal-formal sector migration were set at intermediate levels of 0.016 and 0.40 . The rate of decline in the number of Turkish workers abroad was set at 1 percent per year, whereas the share of remittances in foreign workers' wage income was set at 10 percent. In addition, the substitution elasticity between teachers and education capital in the CES skills upgrading function (that is, the education production function) was set at a low value of 0.3 .

In the money demand specification, the domestic currency interest rate elasticity was set at the commonly estimated value of -0.21 for all households, except for profit earners where the elasticity was set at the estimated value of -0.91. The foreign currency interest rate elasticity was set at the commonly estimated value of -0.63 . Finally, the disposable income elasticity of money demand was set at the commonly estimated value of 0.42 for all households.

In the demand equation for foreign currency deposits, the foreign currency interest rate elasticity was set at the commonly estimated value of 0.37 for the formal sector household and profit earners (the only two categories of households in the model in possession of foreign exchange deposits). In the demand equation for government bonds by profit earners, the foreign currency interest rate elasticity was set at the estimated value of -0.37 , and the domestic currency interest rate elasticity at the estimated value of -0.91 (similar to the money demand elasticity given earlier). In addition, the bond rate elasticity was set at a level of 2.0, above the estimated level of 1.20 , at the suggestion of country experts. 
Turning to the private wage specifications, parameters measuring worker's bargaining strength were set at the same estimated level of 0.63. The public sector wage "leadership" elasticities were set at estimated levels of respectively 0.75 and 0.06 for the unskilled and skilled wage specifications; the expected urban price elasticities were set at estimated levels of respectively 0.32 and 0.26 for the unskilled and skilled wage specifications; and the unemployment elasticities were set at estimated levels of respectively 0.23 and 0.25 for the unskilled and skilled wage specifications. Finally, the minimum wage elasticity was set at an estimated level of 0.47 for the unskilled wage specification. The plausibility of parameter values was assessed through sensitivity analysis.

Production elasticities were not immediately available but we relied to some extent on existing CGE applications for Turkey. The share of land in rural production was assumed to be 0.3 , leaving a production share of 0.7 for unskilled labor (assuming that no capital is used in agricultural production). Similarly, it was assumed that there are moderate substitution possibilities between public sector infrastructure investment and unskilled rural labor, through the adoption of an elasticity of substitution of 0.75. Finally, the elasticity of transformation between domestic market and export of domestic production was taken to be at a middle level, that is, 1.0. In addition, it was assumed as a starting point that there are constant returns to scale in urban informal sector production.

Looking at urban private formal production, the top-level CES substitution elasticity between public infrastructure capital and composite primary production factors was assumed to be a moderate 0.75. At the second level, CES substitution possibilities between formal urban unskilled labor and the composite factor consisting of skilled labor and private physical capital was assumed to be higher at 1.2. Finally, the bottom-nest CES substitution elasticity between skilled labor and the private capital stock was assumed to be 0.4, reflecting little substitution possibilities at this level (as suggested by the evidence). Finally, public sector composite labor was assumed to be moderately substitutable to public infrastructure capital in the top-level public production nest, whereas substitution possibilities between unskilled and skilled public employees was assumed to be moderately high at 1.2.

Parameter estimates for the private investment equation were taken in part from the studies cited in the text. The elasticity with respect to real GDP growth (which captures the accelerator effect) was set at 1.5 and the real lending rate elasticity was set at the relatively high value of -2.5 . How- 
ever, for the infrastructure elasticity of investment demand, we found no reliable estimate in the literature. We chose to set it to a relatively low value, 0.1. Given that we did not consider changes in public investment in infrastructure, this particular choice has actually little effect on the simulation results reported in the text. The partial adjustment rate of actual to desired investment was set at an estimated value of 0.63 .

The relative interest rate elasticity of commercial banks' foreign borrowing was set at an estimated value of 0.46 , whereas the elasticity of commercial banks' demand for government bonds with respect to the expected bond rate was set at the estimated value of 0.46 . The elasticity of the banks' domestic risk premium with respect to the collateral ratio could not be estimated due to a lack of time series data. The elasticity was chosen to be 0.2 , in order to avoid very large (and potentially destabilizing) amplification effects. Similarly, the partial adjustment coefficient of the expected rate of depreciation was chosen to be 0.9 at the suggestion of country experts. Finally, the direct placement ratio of government bonds with commercial banks was set at 0.9 , reflecting the placement ratio of newly issued bonds observed in the 1996 Turkey FSAM. 


\section{References}

Agénor, Pierre-Richard, "Employment Effects of Stabilization Policies," European Journal of Political Economy, (November 2001), 853-75.

—-, "Monetary Policy under Flexible Exchange Rates: An Introduction to Inflation Targeting," in A Decade of Inflation Targeting in the World, ed. by Norman Loayza and Raimundo Soto, Central Bank of Chile (Santiago: 2002). , "Mini-IMMPA: A Framework for Analyzing the Employment and Poverty Effects of Fiscal and Labor Market Reforms," Policy Research Working Paper No. 3067, World Bank (May 2003).

- The Economics of Adjustment and Growth, 2nd. ed., Harvard University Press (Cambridge, Mass.: 2004).

—_ "Fiscal Adjustment and Labor Market Dynamics in an Open Economy," Journal of Development Economics, 76 (February 2005a), 97-125.

—_, "Market Sentiment and Macroeconomic Fluctuations under Pegged Exchange Rates," unpublished, University of Manchester (June 2005b). Forthcoming, Economica.

Agénor, Pierre-Richard, and Nihal Bayraktar, "Contracting Models of the Phillips Curve: Empirical Estimates for Middle-Income Countries," Policy Research Working Paper No. 3139, World Bank (September 2003).

Agénor, Pierre-Richard, and Karim J. P. El Aynaoui, "Labor Market Policies and Unemployment in Morocco: A Quantitative Analysis," Policy Research Working Paper No. 3091, World Bank (June 2003).

Agénor, Pierre-Richard, Reynaldo Fernandes, Eduardo Haddad, and Henning Tarp Jensen, "Analyzing the Impact of Adjustment Policies on the Poor: An IMMPA Framework for Brazil," unpublished, World Bank (November 2003). Agénor, Pierre-Richard, Alejandro Izquierdo, and Hippolyte Fofack, "IMMPA: A Quantitative Macroeconomic Framework for the Analysis of Poverty Reduction Strategies," Policy Research Working Paper No. 3092, World Bank (June 2003).

Agénor, Pierre-Richard, and Mohsin S. Khan, "Foreign Currency Deposits and the Demand for Money in Developing Countries," Journal of Development Economics, 50 (June 1996), 101-18.

Agénor, Pierre-Richard, C. John McDermott, and E. Murat Ucer, "Fiscal Imbalances, Capital Inflows, and the Real Exchange Rate: Evidence for Turkey," European Economic Review, 41 (April 1997), 819-25. 
Agénor, Pierre-Richard, and Peter J. Montiel, Development Macroeconomics, Princeton University Press, 2nd ed. (Princeton, New Jersey: 1999).

Agénor, Pierre-Richard, Mustapha K. Nabli, Tarik Yousef, and Henning T. Jensen, "Labor Market Reforms, Growth, and Unemployment in LaborExporting Countries of the Middle East and North Africa," Policy Research Working Paper No. 3328, World Bank (June 2004).

Agénor, Pierre-Richard, and Mark P. Taylor, "Testing for Credibility Effects," IMF Staff Papers, 39 (September 1992), 545-71.

Atta-Mensah, Joseph, and Ali Dib, "Bank Lending, Credit Shocks, and the Transmission of Canadian Monetary Policy," Working Paper 2003-9, Bank of Canada (April 2003).

Anand, Ritu, and Sweder van Wijnbergen, "Inflation and the Financing of Government Expenditure: An Introductory Analysis with an Application to Turkey," World Bank Economic Review, 3 (March 1989), 17-38.

Beenstock, Michael, Eddy Azoulay, Akiva Offenbacher, and Olga Sulla, "A Macroeconometric Model with Oligopolistic Banks: Monetary Control, Inflation and Growth in Israel," Economic Modelling, 20 (May 2003), 455-86.

Bernanke, Ben S., Mark Gertler, and Simon Gilchrist, "The Financial Accelerator in a Quantitative Business Cycle Framework," in Handbook of Macroeconomics, ed. by John B. Taylor and Mark Woodford, North Holland (Amsterdam: 2000).

Berument, Hakan, and Kamuran Malatyali, "Determinants of Interest Rates in Turkey," Russian and East European Finance and Trade, 37 (January 2001), $5-16$.

Berument, Hakan, and Hakan Tasci, "Monetary Policy Rules in Practice: Evidence from Turkey," International Journal of Finance and Economics, 9 (January 2004), 33-38.

Blanchard, Olivier J., "Fiscal Dominance and Inflation Targeting: Lessons from Brazil," Working Paper No. 10389, National Bureau of Economic Research (March 2004).

Bulutay, Tuncer, "Employment, Unemployment and Wages in Turkey," International Labour Office (Ankara: 1995).

Catao, Luis, and Marco E. Terrones, "Fiscal Deficits and Inflation," Working Paper No. 03/65, International Monetary Fund (April 2003).

Celasun, Oya, R. Gaston Gelos, and Alessandro Prati, "Would 'Cold Turkey' Work in Turkey?," IMF Staff Papers, 51 (September 2004), 493-509.

Chibber, Ajay, and Swever van Wijnbergen, "Public Policy and Private Investment in Turkey," in Reviving Private Investment in Developing Countries, 
ed. by Ajay Chhibber, Mansoor Dailami, and Nemat Shafik, North Holland (Amsterdam: 1992).

Civcir, Irfan, "Dollarization and its Long-Run Determinants in Turkey," unpublished, Ankara University (May 2002).

Cordoba, Juan-Carlos, and Marla Ripoll, "Credit Cycles Redux," International Economic Review, 45 (November 2004), 1011-46.

De Santis, Roberto A., "The Impact of a Customs Union with the EU on Turkey's Welfare, Employment and Income Distribution: An AGE Model with Alternative Labour Market Structures," Journal of Economic Integration, 15 (June 2000), 195-238.

Diao, Xinshen, Terry L. Roe, and A. Erinç Yeldan, "Fiscal Debt Management, Accumulation and Transitional Dynamics in a CGE Model for Turkey," Canadian Journal of Development Studies, 19 (June 1998), 343-75.

Elekdag, Selim, "Exchange Rates and Monetary Policy in Turkey," unpublished, Johns Hopkins University (September 2003).

Erceg, Christopher J., and Andrew T. Levin, "Imperfect Credibility and Inflation Persistence," Journal of Monetary Economics, 50 (May 2003) 915-944.

Erden, Lutfi, "The Effects of Financial Markets on Private Capital Formation: An Empirical Analysis of Turkish Data over 1968-1998," unpublished, Mersin University (March 2002).

Fiess, Norbert, "Capital Flows, Country Risk, and Contagion," Policy Research Working Paper No. 2943, World Bank (January 2003).

Gertler, Mark, Simon Gilchrist, and Fabio M. Natalucci, "External Constraints on Monetary Policy and the Financial Accelerator," unpublished, New York University (February 2001).

Gunaydin, Emek, "Analysing the Sustainability of Fiscal Deficits in Turkey," unpublished, Undersecretariat of the Treasury, Ankara (September 2003).

Guncavdi, Oner, Michael Bleaney, and Andrew McKay, "Financial Liberalisation and Private Investment: Evidence from Turkey," Journal of Development Economics, 57 (December 1998), 443-55.

— - "The Response of Private Investment to Structural Adjustment: A Case Study of Turkey," Journal of International Development, 11 (March 1999), 221-39.

Harris, John, and Michael P. Todaro, "Migration, Unemployment and Development: A Two-Sector Analysis," American Economic Review, 60 (March 1970), 126-43.

Hillier, Brian, and Tim Worrall, "Asymmetric Information, Investment Finance and Real Business Cycles," in The New Macroeconomics: Imperfect Markets 
and Policy Effectiveness, ed. by Huw D. Dixon and Neil Rankin, Cambridge University Press (Cambridge: 1995).

Huh, Chan G., and Kevin J. Lansing, "Expectations, Credibility, and Disinflation in a Small Macroeconomic Model," unpublished, Federal Reserve Bank of San Francisco (June 1999).

Ilkkaracan, Ipek, and Raziye Selim, "The Role of Unemployment in Wage Determination: Further Evidence on the Wage Curve for Turkey," Working Paper No. 2002-11, Center for Economic Policy Analysis, New School University (August 2002).

Isard, Peter, Douglas Laxton, and Ann-Charlotte Eliasson, "Inflation Targeting with NAIRU Uncertainty and Endogenous Policy Credibility," Journal of Economic Dynamics and Control, 25 (January 2001), 115-48.

Jensen, Henning T., and Erinc Yeldan, "Notes on the Social Accounting Matrix underlying IMMPA-Turkey," unpublished, World Bank (June 2004).

Karadag, Metin, and Tony Westaway, "A SAM Based Computable General Equilibrium Tax Model of the Turkish Economy," Economic Research Paper No. 99/18, Loughborough University (October 1999).

Kiyotaki, Nobuhiro, and John Moore, "Credit Cycles," Journal of Political Economy, 105 (April 1997), 211-48.

Krishnamurthy, Arvin, "Collateral Constraints and the Amplification Mechanism," Journal of Economic Theory, 111 (August 2003), 277-292.

Laxton, Douglas, Nicholas Ricketts, and David Rose, "Uncertainty, Learning and Policy Credibility," in Economic Behavior and Policy Choice under Price Stability, Bank of Canada (Ottawa: 1994).

Lewis, Jeffrey D., "Financial Repression and Liberalization in a General Equilibrium Model with Financial Markets," Journal of Policy Modeling, 14 (April 1992), 135-66.

Lim, Cheng Hoon, and Laura Papi, "An Econometric Analysis of the Determinants of Inflation in Turkey," Working Paper No. 97/170, International Monetary Fund (December 1997).

Masson, Paul R., "The Sustainability of Fiscal Deficits," IMF Staff Papers, 32 (December 1985), 577-605.

Nas, Tevfik F., and Mark J. Perry, "Turkish Inflation and Real Output Growth: 1963-2000," in Inflation and Disinflation in Turkey, ed. by Aykut Kibritcioglu, Libby Rittenberg, and Faruk Selcuk, Ashgate Publishing Co. (Aldershot: 2002).

OECD, Economic Surveys: Turkey 1996, OECD (Paris: 1996). 
Onaran, Ozlem, "Measuring Wage Flexibility: The Case of Turkey before and after Structural Adjustment," Applied Economics, 34 (April 2002), 767-81.

Ozatay, Fatih, "A Quarterly Macroeconometric Model for a highly Inflationary and Indebted Country: Turkey," Economic Modelling, 17 (January 2000), $1-11$.

Ozcan, Kivilcim M., Asli Gunay, and Seda Ertac, "Determinants of Private Savings Behaviour in Turkey," Applied Economics, 35 (August 2003), 140516.

Perry, Guillermo, "Can Fiscal Rules Help Reduce Macroeconomic Volatility in the Latin America and the Caribbean Region?," Policy Research Working Paper No. 3080, World Bank (June 2003).

Ruge-Murcia, Francisco J., "Credibility and Changes in Policy Regime," Journal of Political Economy, 103 (February 1995), 176-208.

Saint-Paul, Gilles, "The Political Economy of Employment Protection," Journal of Political Economy, 110 (June 2002), 672-704.

Salman, Ferhan, "Balancing Turkey's Intertemporal Budget Gap," unpublished, Boston University (July 2003).

Sancak, Cemile, "Financial Liberalization and Real Investment: Evidence from Turkish Firms," Working Paper No. 02/100, International Monetary Fund (June 2002).

Schneider, Martin, and Aaron Tornell, "Balance Sheet Effects, Bailout Guarantees, and Financial Crises," Review of Economic Studies, 71 (July 2004), 883-913.

Spaventa, Luigi, "The Growth of Public Debt," IMF Staff Papers, 34 (June 1987), 374-99.

Stokey, Nancy L., "Free Trade, Factor Returns, and Factor Accumulation," Journal of Economic Growth, 1 (June 1996), 421-49.

Svensson, Lars E. O., "What is Wrong with Taylor Rules? Using Judgment in Monetary Policy through Targeting Rules," Journal of Economic Literature, 41 (June 2003), 426-77.

Tansel, Aysit, "Wage Earners, Self Employed and Gender in the Informal Sector in Turkey," unpublished, Middle East Technical University (November 2000).

Tunali, Insan, "Background Study on Labour Market and Employment in Turkey," European training Foundation, Torino (June 2003).

Taymaz, Erol, and Sule Ozler, "Labor Markets," unpublished presentation, Ankara (March 2003).

Tornell, Aaron, and Frank Westermann, "Credit Market Imperfections in MiddleIncome Countries," Working Paper No. 9737, National Bureau of Economic 
Research (May 2003).

Uctum, Merih, and Michael Wickens, "Debt and Deficit Ceilings, and Sustainability of Fiscal Policies: An Intertemporal Analysis," Oxford Bulletin of Economics and Statistics, 62 (May 2000), 197-222.

Voyvoda, Ebru, and Erinc Yeldan, "Managing Turkish Debt: An OLG Investigation of the IMF's Fiscal Programming Model for Turkey," unpublished, Bilkent University (June 2003).

World Bank, Turkey Country Economic Memorandum: Towards Macroeconomic Stability and Sustained Growth, 3 Volumes, the World Bank (May 2003).

Wyplosz, Charles, "Fiscal Discipline in Emerging Market Countries: How to Go about it?," unpublished, Graduate Institute for International Studies, Geneva (May 2002).

Xie, Danyang, and Chi-Wa Yuen, "A Dynamic General Equilibrium Framework of Investment with Financing Constraints," IMF Staff Papers, 50 (July 2003), 274-90.

Yeldan, A. Erinç, "Financial Liberalization and Fiscal Repression in Turkey: Policy Analysis in a CGE Model With Financial Markets," Journal of Policy Modeling, 19 (February 1997), 79-117.

— - "On Structural Sources of the 1994 Turkish Crisis: A CGE Modelling Analysis," International Review of Applied Economics, 12 (September 1998), 397-414.

Yilmaz, Akyüz, and Korkut Boratav, "The Making of the Turkish Financial Crisis," World Development, 31 (September 2003), 1549-66. 
Table 1

Financial Balance Sheets

(in domestic-currency terms, at current prices)

\section{Households}

Assets

Liabilities

\begin{tabular}{l|l}
\hline Cash holdings $(H)$ & Borrowing from Banks $\left(D L_{F}\right)$ \\
Dom. bank dep. $(D D+E R \cdot F D)$ & Net financial wealth $(W T)$ \\
Foreign bank deposits $\left(E R \cdot F D^{W}\right)$ & \\
Government bonds $\left(G B_{E}\right)$ &
\end{tabular}

Firms

Assets

Liabilities

\begin{tabular}{l|l}
\hline Private capital Stock $\left(P K \cdot K_{P}\right)$ & Dom. borr. $\left(D L_{P}+E R \cdot D L F_{P}\right)$ \\
& Foreign borrowing $\left(E R \cdot F L_{P}\right)$ \\
& Net worth $\left(N W_{P}\right)$
\end{tabular}

\section{Commercial Banks}

Assets

Liabilities

\begin{tabular}{l|l}
\hline Government bonds $\left(G B_{B}^{T}\right)$ & Dom. bank dep. $(D D+E R \cdot F D)$ \\
Loans to firms $\left(D L_{P}+E R \cdot D L F_{P}\right)$ & Foreign borrowing $\left(E R \cdot F L_{B}\right)$ \\
Loans to households $\left(D L_{F}\right)$ & Borr. from central bank $\left(D L^{B}\right)$ \\
Reserve requirements $(R R)$ & Net worth $\left(N W^{B}\right)$
\end{tabular}

\section{Central Bank}

Assets

Liabilities

Loans to commercial banks $\left(D L^{B}\right) \quad$ Cash in circulation $(H)$

Foreign reserves $(E R \cdot F F)$

Government bonds $\left(G B_{C B}\right)$

Reserve requirements $(R R)$

Net worth $\left(N W_{C B}\right)$

\section{Government}

Assets

Liabilities

\begin{tabular}{l|l}
\hline Education Capital $\left(P K \cdot K_{E D U}\right)$ & Government bonds $(G B)$ \\
Infrastructure capital $\left(P K \cdot K_{I N F}\right)$ & Foreign borrowing $\left(E R \cdot F L_{G}\right)$ \\
& Net worth $\left(N W^{G}\right)$
\end{tabular}

Consolidated Public Sector

Assets

Liabilities

\begin{tabular}{l|l}
\hline Loans to commercial banks $\left(D L^{B C}\right)$ & Cash in circulation $(H)$ \\
Foreign reserves $(E R \cdot F F)$ & Reserve requirements $(R R)$ \\
Education capital $\left(P K \cdot K_{E D U}\right)$ & Government bonds $(G B)$ \\
Infrastructure capital $\left(P K \cdot K_{I N F}\right)$ & Foreign borrowing $\left(E R \cdot F L_{G}\right)$ \\
& Net worth $\left(N W^{P S}\right)$
\end{tabular}


Table 2

Turkey: Simulation Results

Permanent, 5 Percentage Point Increase in the Official Interest Rate (Percentage deviations from baseline, unless otherwise indicated)

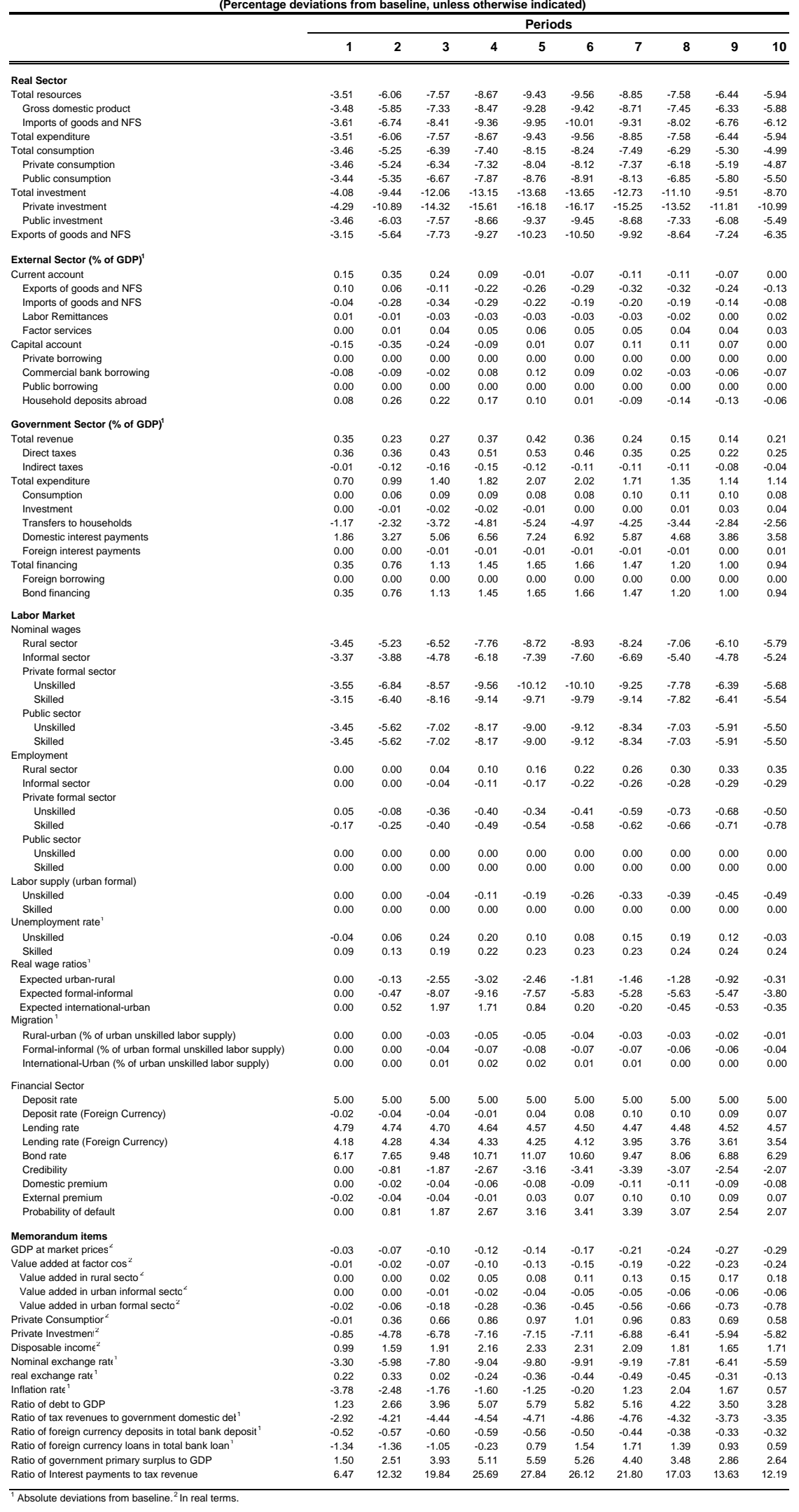


Table 3

Turkey: Prices and Structural Indicators

Permanent, 5 Percentage Point Increase in the Official Interest Rate

(Absolute deviations from baseline, unless otherwise indicated)

\begin{tabular}{|c|c|c|c|c|c|c|c|c|c|c|}
\hline & \multicolumn{10}{|c|}{ Periods } \\
\hline & 1 & 2 & 3 & 4 & 5 & 6 & 7 & 8 & 9 & 10 \\
\hline \multicolumn{11}{|l|}{ Consumer Prices and the Real Exchange Rate ${ }^{1}$} \\
\hline Rural CPI & -3.44 & -5.37 & -6.68 & -7.87 & -8.77 & -8.91 & -8.14 & -6.85 & -5.81 & -5.50 \\
\hline Urban CPI & -3.45 & -5.62 & -7.02 & -8.17 & -9.00 & -9.12 & -8.34 & -7.03 & -5.91 & -5.50 \\
\hline Real exchange rate & 0.22 & 0.33 & 0.02 & -0.24 & -0.36 & -0.44 & -0.49 & -0.45 & -0.31 & -0.13 \\
\hline \multicolumn{11}{|l|}{ Value Added Prices $^{1}$} \\
\hline Rural & -3.45 & -5.23 & -6.50 & -7.71 & -8.63 & -8.81 & -8.10 & -6.90 & -5.92 & -5.60 \\
\hline Urban private informal & -3.37 & -3.89 & -4.81 & -6.26 & -7.51 & -7.76 & -6.88 & -5.61 & -5.00 & -5.46 \\
\hline Urban private formal & -3.50 & -6.85 & -8.71 & -9.65 & -10.11 & -10.06 & -9.27 & -7.83 & -6.35 & -5.46 \\
\hline Urban public & -3.45 & -5.62 & -7.02 & -8.17 & -9.00 & -9.12 & -8.34 & -7.03 & -5.91 & -5.50 \\
\hline \multicolumn{11}{|l|}{ Real Disposable Income $^{1}$} \\
\hline Rural households & 0.31 & 0.70 & 1.40 & 1.91 & 2.12 & 2.07 & 1.88 & 1.65 & 1.47 & 1.40 \\
\hline Urban households & -0.12 & 0.29 & 0.46 & 0.54 & 0.62 & 0.69 & 0.70 & 0.61 & 0.45 & 0.30 \\
\hline Informal & 0.35 & 1.70 & 2.16 & 1.97 & 1.61 & 1.45 & 1.50 & 1.45 & 1.04 & 0.35 \\
\hline Formal & -1.34 & -3.95 & -7.49 & -10.66 & -12.10 & -11.50 & -9.64 & -7.57 & -6.00 & -5.17 \\
\hline Capitalists and rentiers & 0.84 & 3.03 & 5.72 & 8.23 & 9.84 & 10.15 & 9.17 & 7.61 & 6.39 & 5.99 \\
\hline \multicolumn{11}{|l|}{ Real Private Consumption $^{1}$} \\
\hline Rural households & 1.38 & 2.23 & 2.82 & 3.15 & 3.20 & 2.98 & 2.58 & 2.19 & 1.99 & 2.03 \\
\hline Urban households & 0.84 & 1.47 & 1.73 & 1.93 & 2.07 & 2.08 & 1.90 & 1.64 & 1.44 & 1.40 \\
\hline Informal & 0.73 & 2.20 & 2.63 & 2.39 & 1.99 & 1.79 & 1.79 & 1.70 & 1.29 & 0.62 \\
\hline Formal & -0.93 & -3.38 & -6.98 & -10.23 & -11.72 & -11.18 & -9.39 & -7.39 & -5.82 & -4.95 \\
\hline Capitalists and rentiers & 3.11 & 5.71 & 8.38 & 10.79 & 12.30 & 12.46 & 11.28 & 9.54 & 8.28 & 7.98 \\
\hline \multicolumn{11}{|l|}{ Production Structure } \\
\hline Size of informal sector (\% of total output) & 0.00 & 0.01 & 0.02 & 0.03 & 0.04 & 0.04 & 0.05 & 0.06 & 0.07 & 0.07 \\
\hline Size of rural sector (\% of total output) & 0.00 & 0.01 & 0.02 & 0.03 & 0.04 & 0.06 & 0.07 & 0.08 & 0.09 & 0.10 \\
\hline \multicolumn{11}{|l|}{ Composition of Employment } \\
\hline Employment in rural sector (\% of total employment) & 0.00 & 0.01 & 0.04 & 0.07 & 0.09 & 0.11 & 0.14 & 0.16 & 0.16 & 0.16 \\
\hline Employment in informal sector (\% of total employment) & 0.00 & 0.01 & 0.01 & -0.01 & -0.03 & -0.04 & -0.05 & -0.05 & -0.05 & -0.06 \\
\hline Employment in informal sector (\% of urban employment) & 0.01 & 0.03 & 0.05 & 0.04 & 0.03 & 0.02 & 0.03 & 0.03 & 0.03 & 0.02 \\
\hline Employment in public sector (\% of total employment) & 0.00 & 0.00 & 0.00 & 0.00 & 0.00 & 0.00 & 0.00 & 0.00 & 0.00 & 0.00 \\
\hline Employment in public sector (\% of urban employment) & 0.00 & 0.00 & 0.00 & 0.00 & 0.00 & 0.00 & 0.01 & 0.01 & 0.01 & 0.01 \\
\hline \multicolumn{11}{|l|}{ Private Expenditures } \\
\hline Consumption (\% of GDP) & 0.01 & 0.45 & 0.76 & 0.90 & 0.98 & 1.02 & 1.02 & 0.95 & 0.82 & 0.71 \\
\hline Consumption (\% of total consumption) & 0.00 & 0.01 & 0.04 & 0.07 & 0.10 & 0.11 & 0.11 & 0.10 & 0.09 & 0.10 \\
\hline Investment (\% of GDP) & -0.16 & -0.84 & -1.04 & -1.03 & -1.00 & -1.00 & -0.98 & -0.92 & -0.83 & -0.76 \\
\hline Investment (\% of total investment) & -0.16 & -1.12 & -1.71 & -1.83 & -1.83 & -1.83 & -1.78 & -1.66 & -1.52 & -1.46 \\
\hline \multicolumn{11}{|l|}{ Public Expenditures } \\
\hline Consumption (\% of GDP) & 0.00 & 0.06 & 0.09 & 0.09 & 0.08 & 0.08 & 0.10 & 0.11 & 0.10 & 0.08 \\
\hline Investment (\% of GDP) & 0.00 & -0.01 & -0.02 & -0.02 & -0.01 & 0.00 & 0.00 & 0.01 & 0.03 & 0.04 \\
\hline Infrastructure (\% of public investment) & 0.00 & 0.00 & 0.00 & 0.00 & 0.00 & 0.00 & 0.00 & 0.00 & 0.00 & 0.00 \\
\hline Education (\% of public investment) & 0.00 & 0.00 & 0.00 & 0.00 & 0.00 & 0.00 & 0.00 & 0.00 & 0.00 & 0.00 \\
\hline Public sector wage bill (\% of public expenditure) & 0.70 & 1.69 & 3.52 & 5.62 & 6.65 & 6.10 & 4.79 & 3.61 & 2.86 & 2.56 \\
\hline \multicolumn{11}{|l|}{ External Sector } \\
\hline Rural sector exports (\% of total exports) & 0.00 & -0.06 & -0.07 & -0.06 & -0.04 & -0.02 & -0.01 & 0.01 & 0.04 & 0.08 \\
\hline Imports of non-rural sector goods (\% of total imports) & -0.01 & -0.06 & -0.07 & -0.06 & -0.05 & -0.05 & -0.05 & -0.05 & -0.04 & -0.03 \\
\hline External debt (\% of GDP) & -0.13 & -0.51 & -0.76 & -0.84 & -0.83 & -0.77 & -0.67 & -0.57 & -0.49 & -0.46 \\
\hline Degree of openness (total trade in $\%$ of GDP) & 0.06 & -0.22 & -0.45 & -0.50 & -0.47 & -0.48 & -0.52 & -0.50 & -0.38 & -0.21 \\
\hline
\end{tabular}


Table 4

Turkey: Simulation Results

Permanent, 2.5 Percentage Point Increase in the Value Added Tax Rate (Percentage deviations from baseline, unless otherwise indicated)

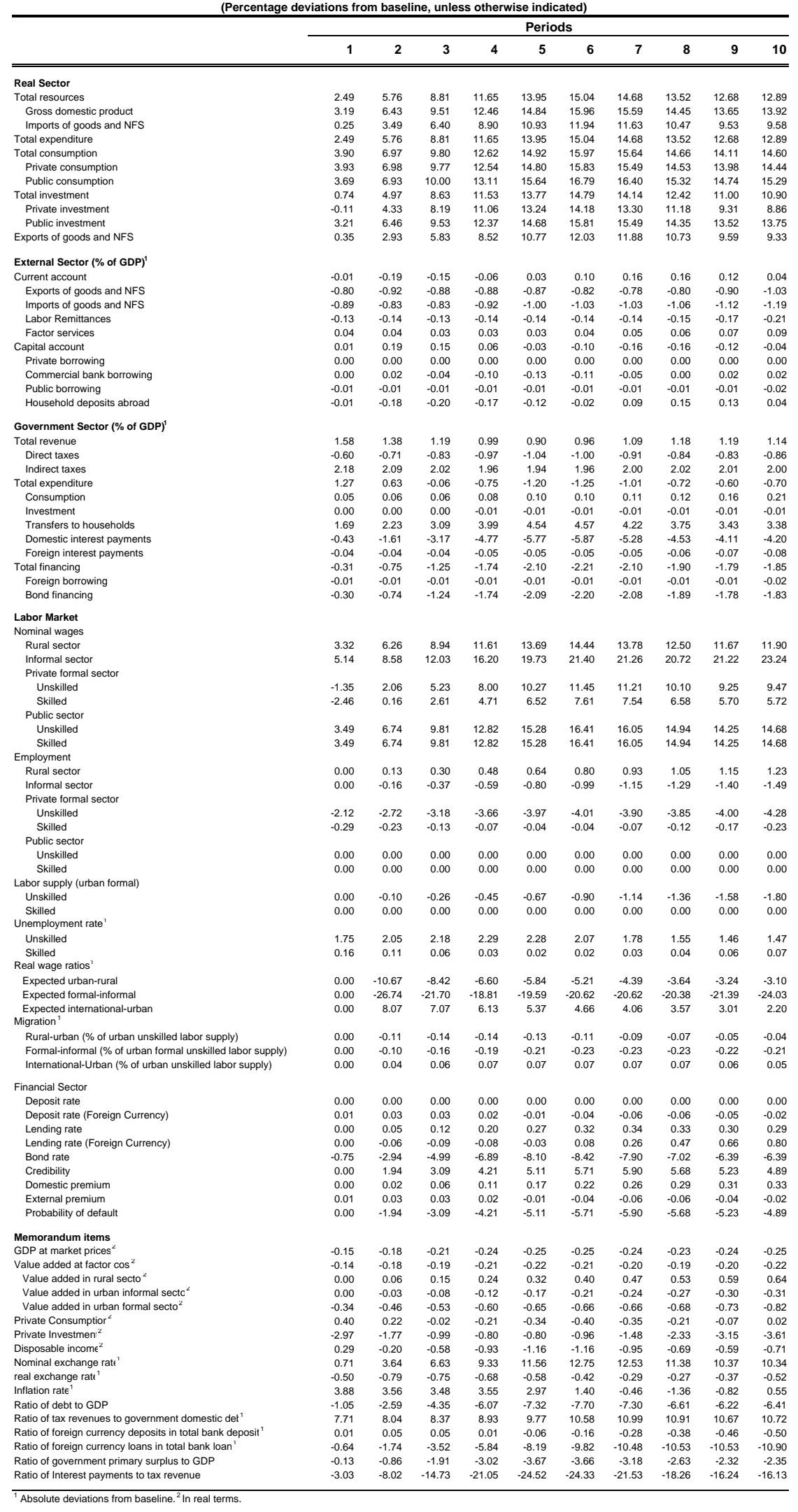


Table 5

Turkey: Prices and Structural Indicators

Permanent, 2.5 Percentage Point Increase in the Value Added Tax Rate (Absolute deviations from baseline, unless otherwise indicated)

\begin{tabular}{|c|c|c|c|c|c|c|c|c|c|c|}
\hline & \multicolumn{10}{|c|}{ Periods } \\
\hline & 1 & 2 & 3 & 4 & 5 & 6 & 7 & 8 & 9 & 10 \\
\hline \multicolumn{11}{|l|}{ Consumer Prices and the Real Exchange Rate ${ }^{1}$} \\
\hline Rural CPI & 3.67 & 6.92 & 10.00 & 13.12 & 15.65 & 16.80 & 16.40 & 15.32 & 14.73 & 15.27 \\
\hline Urban CPI & 3.49 & 6.74 & 9.81 & 12.82 & 15.28 & 16.41 & 16.05 & 14.94 & 14.25 & 14.68 \\
\hline Real exchange rate & -0.50 & -0.79 & -0.75 & -0.68 & -0.58 & -0.42 & -0.29 & -0.27 & -0.37 & -0.52 \\
\hline \multicolumn{11}{|l|}{ Value Added Prices $^{1}$} \\
\hline Rural & 3.32 & 6.35 & 9.14 & 11.93 & 14.13 & 14.99 & 14.40 & 13.18 & 12.41 & 12.69 \\
\hline Urban private informal & 5.14 & 8.45 & 11.71 & 15.66 & 18.99 & 20.46 & 20.17 & 19.51 & 19.89 & 21.80 \\
\hline Urban private formal & -2.82 & 0.13 & 2.89 & 5.22 & 7.18 & 8.31 & 8.18 & 7.16 & 6.24 & 6.28 \\
\hline Urban public & 3.49 & 6.74 & 9.81 & 12.82 & 15.28 & 16.41 & 16.05 & 14.94 & 14.25 & 14.68 \\
\hline \multicolumn{11}{|l|}{ Real Disposable Income $^{1}$} \\
\hline Rural households & -0.59 & -0.61 & -0.94 & -1.33 & -1.64 & -1.83 & -1.93 & -1.96 & -1.99 & -2.06 \\
\hline Urban households & 0.76 & 0.52 & 0.29 & 0.17 & 0.09 & 0.08 & 0.18 & 0.38 & 0.61 & 0.77 \\
\hline Informal & 1.37 & 1.39 & 1.53 & 2.20 & 2.81 & 3.06 & 3.15 & 3.48 & 4.24 & 5.28 \\
\hline Formal & 0.91 & 2.16 & 4.38 & 6.77 & 8.24 & 8.25 & 7.20 & 5.88 & 4.92 & 4.65 \\
\hline Capitalists and rentiers & -0.41 & -2.89 & -5.75 & -8.64 & -10.61 & -11.18 & -10.51 & -9.39 & -8.74 & -8.97 \\
\hline \multicolumn{11}{|l|}{ Real Private Consumption ${ }^{1}$} \\
\hline Rural households & -0.59 & -0.92 & -1.25 & -1.54 & -1.73 & -1.74 & -1.61 & -1.47 & -1.46 & -1.63 \\
\hline Urban households & 0.67 & 0.16 & -0.22 & -0.52 & -0.69 & -0.63 & -0.36 & -0.03 & 0.20 & 0.23 \\
\hline Informal & 1.37 & 1.32 & 1.46 & 2.15 & 2.79 & 3.08 & 3.22 & 3.59 & 4.36 & 5.38 \\
\hline Formal & 0.91 & 2.02 & 4.23 & 6.66 & 8.19 & 8.30 & 7.38 & 6.16 & 5.22 & 4.89 \\
\hline Capitalists and rentiers & -0.41 & -3.11 & -5.97 & -8.79 & -10.67 & -11.11 & -10.27 & -9.02 & -8.33 & -8.64 \\
\hline \multicolumn{11}{|l|}{ Production Structure } \\
\hline Size of informal sector (\% of total output) & 0.05 & 0.05 & 0.05 & 0.04 & 0.04 & 0.03 & 0.01 & 0.01 & 0.01 & 0.01 \\
\hline Size of rural sector (\% of total output) & 0.03 & 0.05 & 0.07 & 0.09 & 0.11 & 0.13 & 0.14 & 0.15 & 0.17 & 0.18 \\
\hline \multicolumn{11}{|l|}{ Composition of Employment } \\
\hline Employment in rural sector (\% of total employment) & 0.09 & 0.17 & 0.25 & 0.33 & 0.41 & 0.47 & 0.51 & 0.55 & 0.59 & 0.63 \\
\hline Employment in informal sector (\% of total employment) & 0.08 & 0.05 & -0.01 & -0.07 & -0.12 & -0.18 & -0.22 & -0.26 & -0.28 & -0.28 \\
\hline Employment in informal sector (\% of urban employment) & 0.22 & 0.22 & 0.20 & 0.17 & 0.14 & 0.09 & 0.03 & -0.01 & -0.03 & -0.03 \\
\hline Employment in public sector (\% of total employment) & 0.00 & 0.00 & 0.00 & 0.00 & 0.00 & 0.00 & 0.00 & 0.00 & 0.00 & 0.01 \\
\hline Employment in public sector (\% of urban employment) & 0.00 & 0.01 & 0.01 & 0.01 & 0.02 & 0.02 & 0.02 & 0.02 & 0.03 & 0.03 \\
\hline \multicolumn{11}{|l|}{ Private Expenditures } \\
\hline Consumption (\% of GDP) & 0.48 & 0.35 & 0.17 & 0.06 & -0.03 & -0.08 & -0.06 & 0.05 & 0.19 & 0.30 \\
\hline Consumption (\% of total consumption) & 0.02 & 0.01 & -0.02 & -0.06 & -0.09 & -0.11 & -0.11 & -0.10 & -0.10 & -0.11 \\
\hline Investment (\% of GDP) & -0.61 & -0.31 & -0.17 & -0.16 & -0.18 & -0.21 & -0.27 & -0.40 & -0.54 & -0.63 \\
\hline Investment (\% of total investment) & -0.62 & -0.43 & -0.27 & -0.27 & -0.29 & -0.33 & -0.45 & -0.67 & -0.91 & -1.07 \\
\hline \multicolumn{11}{|l|}{ Public Expenditures } \\
\hline Consumption (\% of GDP) & 0.05 & 0.06 & 0.06 & 0.08 & 0.10 & 0.10 & 0.11 & 0.12 & 0.16 & 0.21 \\
\hline Investment (\% of GDP) & 0.00 & 0.00 & 0.00 & -0.01 & -0.01 & -0.01 & -0.01 & -0.01 & -0.01 & -0.01 \\
\hline Infrastructure (\% of public investment) & 0.00 & 0.00 & 0.00 & 0.00 & 0.00 & 0.00 & 0.00 & 0.00 & 0.00 & 0.00 \\
\hline Education (\% of public investment) & 0.00 & 0.00 & 0.00 & 0.00 & 0.00 & 0.00 & 0.00 & 0.00 & 0.00 & 0.00 \\
\hline Public sector wage bill (\% of public expenditure) & -0.94 & -1.35 & -2.23 & -3.29 & -3.94 & -3.90 & -3.44 & -2.93 & -2.61 & -2.56 \\
\hline \multicolumn{11}{|l|}{ External Sector } \\
\hline Rural sector exports (\% of total exports) & -0.13 & -0.11 & -0.09 & -0.09 & -0.09 & -0.08 & -0.07 & -0.07 & -0.08 & -0.08 \\
\hline Imports of non-rural sector goods (\% of total imports) & -0.11 & -0.10 & -0.11 & -0.12 & -0.13 & -0.13 & -0.12 & -0.12 & -0.13 & -0.13 \\
\hline External debt (\% of GDP) & -0.26 & -0.08 & 0.07 & 0.12 & 0.09 & 0.00 & -0.15 & -0.32 & -0.47 & -0.55 \\
\hline Degree of openness (total trade in \% of GDP) & -1.69 & -1.75 & -1.72 & -1.80 & -1.87 & -1.85 & -1.81 & -1.86 & -2.02 & -2.21 \\
\hline
\end{tabular}

${ }^{1}$ Percentage deviations from baseline. 
Table 6

Turkey: Simulation Results

Permanent, 5 Percentage Point Increase in Income Tax Rate on Profit Earners (Percentage deviations from baseline, unless otherwise indicated)

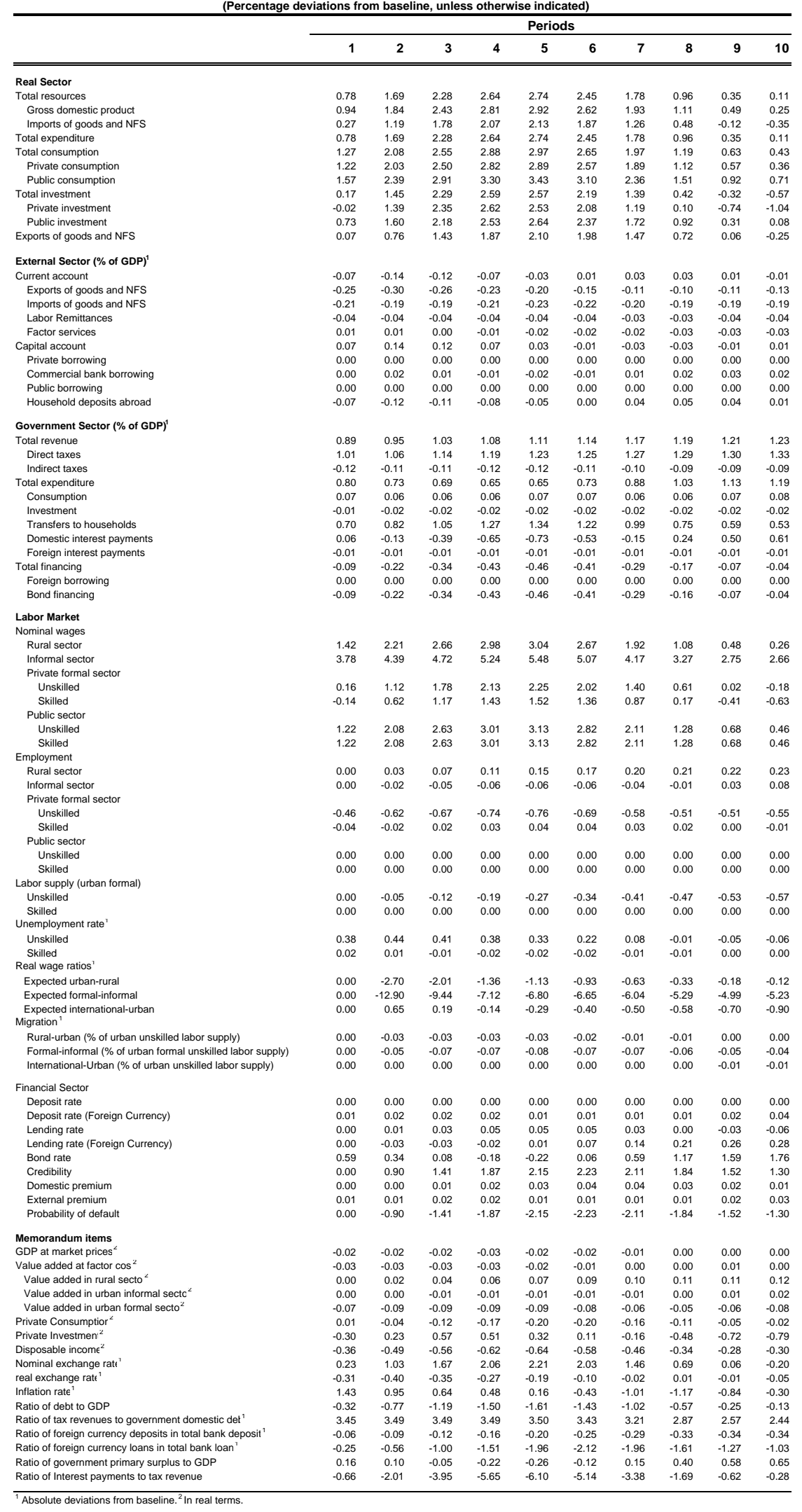


Table 7

Turkey: Simulation Results

Permanent, 5 Percentage Point Increase in Income Tax Rate on Profit Earners (Absolute deviations from baseline, unless otherwise indicated)

\begin{tabular}{|c|c|c|c|c|c|c|c|c|c|c|}
\hline & \multicolumn{10}{|c|}{ Periods } \\
\hline & 1 & 2 & 3 & 4 & 5 & 6 & 7 & 8 & 9 & 10 \\
\hline \multicolumn{11}{|l|}{ Consumer Prices and the Real Exchange Rate ${ }^{1}$} \\
\hline Rural CPI & 1.53 & 2.38 & 2.90 & 3.30 & 3.43 & 3.10 & 2.35 & 1.51 & 0.91 & 0.69 \\
\hline Urban CPI & 1.22 & 2.08 & 2.63 & 3.01 & 3.13 & 2.82 & 2.11 & 1.28 & 0.68 & 0.46 \\
\hline Real exchange rate & -0.31 & -0.40 & -0.35 & -0.27 & -0.19 & -0.10 & -0.02 & 0.01 & -0.01 & -0.05 \\
\hline \multicolumn{11}{|l|}{ Value Added Prices $^{1}$} \\
\hline Rural & 1.42 & 2.23 & 2.70 & 3.05 & 3.13 & 2.78 & 2.03 & 1.20 & 0.61 & 0.39 \\
\hline Urban private informal & 3.78 & 4.37 & 4.68 & 5.19 & 5.42 & 5.03 & 4.14 & 3.26 & 2.78 & 2.72 \\
\hline Urban private formal & -0.17 & 0.67 & 1.29 & 1.58 & 1.67 & 1.49 & 0.96 & 0.23 & -0.36 & -0.58 \\
\hline Urban public & 1.22 & 2.08 & 2.63 & 3.01 & 3.13 & 2.82 & 2.11 & 1.28 & 0.68 & 0.46 \\
\hline \multicolumn{11}{|l|}{ Real Disposable Income $^{1}$} \\
\hline Rural households & -0.22 & -0.19 & -0.27 & -0.37 & -0.43 & -0.43 & -0.39 & -0.34 & -0.29 & -0.25 \\
\hline Urban households & 0.16 & 0.05 & -0.05 & -0.09 & -0.10 & -0.10 & -0.06 & 0.01 & 0.07 & 0.11 \\
\hline Informal & 2.01 & 1.82 & 1.67 & 1.80 & 1.92 & 1.88 & 1.77 & 1.74 & 1.85 & 2.00 \\
\hline Formal & 0.89 & 1.27 & 1.98 & 2.66 & 2.92 & 2.66 & 2.10 & 1.53 & 1.15 & 1.02 \\
\hline Capitalists and rentiers & -3.87 & -4.32 & -4.81 & -5.32 & -5.52 & -5.27 & -4.63 & -3.91 & -3.41 & -3.22 \\
\hline \multicolumn{11}{|l|}{ Real Private Consumption ${ }^{1}$} \\
\hline Rural households & -0.22 & -0.31 & -0.35 & -0.38 & -0.37 & -0.30 & -0.20 & -0.10 & -0.06 & -0.07 \\
\hline Urban households & -0.15 & -0.34 & -0.45 & -0.50 & -0.51 & -0.44 & -0.31 & -0.18 & -0.10 & -0.09 \\
\hline Informal & 2.01 & 1.80 & 1.65 & 1.80 & 1.93 & 1.91 & 1.81 & 1.80 & 1.90 & 2.04 \\
\hline Formal & 0.89 & 1.21 & 1.95 & 2.66 & 2.95 & 2.73 & 2.20 & 1.66 & 1.27 & 1.11 \\
\hline Capitalists and rentiers & -3.87 & -4.40 & -4.86 & -5.32 & -5.48 & -5.17 & -4.47 & -3.72 & -3.23 & -3.08 \\
\hline \multicolumn{11}{|l|}{ Production Structure } \\
\hline Size of informal sector (\% of total output) & 0.01 & 0.01 & 0.01 & 0.01 & 0.01 & 0.00 & 0.00 & 0.00 & 0.00 & 0.01 \\
\hline Size of Rural sector (\% of total output) & 0.01 & 0.01 & 0.01 & 0.02 & 0.02 & 0.02 & 0.02 & 0.02 & 0.02 & 0.02 \\
\hline \multicolumn{11}{|l|}{ Composition of Employment } \\
\hline Employment in rural sector (\% of total employment) & 0.02 & 0.04 & 0.05 & 0.06 & 0.07 & 0.07 & 0.07 & 0.07 & 0.07 & 0.07 \\
\hline Employment in informal sector (\% of total employment) & 0.02 & 0.01 & 0.00 & 0.00 & -0.01 & -0.01 & -0.01 & -0.01 & 0.00 & 0.01 \\
\hline Employment in informal sector (\% of urban employment) & 0.05 & 0.05 & 0.05 & 0.05 & 0.05 & 0.04 & 0.03 & 0.04 & 0.05 & 0.06 \\
\hline Employment in public sector (\% of total employment) & 0.00 & 0.00 & 0.00 & 0.00 & 0.00 & 0.00 & 0.00 & 0.00 & 0.00 & 0.00 \\
\hline Employment in public sector (\% of urban employment) & 0.00 & 0.00 & 0.00 & 0.00 & 0.00 & 0.00 & 0.00 & 0.00 & 0.00 & 0.00 \\
\hline \multicolumn{11}{|l|}{ Private Expenditures } \\
\hline Consumption (\% of GDP) & 0.18 & 0.13 & 0.05 & 0.01 & -0.02 & -0.03 & -0.03 & 0.01 & 0.05 & 0.07 \\
\hline Consumption (\% of total consumption) & -0.04 & -0.04 & -0.05 & -0.06 & -0.07 & -0.07 & -0.06 & -0.06 & -0.05 & -0.05 \\
\hline Investment (\% of GDP) & -0.18 & -0.07 & -0.01 & -0.02 & -0.05 & -0.07 & -0.10 & -0.14 & -0.17 & -0.18 \\
\hline Investment (\% of total investment) & -0.14 & -0.04 & 0.04 & 0.02 & -0.03 & -0.07 & -0.12 & -0.19 & -0.25 & -0.28 \\
\hline \multicolumn{11}{|l|}{ Public Expenditures } \\
\hline Consumption (\% of GDP) & 0.07 & 0.06 & 0.06 & 0.06 & 0.07 & 0.07 & 0.06 & 0.06 & 0.07 & 0.08 \\
\hline Investment (\% of GDP) & -0.01 & -0.02 & -0.02 & -0.02 & -0.02 & -0.02 & -0.02 & -0.02 & -0.02 & -0.02 \\
\hline Infrastructure (\% of public investment) & 0.00 & 0.00 & 0.00 & 0.00 & 0.00 & 0.00 & 0.00 & 0.00 & 0.00 & 0.00 \\
\hline Education (\% of public investment) & 0.00 & 0.00 & 0.00 & 0.00 & 0.00 & 0.00 & 0.00 & 0.00 & 0.00 & 0.00 \\
\hline Public sector wage bill (\% of public expenditure) & -0.39 & -0.52 & -0.82 & -1.17 & -1.33 & -1.21 & -0.95 & -0.71 & -0.57 & -0.53 \\
\hline \multicolumn{11}{|l|}{ External Sector } \\
\hline Rural exports (\% of total exports) & -0.05 & -0.05 & -0.04 & -0.04 & -0.04 & -0.04 & -0.03 & -0.03 & -0.03 & -0.03 \\
\hline Imports of non-rural sector goods (\% of total imports) & -0.04 & -0.03 & -0.03 & -0.04 & -0.04 & -0.03 & -0.03 & -0.03 & -0.03 & -0.03 \\
\hline External debt (\% of GDP) & -0.01 & 0.13 & 0.24 & 0.31 & 0.34 & 0.35 & 0.33 & 0.31 & 0.30 & 0.32 \\
\hline Degree of openness (total trade in $\%$ of GDP) & -0.46 & -0.49 & -0.44 & -0.44 & -0.42 & -0.37 & -0.31 & -0.28 & -0.30 & -0.32 \\
\hline
\end{tabular}




\begin{tabular}{|c|c|c|c|c|c|c|c|c|c|c|c|c|}
\hline & Activities & Commodities & Labor Factor & $\begin{array}{l}\text { Capital } \\
\text { Factor }\end{array}$ & Households & $\begin{array}{c}\text { Domestic } \\
\text { Banks }\end{array}$ & Central Bank & Government & $\begin{array}{c}\text { Private } \\
\text { Investment }\end{array}$ & $\begin{array}{c}\text { Public } \\
\text { Investment }\end{array}$ & Row & $\begin{array}{c}\text { Total } \\
\text { Receipts }\end{array}$ \\
\hline Activities & & $25,276,448$ & & & & & & & & & & $25,276,448$ \\
\hline Commodities & $11,752,353$ & & & & $10,543,236$ & & & $1,170,126$ & $2,893,335$ & 796,975 & $3,182,305$ & $30,338,330$ \\
\hline Labor Factor & $4,993,374$ & & & & & & & 296,717 & & & & $5,290,091$ \\
\hline Capital Factor & $7,734,324$ & & & & & & & 599,936 & & & 287,550 & $8,621,809$ \\
\hline Households & & & $4,616,421$ & $5,789,799$ & & $1,898,905$ & & 464,618 & & 55,279 & 287,387 & $13,112,408$ \\
\hline Domestic Banks & 46,811 & & & 375,181 & 598,218 & & 2,914 & & & $1,109,926$ & & $2,133,051$ \\
\hline Central Bank & & & & & & 2,904 & & & & 150,574 & 30,021 & 183,500 \\
\hline Government & 749,586 & 951,298 & 673,670 & 864,225 & 301,420 & 94,032 & 180,586 & & & & & $3,814,817$ \\
\hline Private Investment & & & & $1,419,097$ & $1,669,534$ & 64,358 & 0 & & & $-997,648$ & 737,995 & $2,893,335$ \\
\hline Public Investment & & & & & & & & $1,283,420$ & & & & $1,283,420$ \\
\hline Rest of the World & & $4,110,584$ & & 173,507 & & 72,853 & & & & 168,314 & & $4,525,258$ \\
\hline Total Expenditures & $25,276,448$ & $30,338,330$ & $5,290,091$ & $8,621,809$ & $13,112,408$ & $2,133,051$ & 183,500 & $3,814,817$ & $2,893,335$ & $1,283,420$ & $4,525,258$ & \\
\hline
\end{tabular}


Table C2. Financial 1996 MacroSAM for Turkey (Billions of Turkish Lira)

\begin{tabular}{|c|c|c|c|c|c|c|c|c|}
\hline & HOUSEHOLDS & CAPITAL & GOVERNMENT & $\begin{array}{c}\text { DOMESTIC } \\
\text { BANKS } \\
\end{array}$ & $\begin{array}{c}\text { REST OF THE } \\
\text { WORLD }\end{array}$ & CENTRAL BANK & $\begin{array}{c}\text { PRIVATE } \\
\text { INVESTMENT }\end{array}$ & TOTAL \\
\hline HOUSEHOLDS & & & 8,851 & $1,878,328$ & 70,816 & 129,559 & & $2,087,554$ \\
\hline CAPITAL & & & & & & & $2,893,335$ & $2,893,335$ \\
\hline GOVERNMENT & & & & & & & & 0 \\
\hline DOMESTIC BANKS & 418,020 & $1,341,625$ & 922,757 & & & 218,150 & & $2,900,552$ \\
\hline REST OF THE WORLD & & 132,613 & $-29,564$ & 955,982 & & & & $1,059,031$ \\
\hline CENTRAL BANK & & & 95,604 & 1,885 & 250,220 & & & 347,709 \\
\hline PRIVATE INVESTMENT & $1,669,534$ & $1,419,097$ & $-997,648$ & 64,358 & 737,995 & & & $2,893,335$ \\
\hline TOTAL & $2,087,554$ & $2,893,335$ & 0 & $2,900,552$ & $1,059,031$ & 347,709 & $2,893,335$ & \\
\hline
\end{tabular}




\section{Figure 1}

Turkey: Macroeconomic Indicators, 1987-2003

(In percent per annum, unless otherwise indicated)
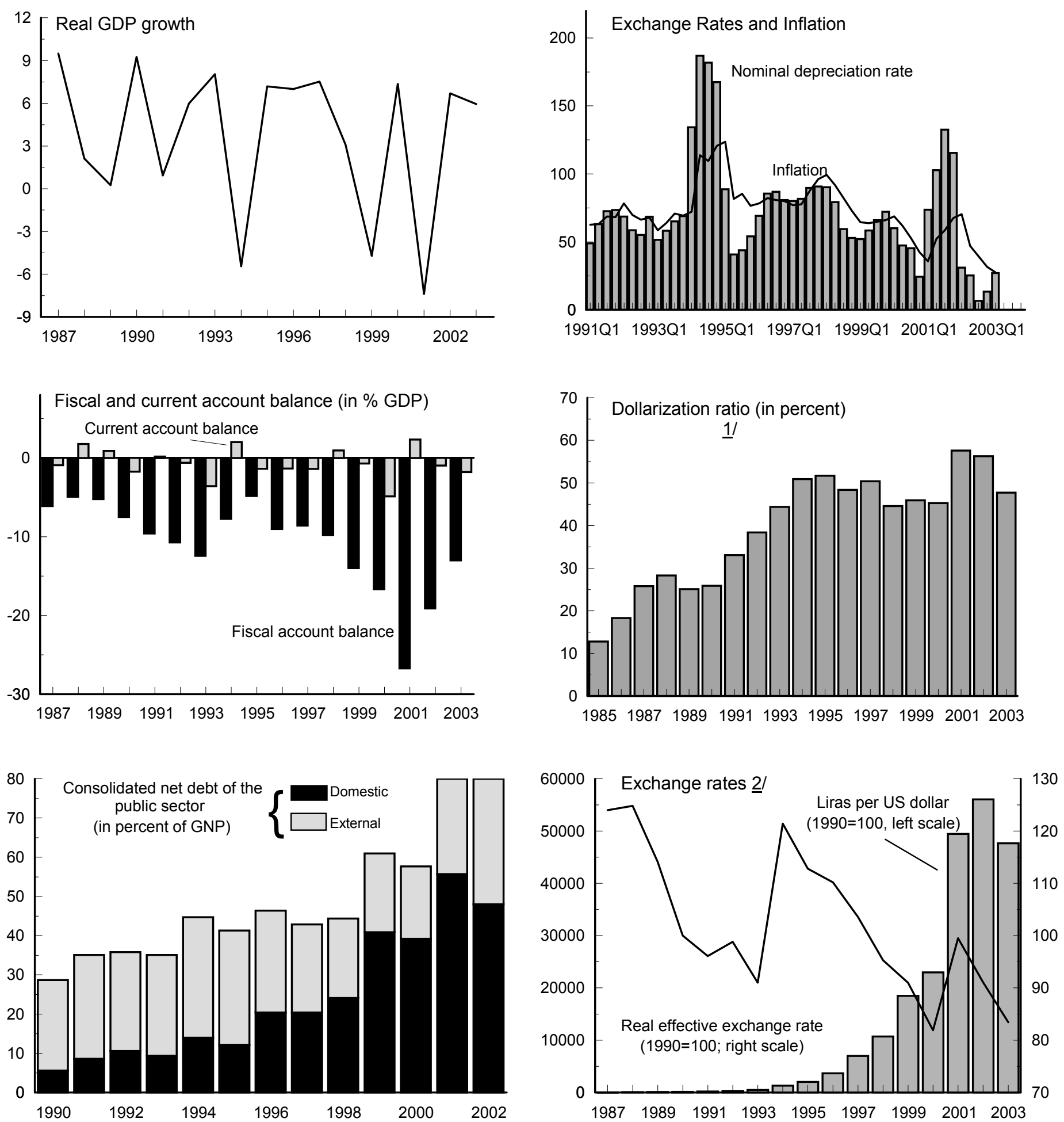

Source: International Monetary Fund and official estimates. 1 / Share of foreign currency deposits in total bank deposits. $\underline{2} / \mathrm{A}$ rise is a depreciation. 
Figure 2

Turkey:Wages and Unemployment
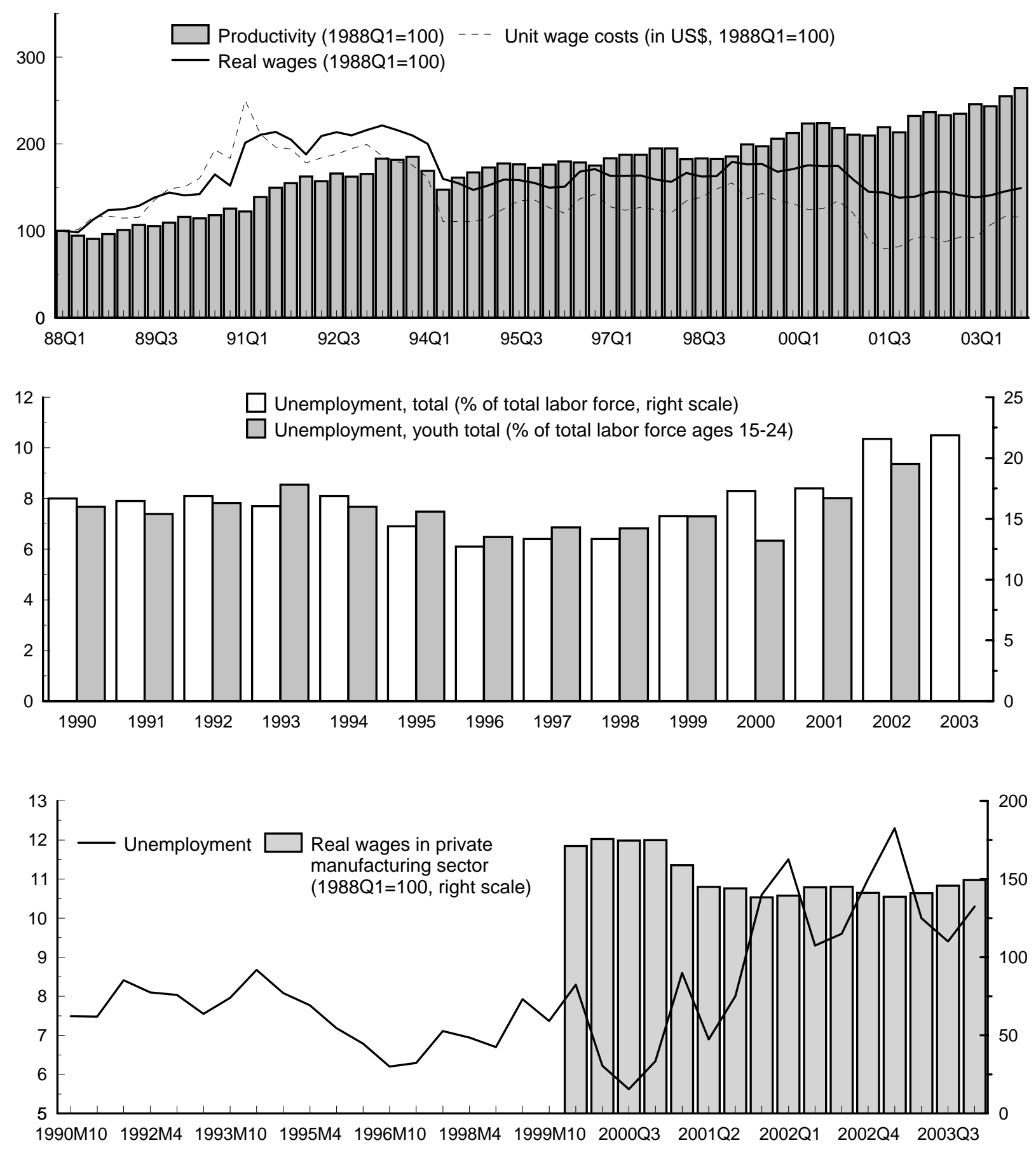

Source: Central Bank of Turkey. 
Figure 3

Turkey: Saving and Interest Rates, 1992-2002

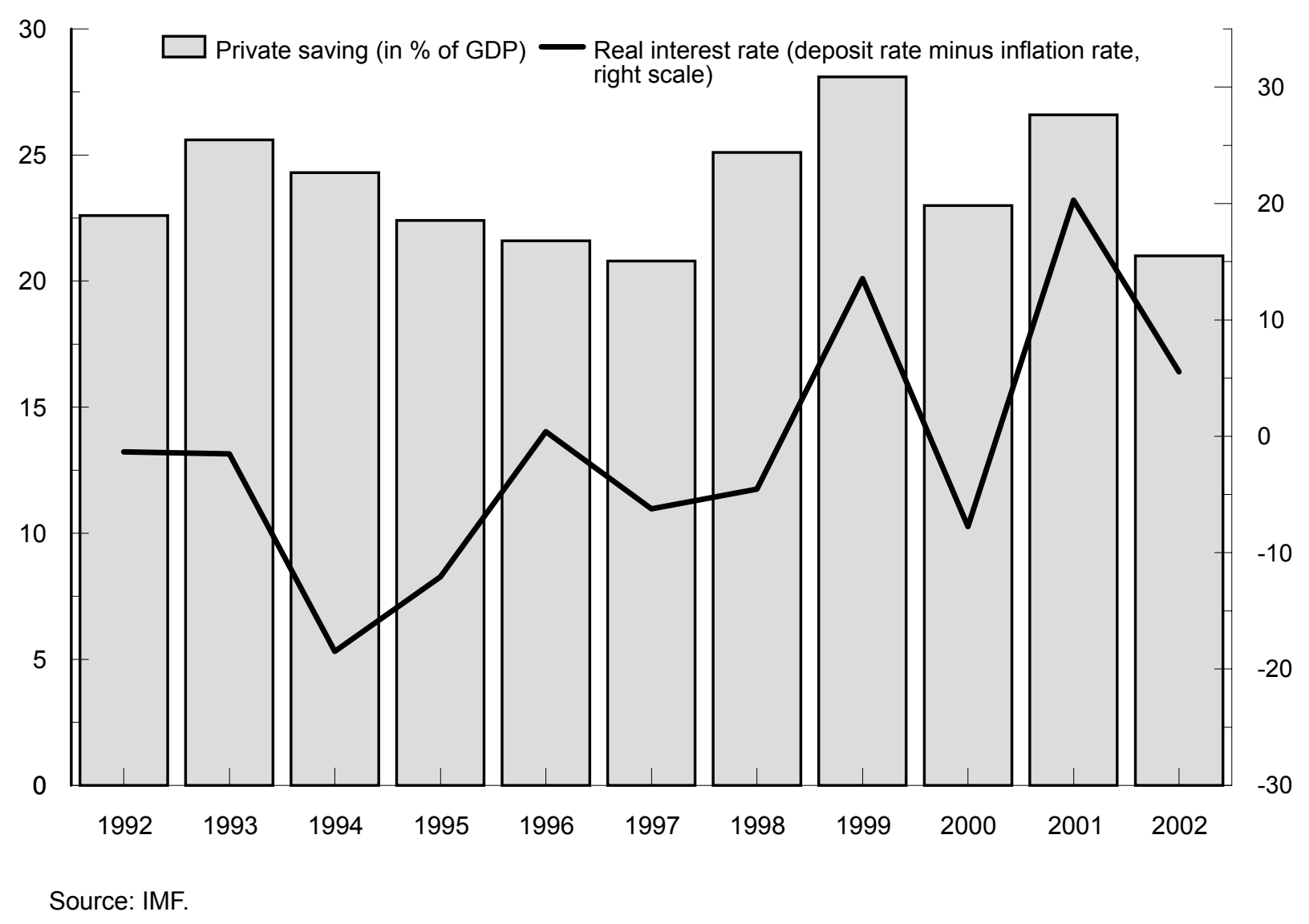


Figure 4

Turkey: Investment, Growth, and Interest Rates, 1970-2000
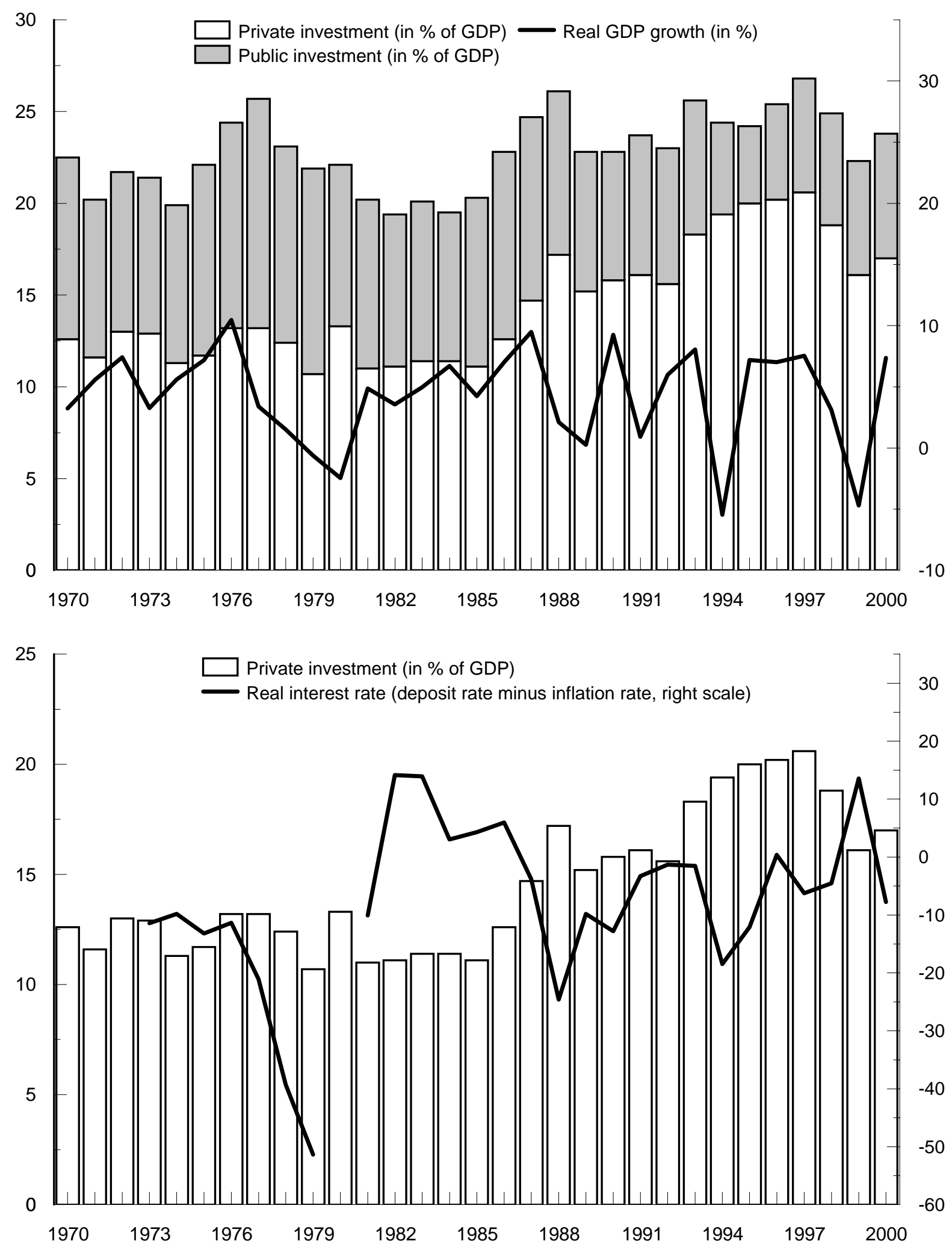

Source: Everhart and Sumlinski (2001) and WDI. 
Figure 5

Turkey: Domestic Interest Rates

(Monthly, in percent)
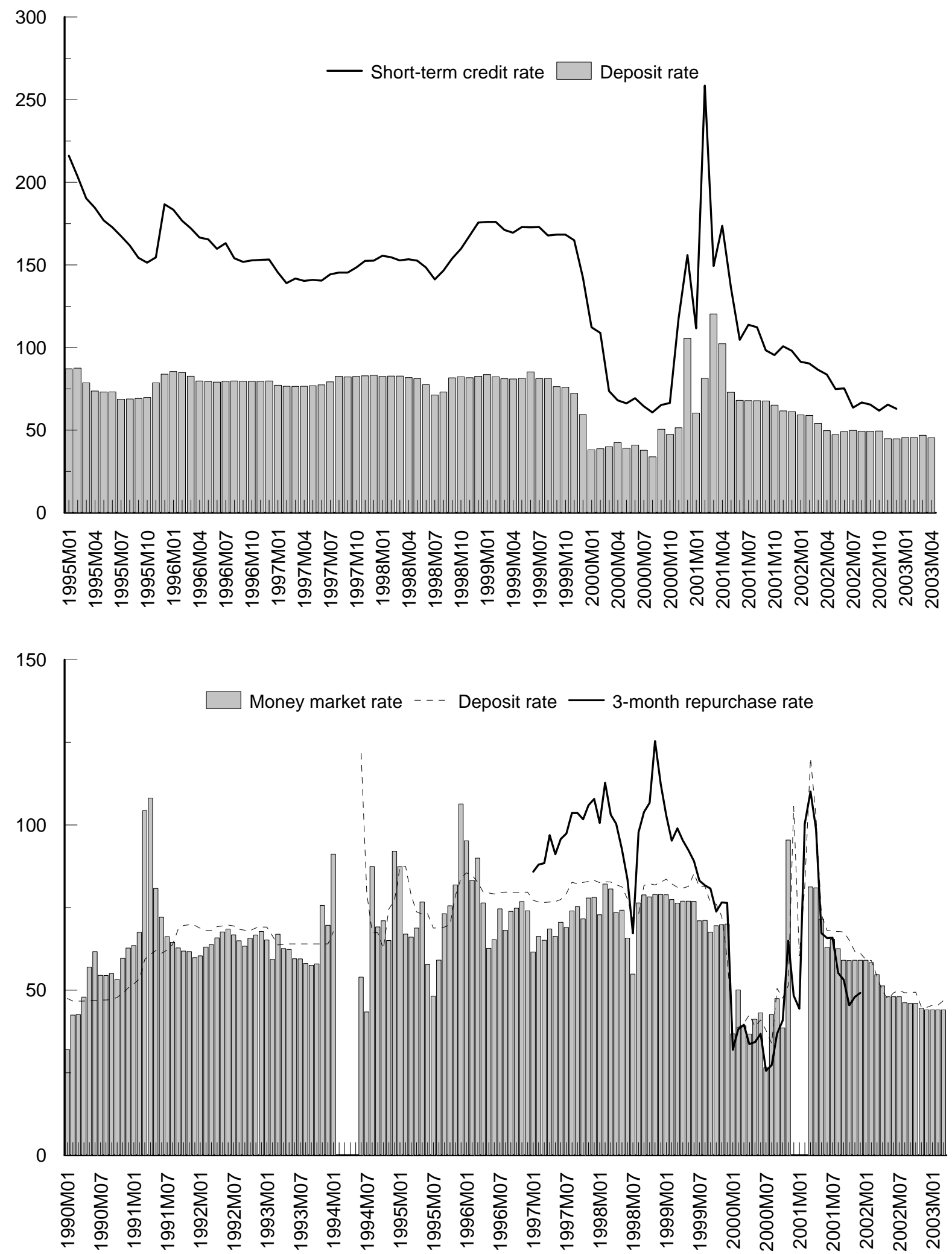

Source: IMF and Central Bank of Turkey. 
Figure 6

Turkey: Interest Rates and Exchange Rate Expectations

(in percent, annualized)
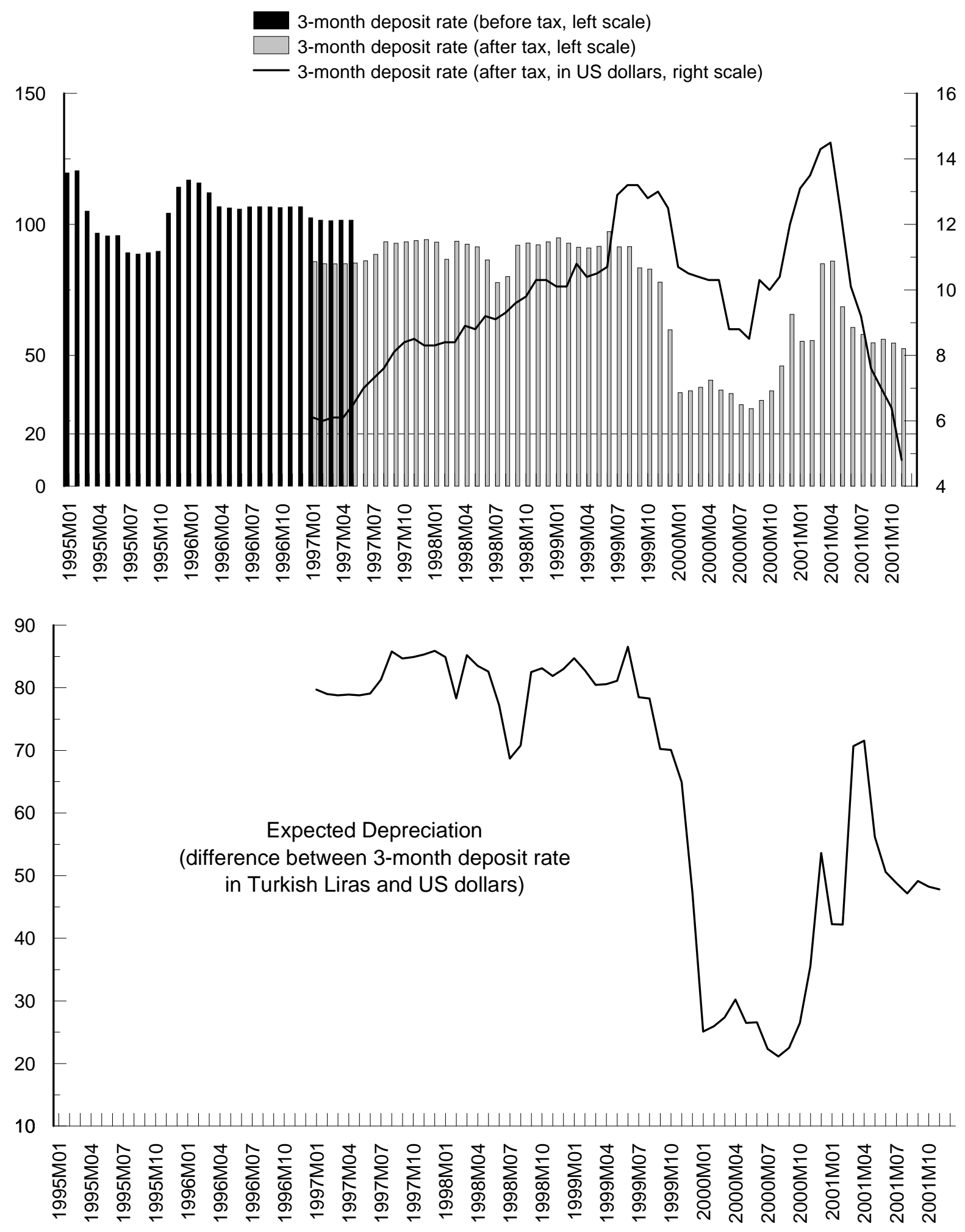

Source: IMF.

Note: Expected depreciation is the difference between 3 month time deposit rates after tax in Turkish Lira and in US dollars. 
Figure 7

Turkey: External Spreads, June 1999-June 2003

(in basis points)

$\square$ JPM EMBI and composite - stripped spread (US\$)
$\square$ JPM EMBI and Turkey - stripped spread (US\$)

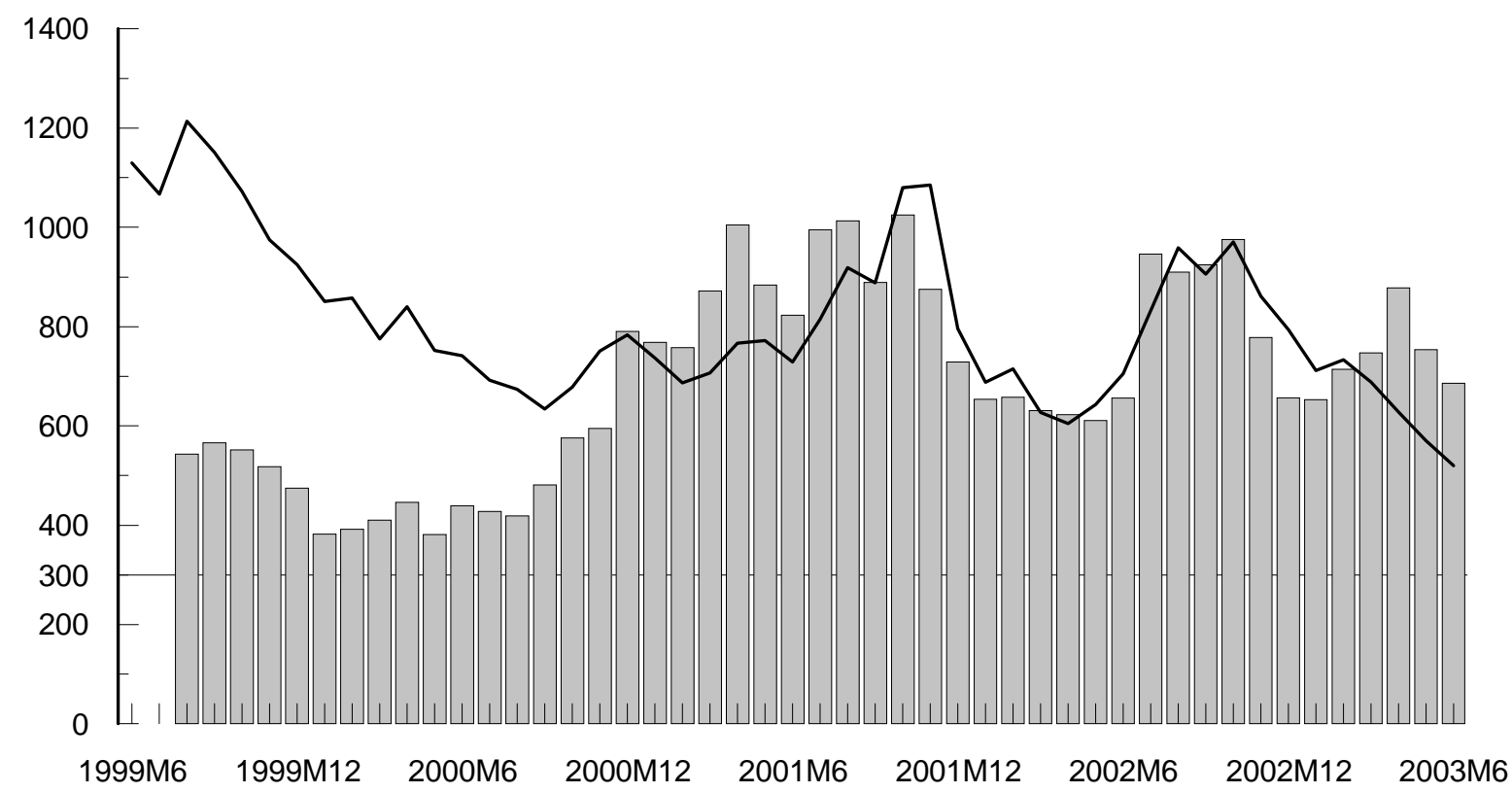

Source: JP Morgan. 
Figure 8

Turkey: Bank Lending Spread and Cyclical Output, 1987-2002

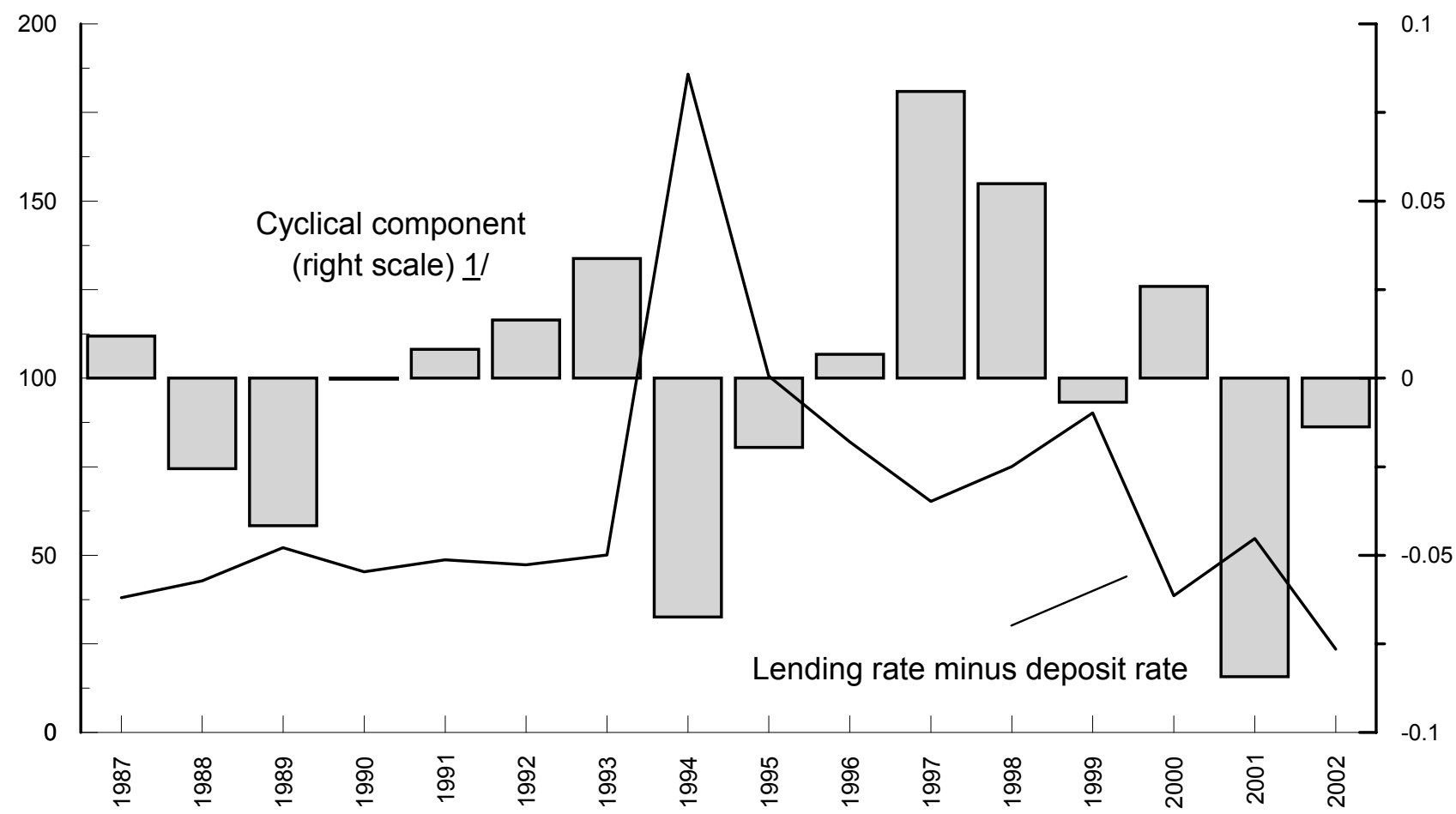

Source: International Monetary Fund and Central Bank of Turkey.

1/ Cyclical component is the log difference between manufacturing production and the Hodrick-Prescott trend of it. 